\title{
Mitigating Ruminant Methane: Exploring the \\ Commercialisation of Technologies for Reducing Livestock Methane Emissions
}

By

\author{
Mitchell Alexander Easter \\ 300300420 \\ Word Count: 32470
}

\begin{abstract}
A thesis
Submitted to the Victoria University of Wellington In fulfilment of the requirements for the degree of Master of Innovation and Commercialisation
\end{abstract}

Victoria University of Wellington (2019) 
Mitigating Ruminant Methane: Exploring the Conïmercialisation of Technologies for Reducing Livestock Methane Emissions 


\section{Abstract}

Climate change is a global issue requiring unified action. Methane gas is a major component of greenhouse gas emissions contributing to global warming. This project is exploring the commercial potential of Pastoral Greenhouse Gas Research Consortium (PGgRc) developed technologies designed to mitigate the largest source of agricultural methane emissions. These technologies are methane vaccines and inhibitors targeting emissions from enteric fermentation in ruminant livestock. The two technologies share functional aspects but require different administration and upkeep.

As novel technologies designed for a developing market the commercial potential of PGgRc's methane vaccines and inhibitors is uncertain. To validate the potential methane mitigation products this project focuses on farmer adoption and interaction with the technologies. Interviews with farmers around New Zealand have been used to identify the strengths and weaknesses of methane vaccines and inhibitors from the perspective of the end user.

A thematic analysis of the transcribed data highlighted various concerns among the participating farmers and provides a map of areas needing further investigation when moving forward with developing the technologies. Of key importance was the value methane vaccines and inhibitors offered the participants. Currently, methane mitigation offers no financial benefits to participants and good feelings about acting against climate change are not substantial enough to mitigate purchase and administration costs.

There is potential that using PGgRc's methane vaccines and inhibitors could improve livestock productivity, but it is yet to be verified based on current testing and development. Establishing that using the technologies leads to increased live weight gain or milk and wool production could provide profitability benefits that farmers would value. This hinges on any benefits providing substantial enough gains to the farmer to offset the purchase and administration costs.

If no productivity benefits are identified government regulations creating a methane cost or subsidising the technologies could be necessary for methane vaccines and inhibitors to have value within the agricultural sector. Alternatively, if consumer purchasing behaviour shifts in favour of low emissions products the agricultural sector will need to shift production methods to remain competitive in the new market environment.

PGgRc aims to employ a licensing business model using the methane vaccine and inhibitor IP they possess. Partnering with an experienced company would provide PGgRc with the market knowledge and manufacturing capabilities producing their technologies requires. As part of their 
development strategy they aim to develop their technology to a proof of concept stage before forming any production partnerships.

This project highlights the critical factors for successfully commercialising PGgRc's technologies. It is designed to guide the continued development of the methane mitigation technologies and help shape PGgRc's market approach. 


\section{Acknowledgements}

I would like to begin by thanking Suzi Kerr, whose patience, economic knowledge and writing advice have helped me reach this point.

No less important is Mark Aspin, of PGgRc whose assistance and willingness to answer questions throughout this research process has been invaluable, I hope you find this document helpful.

To Jenny Douché, thank you for your support and direction throughout this project, without your contributions this research would never have started.

Thank you to Jennifer Anderson, whose mentoring during the early stages help direct the project and validate that these technologies really are leading the field.

Darshana Patel, thank you for spending all those hours at university with me, answering all my formatting questions and explaining simple design principles. Without you this would have been a very different thesis.

I would be remiss to not thank my research participants, you all welcomed me into your homes, offered me a cup of tea, and I have left with a new appreciation for New Zealand's farming community

And finally, I would like to thank my family, Simon, Kay and Chelsea for their occasional questions about progress. My friends for keeping me entertained and at times providing a bed to sleep in while traveling for interviews. And my course-mates for all their support throughout this project, particularly Ani and Flora for their writing company. 


\section{Table of Contents}

Mitigating Ruminant Methane: Exploring the Commercialisation of Technologies for Reducing Livestock

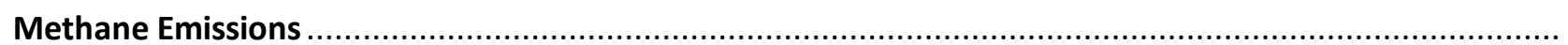

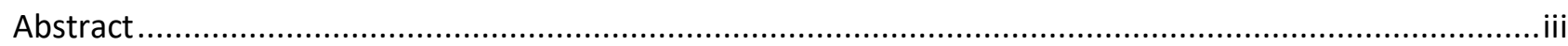

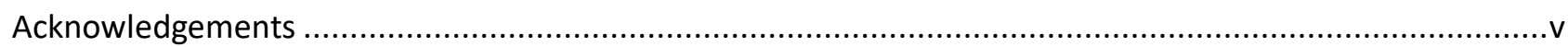

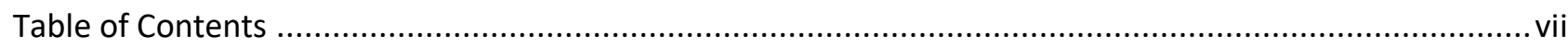

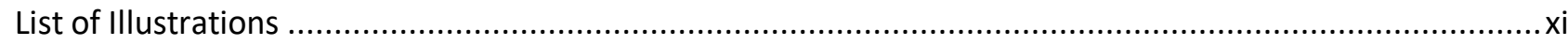

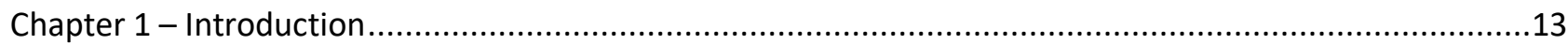

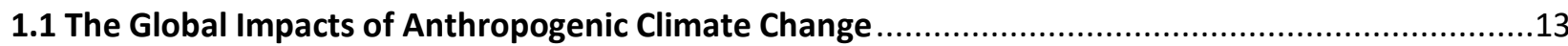

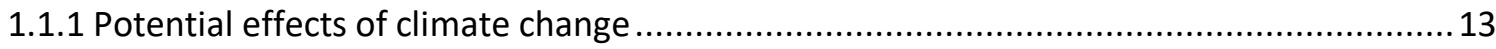

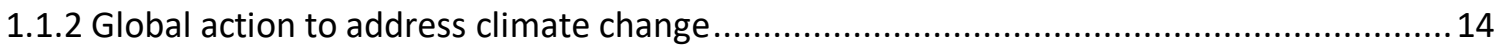

1.1.3 Climate change is not just an issue for small island nations .......................................... 15

1.2 The Importance of Methane and Agriculture in Global Greenhouse Gas Emissions .......................15

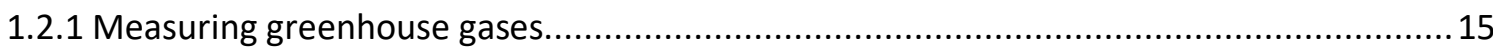

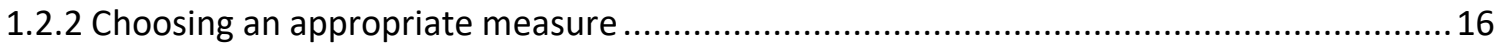

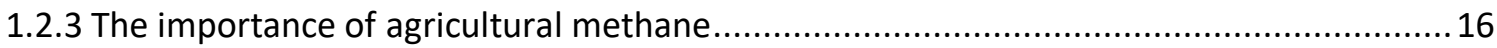

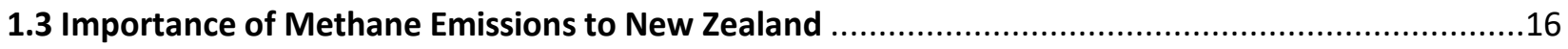

1.3.1 The potential effects of climate change on New Zealand ............................................. 17

1.3.2 Addressing New Zealand's agricultural emissions .................................................... 17

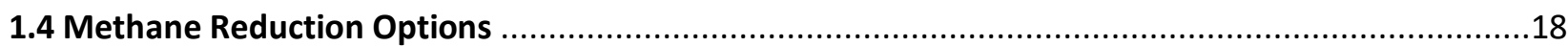

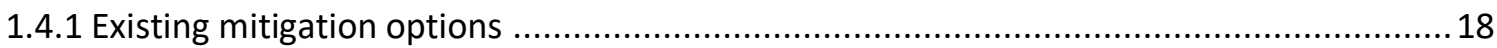

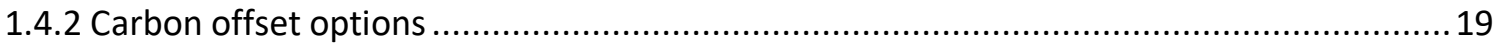

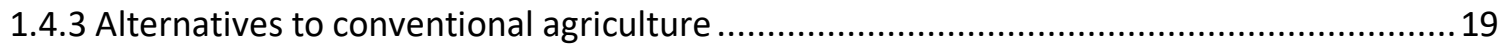

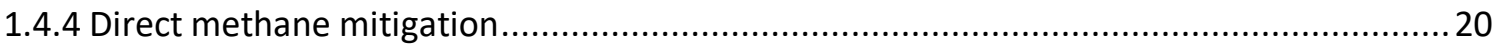

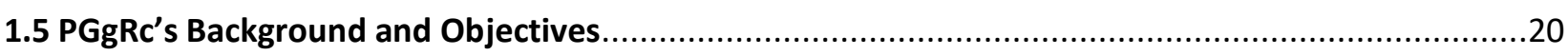

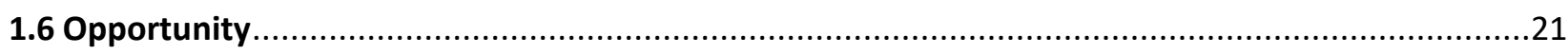

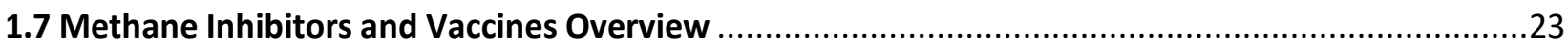

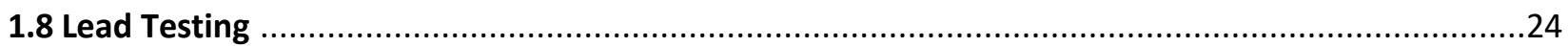

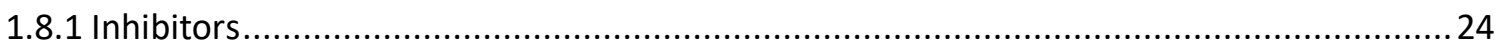

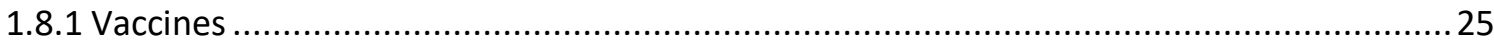

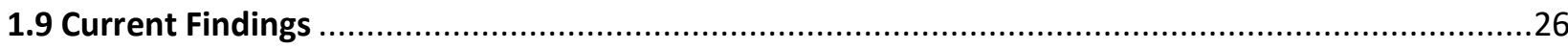

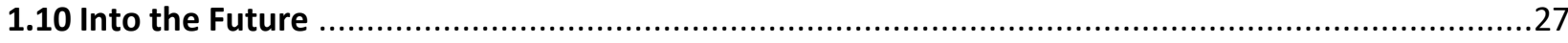

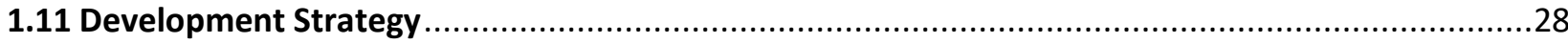




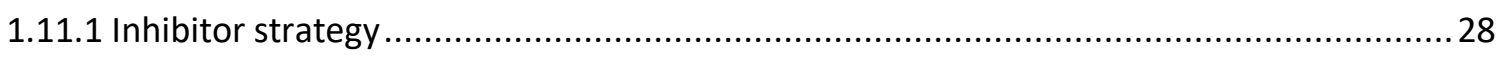

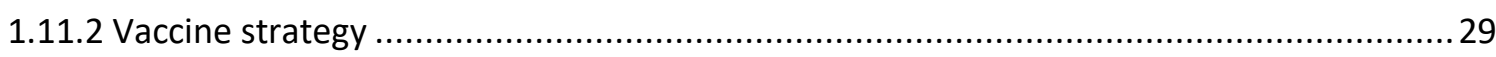

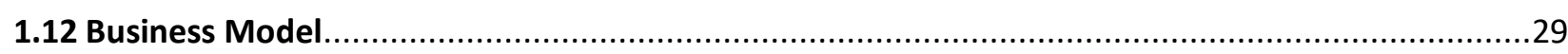

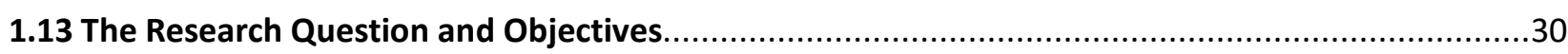

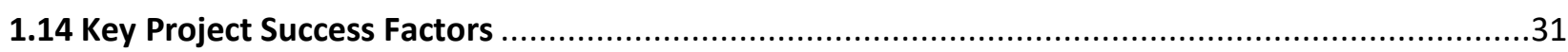

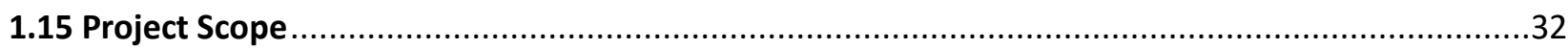

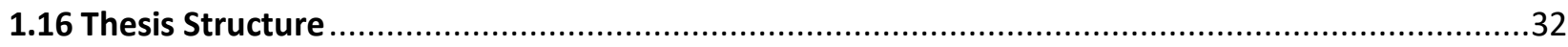

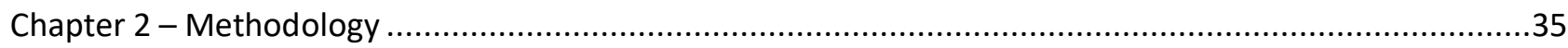

2.1 Research Scope

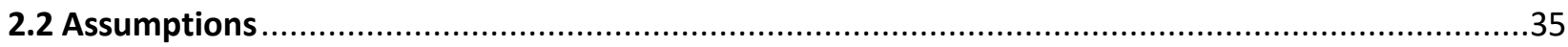

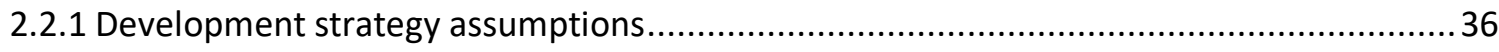

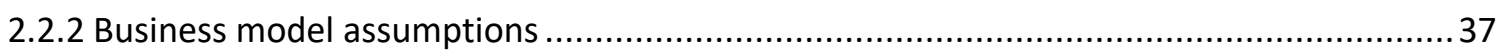

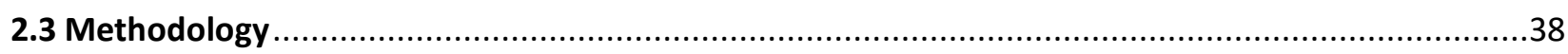

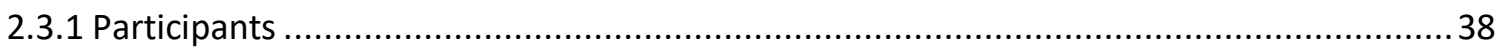

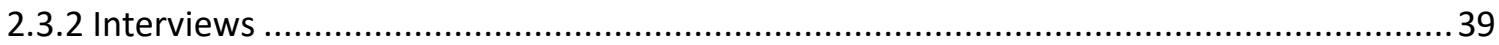

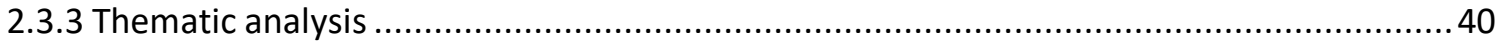

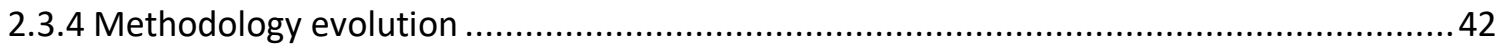

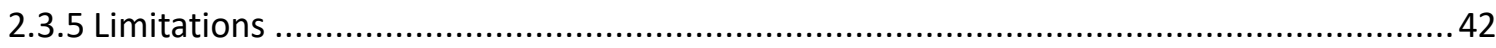

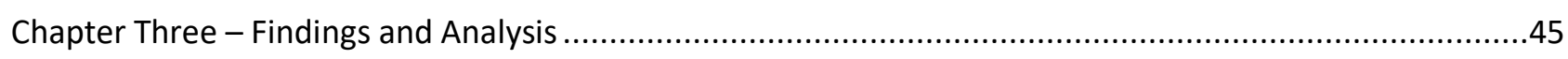

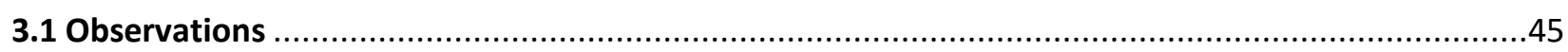

3.1.1 Semantic Theme 1 - Farmer concerns about PGgRc's technologies ................................ 45

3.1.2 Semantic Theme 2 - What value farmers perceive in PGgRc's technologies .................... 47

3.1.3 Semantic Theme 3 - Farmer access and use of the technologies.................................. 48

3.1.4 Matrix of farmer/sub-theme interactions .................................................................. 49

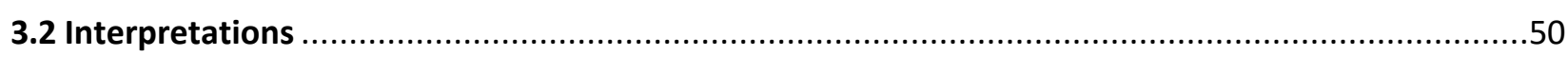

3.2.1 Latent Theme 1 - Farmer Interest in natural options ................................................. 50

3.2.2 Latent Theme 2 - Farmer adoption of technology …….............................................. 54

3.2.3 Latent Theme 3 - Farmer views on mitigating methane .......................................... 58

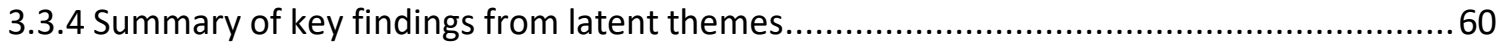

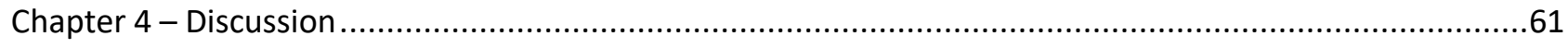

4.1 Major Findings

4.1.1 Finding 1 - Farmers value the technologies if they can mitigate methane costs...............6 61 
4.1.2 Finding 2 - Methane emissions are viewed as important .......................................63

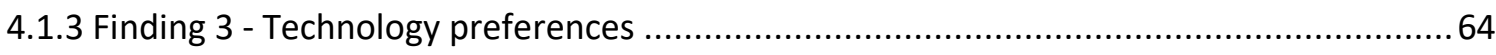

4.1.4 Finding 4 - Some farmers are interested in subsidies .........................................68

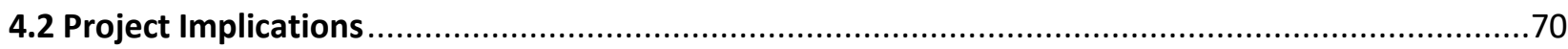

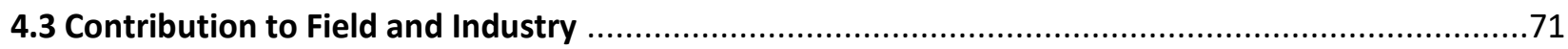

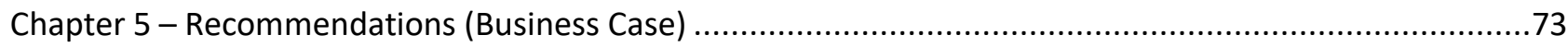

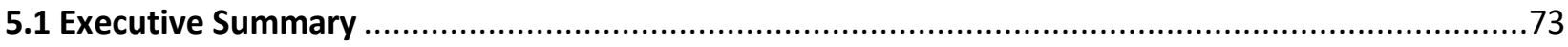

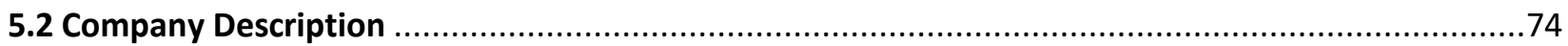

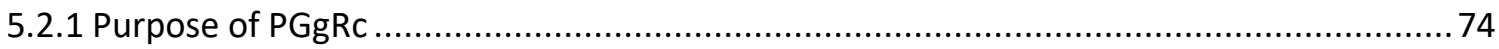

5.2 .2 Business model.................................................................................... 74

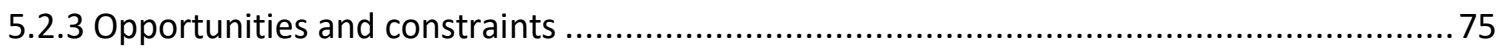

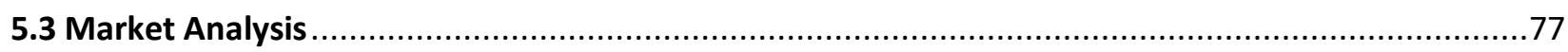

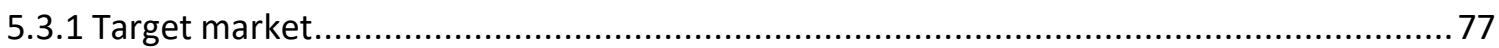

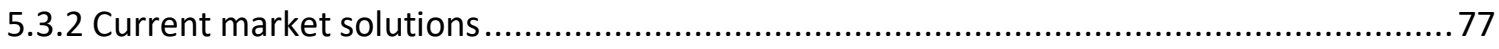

5.3.3 Barriers to changing market behaviour ....................................................... 78

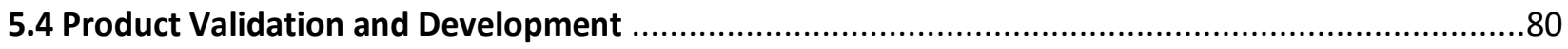

5.4 .1 Current status of the technologies............................................................ 81

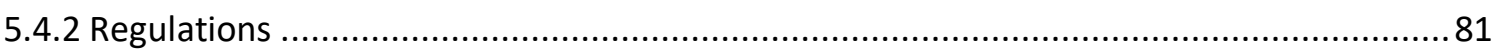

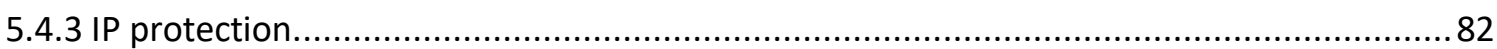

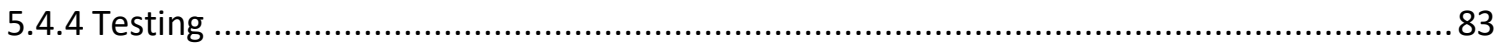

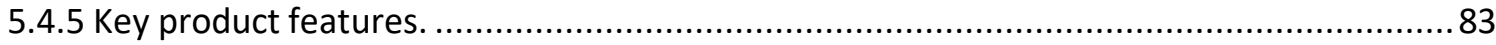

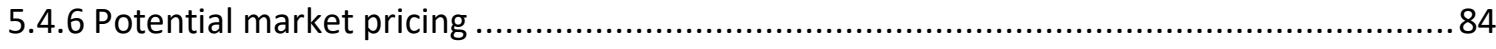

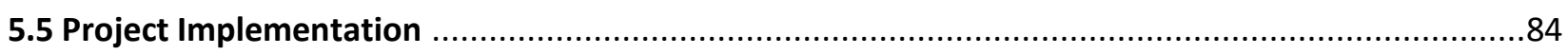

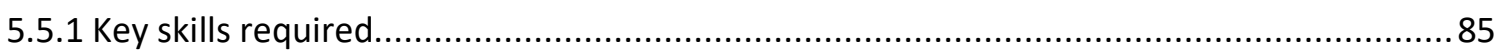

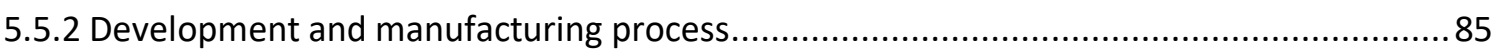

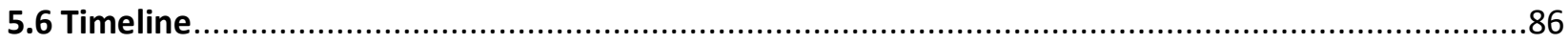

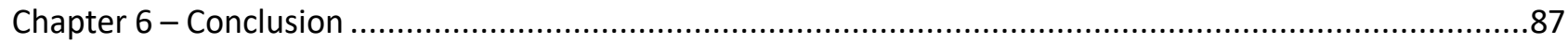

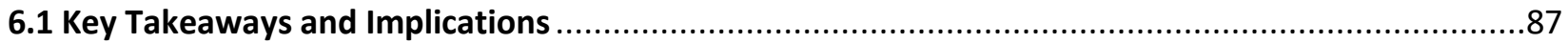

6.1.1 Scenario 1 -The technology can provide benefits to animal performance, and mitigates methane 
6.1.2 Scenario 2 - The technology doesn't provide enough benefits to animal performance that it would be adopted without regulation but can mitigate methane costs introduced in New Zealand and overseas. 89

Recommendations 90

Future Development 90

Government policy 90

Appendices. .93

Appendix 1 - Semi-Structured Interview Question Guide .93

Appendix 2 - Initial Thematic Map. .96

Appendix 3 - Candidate Thematic Map .97

Appendix 4 - Final Thematic Map .98

References. .99 


\section{List of Illustrations}

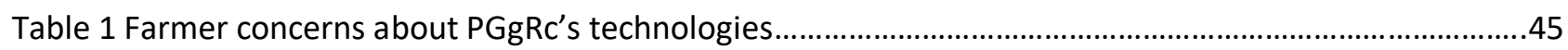

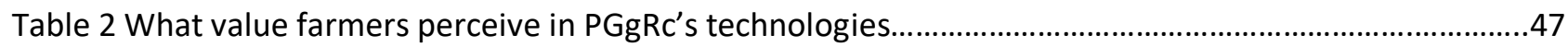

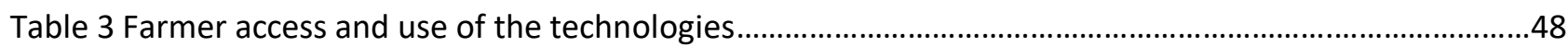

Table 4 Matrix displaying farmer/sub-theme interactions...............................................................................49

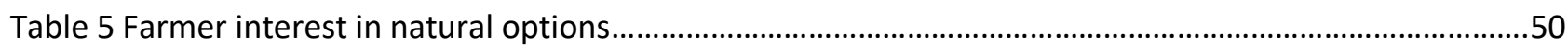

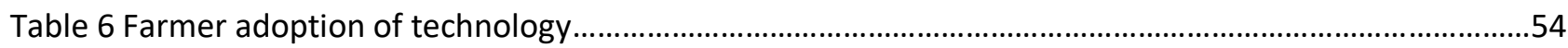

Table 7 Farmer views on mitigating methane .....................................................................................................58

Table 8 SWOT analysis of PGgRc's methane vaccines and inhibitors.................................................................76

Table 9 Regulatory bodies in the relevant countries PGgRc has patents..........................................................81

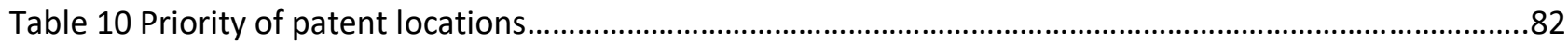

Table 11 Key features of methane vaccines and inhibitors...............................................................................

Figure 12 Visual representation of key skills required.............................................................................................

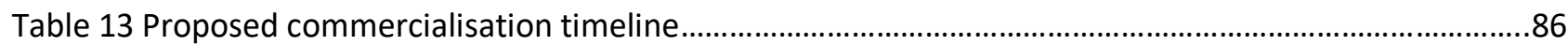




\section{Chapter 1 - Introduction}

This thesis explores the commercial viability of novel technology designed to reduce methane emissions from ruminant livestock. Methane contributes to climate change as a greenhouse gas (GHG) and is a major component of agricultural emissions globally. Reducing methane emissions is one way to mitigate climate change driven by GHGs. This research project examines two technologies being developed by the Pastoral Greenhouse Gas Research Consortium (PGgRc) designed to mitigate methane emissions from ruminant livestock. The research has been conducted in partnership with PGgRc as part of the Master in Innovation and Commercialisation programme at Victoria University of Wellington, New Zealand. PGgRc control the patents related to their methane reduction technologies, a vaccine and an inhibitor, and have provided assistance with technology details, and facilitated communication with members of the farming industry. The aim of this project is to verify assumptions made about their intended market, focusing on farmer adoption and use. Interviews have been conducted with farmers around New Zealand and analysed to build a business case for further developing the technology.

This chapter begins by discussing climate change which is at the core of this research. This leads into the importance of methane as a GHG and its implications for New Zealand agriculture. Next, the available options for methane mitigation are discussed and the opportunities for PGgRc's methane reduction technologies are explored before explaining the specifics of those technologies. It then outlines the proposed development strategy and business model before outlining the research question and objectives of this project. It then states the key success factors and unknowns for the project, and the scope of the thesis. It concludes by outlining the structure of the thesis.

\subsection{The Global Impacts of Anthropogenic Climate Change}

Global warming and resulting climate change are pressing societal and environmental issues facing us all. There is a consensus among the scientific community that anthropogenic GHG emissions are contributing to global warming (Cook, et al., 2014; Powell, 2016). The resulting environmental and social changes caused by global warming could be extensive.

\subsubsection{Potential effects of climate change}

Environmental impacts range from increased number of wildfires in the western continental United States (Abatzoglou \& Williams, 2016), to rising sea levels along coastal areas (Nicholls \& Cazenave, 2010; Weissenberger \& Chouinard, 2015, pp. 7-18). Climate change is likely 
to affect global agriculture, as environmental stress such as drought and extreme temperatures can negatively affect livestock productivity (Sejian, Bhatta, Soren, Malik, \& Lal, 2015). Climate change could reshape the global economy if no action is taken, reducing the average global income by $23 \%$ by 2100 and possibly amplifying existing global economic inequalities when compared to scenarios without climate change (Burke, Miguel, \& Hsiang, 2015).

The potential social effects are best exemplified by the many small Pacific island nations, or Small Island Developing States (SIDS). These SIDS are vulnerable to the many challenges of rising sea levels such as costal erosion, increased incidence of drought, and more destructive storm surges (Farbotko \& Lazrus, 2012). How the people of these SIDS respond to their changing environments, and whether the countries producing the majority of GHG emissions have a responsibility to assist affected SIDS is still being discussed and explored.

\subsubsection{Global action to address climate change}

The threats posed by climate change are driving nations around the globe to act against GHG emissions. The recent Paris Agreement is one example of societal change in response to global warming, with all but three world nations committing to GHG emission reduction targets. Participants have agreed a long-term goal of keeping global temperature rise this century to well below $2^{\circ} \mathrm{C}$ above pre-industrial levels and pursue efforts to limit the temperature increase to $1.5^{\circ} \mathrm{C}$. Parties involved set "nationally determined contributions" (NDCs) which outline their emissions and reduction implementation efforts/plans. The agreement accounts for the difficulties developing and vulnerable countries will face, providing a framework for action and support (United Nations, 2017; European Commission, 2017).

While the Paris Agreement is an example of global cooperation against climate change, many island nations feel action being taken is inadequate (United Nations, 2017). SIDS, such as Tuvalu, are expected to suffer the worst effects of climate change and have little ability to mitigate global emissions (Barnett, 2011). UN climate change policy is a point of contention between SIDS and industrial nations (Paepcke, 2014, p. 26). Rising sea levels further aggravate existing threats to SIDS such as storm surges and erosion, potentially rendering islands uninhabitable (Paepcke, 2014, p. 18). As habitable land is lost, there is potential for millions of lives to be disrupted over the next 50 years (Christian Aid, 2007). 


\subsubsection{Climate change is not just an issue for small island nations}

While SIDS are the most dramatic example of climate change impact, developed countries are also expected to face costs resulting from environmental changes. For example, loss of coastal land in Europe could lead to increased value of remaining land, resulting in increased market rent. In this way, even people and organisations not directly affected by the sea level changed will feel the economic effects (Bosello, Nicholls, Richards, Roson, \& Tol, 2012). An OECD paper assessing climate change impact on port cities used Copenhagen as a case study. The study concluded that despite Copenhagen having low risk of coastal flooding, a sea level rise of $150 \mathrm{~cm}$ could result in losses reaching EUR 3 billion because of 120 -yr storm surge events. It is impossible to precisely predict how much sea levels will rise, so adapting current costal flood protection through continued maintenance and upgrading would limit future risk and mitigate excess infrastructure spending (Hallegatte, et al., 2008).

Action needs to be taken by all to mitigate the future impact of climate change. The development of novel technologies is one route, but no less important than taking what actions we already can to mitigate our carbon footprint.

\subsection{The Importance of Methane and Agriculture in Global Greenhouse Gas Emissions}

The primary GHGs are $\mathrm{CO}_{2}$ and methane, which make up the majority of GHGs, comprising $76 \%$ and $16 \%$ respectively of global emissions in metric tons $\mathrm{CO}_{2}$ equivalent $\left(\mathrm{CO}_{2} \mathrm{e}\right)$ during 2013 (StatsNZ, 2018).

\subsubsection{Measuring greenhouse gases}

There are multiple metrics for comparing GHGs. Most metrics utilise $\mathrm{CO}_{2}$ as a standard against which other gases are compared. The two most common metrics are Global Warming Potential (GWP) and Global Temperature change Potential (GTP). GWP over 100 years is used as the standard metric in Intergovernmental Panel on Climate Change (IPCC) assessments under the United Nations Framework Convention on Climate Change (UNFCCC). GWP measures the cumulative warming effect of $1 \mathrm{~kg}$ of a GHG relative to $1 \mathrm{~kg}$ of $\mathrm{CO}_{2}$ over a given period of time. The current best estimate of methane GWP over a 100-year period is 28. GTP is an alternative measure that is being increasingly considered. GTP is based on global temperature change over a given period of time as a result of $1 \mathrm{~kg}$ of a GHG compared to $1 \mathrm{~kg}$ of $\mathrm{CO}_{2}$. The current best estimate for GTP for methane over a 100 -year period is 4 . The difference in methane GWP and GTP values is 
predominantly due to methane's warming occurring during the first 30 years after emission, favouring higher values under GWPs cumulative calculation (Hollis, et al., 2016).

\subsubsection{Choosing an appropriate measure}

Which measurement metric between GWP and GTP is most appropriate depends on what the measurements are for. If global policy is to limit warming to $2^{\circ} \mathrm{C}$ above pre-industrial levels as outlined under the Paris Agreement, then the value of methane should be less than the 100 -year GWP value of 28 until $\mathrm{CO}_{2}$ levels approach zero. However, the value of methane emissions is combination of scientific, political, and economic decisions and will shift accordingly. There are many cases to be argued for certain policies, and all change how best to value methane emissions. It could already be too late to limit greenhouse gases to $2^{\circ} \mathrm{C}$, as some modelling estimates there is a $5 \%$ chance of achieving the limitation goal by 2100 unless drastic changes in carbon intensity occur (Raftery, Zimmer, Frierson, Startz, \& Lui, 2017). Achieving drastic changes in emissions intensity in the next 80 years to limit 2100 temperature change will require greater action against methane than if the focus is on the effect of gases over a 100-year period.

\subsubsection{The importance of agricultural methane}

It is important to understand where global methane emissions are coming from and what is contributing to them. The agricultural sector contributes $\sim 50 \%$ of global methane emissions, with the largest contributions coming from enteric fermentation, rice cultivation and agricultural manure. Enteric fermentation, a process that occurs in ruminant livestock, is predicted to account for $27 \%$ of global methane emissions in 2020 (Global Methane Initiative, 2016). In this situation over a quarter of global methane emissions would be generated by agricultural ruminants.

Agriculture is unlikely to undergo any rapid changes in the next 5-10 years simply because demand for food is a constant, and any dramatic innovations in developed counties are unlikely to affect developing countries unless they are charitable endeavours. As livestock are a major producer of methane and are unlikely to be going away very soon, potential methods for mitigating agricultural emissions within existing systems are potentially very valuable.

\subsection{Importance of Methane Emissions to New Zealand}

New Zealand occupies a unique position for a developed country. It is geographically isolated from most of the developed world, and still has an economy primarily based on agriculture and resource exports. A significant proportion of New Zealand greenhouse gas 
emissions come from its agricultural sector, 48\% of $\mathrm{CO}_{2} \mathrm{e}$ in 2015 (Ministry for the Environment, 2017), making it the largest contributor that year. The largest source of emissions from the agricultural sector in 2015 was methane (73.1\% of total sector emissions), followed by $\mathrm{N}_{2} \mathrm{O}$ emissions (20.6\% of total sector emissions).

\subsubsection{The potential effects of climate change on New Zealand}

Climate change is likely to have some significant impacts on New Zealand. Many of our major cities are coastal; such as Auckland, Wellington, and Christchurch, which places them at risk from sea level rises. Additionally, agriculture is one of the economic sectors likely to suffer because of climate change (Sejian, et al., 2015). However, it is possible the greatest impact to New Zealand could be how climate change affects other nations and the global economy. While New Zealand could be less vulnerable to the economic impact of climate change as a wealthier country (Burke, et al., 2015), this doesn't necessarily mitigate global economic losses come 2100 . As an export-oriented nation, it seems sensible for New Zealand to take proactive measures to mitigate climate change contributions and impacts, to strive for a stronger global economy come the end of the century compared to what could be without taking action.

\subsubsection{Addressing New Zealand's agricultural emissions}

Under the Paris Agreement, New Zealand has set goals to reduce its greenhouse gas emissions, measured in carbon dioxide equivalent $\left(\mathrm{CO}_{2} \mathrm{e}\right)$, to 30 percent below 2005 levels by 2030 (Ministry for the Environment, 2016). As previously stated, agriculture contributes a significant proportion of New Zealand greenhouse gas emissions. Reducing agricultural emissions is important if New Zealand's current emissions goals are to be reached, but how to target the agricultural sector requires careful consideration of multiple factors. As outlined in a working report by Kerr (2016), there are multiple reasons why agriculture could receive differential treatment. For example, people must have food to live, and food cannot be produced with zero emissions. While changing production systems away from ruminant livestock would reduce methane emissions, $\mathrm{N}_{2} \mathrm{O}$ emissions occur in even the most efficient systems. However, there are potentially more economic benefits if New Zealand treats agricultural emissions like any other greenhouse gas emission.

If internationally policy on climate change treats methane like any other emission, the global market could favour producers of agricultural products who produce less methane. Countries such as New Zealand are well positioned as established producers with high efficiency. 
Additionally, inclusion of agricultural emissions in global policy will reduce global costs of mitigating climate change. Without the agricultural sector reducing their emissions other sources of greenhouse gases will have to make greater reductions to reach mitigation targets, driving up the cost of $\mathrm{CO}_{2}$. Including agriculture should lead to lower emissions, benefiting New Zealand and other countries (Dorner \& Kerr, 2017).

Agriculture needs to be actively involved if New Zealand hopes to reach its emissions goals without purchasing some form of carbon offset. Novel methods for reducing methane emissions are useful tools in this task, offering farmers alternative routes to reducing their GHG emissions. The development of novel technologies is an opportunity to fulfil a developing market need. PGgRc is an organisation that was established to find options for mitigating New Zealand's pastoral greenhouse gas emissions. They have been exploring methane mitigation routes such as diet and selective breeding to generate lower methane producing animals alongside their research into methane vaccines and inhibitors. Their goal is to identify and provide methods for reducing methane emissions from the agricultural sector, with hopes to sell these products within New Zealand and abroad.

\subsection{Methane Reduction Options}

Having the ability to directly mitigate or reduce methane emissions could be of benefit to New Zealand and other nations with significant agricultural sectors. PGgRc intend to provide farmers with options to directly mitigate the methane produced by their livestock, but there are other routes and technologies that could offer solutions to methane emissions.

\subsubsection{Existing mitigation options}

There are options for agricultural sectors around the world to mitigate their emissions. Improving farm system productivity can reduce the intensity of on-farm emissions by generating more product per unit of GHG (Beukes, Gregorini, Romera, Levy, \& Waghorn, 2010). Effluent management is another opportunity but is limited by the farm system. In New Zealand our predominantly pastoral grazing systems limit the opportunities for effluent methane capture and elimination, as animal excreta is deposited directly onto the pasture. However, when livestock are off pasture their effluent must be removed and processed. Approximately $6-10 \%$ of animal excreta on a dairy farm is deposited in the collecting yards and milking shed (Bolan, Laurenson, Luo, \& Sukias, 2009), and herd housing situation require management of all effluent while animals are being housed. Farm effluent is generally managed using pond systems, which presents an 
opportunity for methane capture and utilisation with the right infrastructure (Bolan, et al., 2009). Diet management through feed offers another route for methane mitigation, with certain feed crops reducing the methane generated via enteric fermentation (Gluckman, 2018). Again, this option is limited in New Zealand, as supplementary feed isn't a constant aspect of most pastoral systems. Transition away from livestock-based agriculture into horticulture is another option. By reducing ruminant numbers, the amount of methane emissions from the sector will be reduced. However, there is land used for farming that isn't suited for horticulture which is productive when used for supporting livestock. For farmers with such land there is little reason to transition away from livestock.

\subsubsection{Carbon offset options}

Methods of carbon sequestration are also viable, such as soil sequestration and afforestation. Due to the relatively high organic content already in New Zealand soils by international standards, it is less of an opportunity here than in countries such as Australia and the USA. Afforestation offers a potentially profitable route through conversion of more marginal farm land into forests that can sequester large quantities of carbon and produce valuable fibre (Kerr, 2016).

\subsubsection{Alternatives to conventional agriculture}

It is also important to consider the growing interest in synthetic meats and lab grown meats. As of 2015 , technology can produce meat suitable for mincing, but not proper muscle suitable for other forms of meat (Ryan, 2015). This hasn't discouraged interest in such technology from investors, with the company Memphis Meats raising \$17 million in 2017 from investors such as Cargill, Bill Gates, and Richard Branson (Singh, 2017). Alongside synthetic meat is a growing industry of synthetic milk. Produced via plant-based proteins or genetically engineered (GE) yeast, development is simpler than for synthetic meats. For example, the company Perfect Day is a US based start-up using microflora to produce milk proteins (Perfect Day, 2018). The process occurs in large fermentation tanks and generates dairy proteins, casein and whey, that are functionally the same as those generated from cattle. Synthetic meats and milk can be produced with far less water usage and methane production than conventional livestock rearing. The process doesn't require land for livestock to graze, and there is no rumen involved in the process so substantially less methane is produced. Any emissions are occurring in a controlled space, so are easier to manage than in pastoral agricultural systems. Synthetic products offer an alternative route to 
mitigating agricultural emissions while maintaining food production. Despite the purported benefits, synthetic meat technology is still in its infancy and faces challenges with public perception. Genetically modified organisms (GMO) and GE are still met with public scepticism based on concerns about what is 'natural' and arguments of 'interfering with nature' (Marcu, et al., 2015).

\subsubsection{Direct methane mitigation}

Finally, inhibitor technology offers another route for methane reduction. Enteric fermentation can be limited by targeting methane producing microorganisms (methanogens) that exist in the rumen of ruminant livestock. These technologies reduce the ability of methanogens to produce methane by reducing their numbers or inhibiting their methane producing pathways. Methane inhibitor technologies are in development by PGgRc and the Dutch company DSM Nutritional products (DSM). Inhibitors are compound-based products that require regular doses to remain effective. PGgRc is also investigating methane vaccines that aim to inhibit methanogens in a similar manner to inhibitors, but use the ruminant's immune system instead of a chemical compound. Additionally, researchers have been exploring the effect of tropical macroalgae (seaweed) on methane production when fed to ruminants. A recent study highlighted two species based on their ability to mitigate methane production, Dictyota and Asparagopsis. These species reduced methane output by $92.2 \%$ and $98.9 \%$ respectively in the study, however further research is needed to verify their safety and impact on host animal health (Machado, Magnusson, Paul, de Nys, \& Tomkins, 2014).

\subsection{PGgRc's Background and Objectives}

Formed in 2002, PGgRc is an Unincorporated Joint Venture (UJV). The partners in the UJV are Fonterra, DairyNZ, Beef+LambNZ, DeeResearch, AgResearch, PGGWrightson, Fertiliser Association and Landcorp Farming. Funding from the partners is matched 1:1 by investment from the Ministry of Business, Innovation and Employment (MBIE) through a partnership funding scheme. The objectives of PGgRc are:

1. To undertake a greenhouse gas emissions mitigation research programme;

2. To maximise the research opportunities and benefits primarily for New Zealand farmers and where compatible with the priority, the profitability of the Joint Venture;

3. To deliver the Joint Venture's research results to New Zealand and when appropriate globally. 
PGgRc has sole ownership of all intellectual property (IP) for commercialisation purposes. Research conducted with MBIE had agreement terms giving control of all IP to PGgRc. However, since 2009 some research has been joint funded by the Ministry for Primary Industries (MPI) which had a different agreement providing shared ownership of the IP. Jointly owned IP can complicate any partnership discussions, and after negotiations about joint ownership MPI agreed to assign any partially owned vaccine and inhibitor IP to PGgRc. This provides PGgRc with freedom to operate in their commercialisation matters. PGgRc is focused on four methods of methane reduction:

1. Animal genetics;

2. Low GHG feed;

3. Methanogen Inhibitors;

4. Methanogen Vaccine.

Of these four areas inhibitors and vaccines have the greatest potential to make a large impact on methane emission levels, as such they are the commercialisation focus for PGgRc and this project.

\subsection{Opportunity}

PGgRc hope to successfully commercialise their methane vaccines and inhibitors, both in New Zealand and overseas. Action must be taken to address climate change if warming is to be limited to $2^{\circ} \mathrm{C}$, and methane is one of the primary GHGs. How GHG mitigation is prioritised will vary from country to country based on what global and local policies are in place and what their emissions profile is. New Zealand is likely to place more emphasis on methane than many developed countries due to its significant agricultural emissions. PGgRc is positioning to deliver products suited for grazing farm systems, with their technology being developed in New Zealand for local farming environments. Because development is funded through investment from New Zealand agriculture and the New Zealand government PGgRc expects to position their products competitively for market, as they have less capital invested into their research to regain allowing them more freedom with pricing. Their technology must still perform the task it is intended to do, and there is an expectation from government and the agricultural industry that their investment will generate a return, both in methane mitigation and as a business. While they are not alone in developing methane inhibitors, competition with DSM could provide benefits within the market by offering farmers a choice. PGgRc could have an advantage in marketing their technology to pastoral grazing systems, as there is potential to work with the New Zealand agricultural industry 
to design and test their products. There is potential to license any solutions they find for using an inhibitor within a pastoral system to DSM, thus profiting from their competition in markets they have not entered.

The 2017 New Zealand elections resulted in a change in government, with a Labour led coalition replacing the previous National led government. The Labour government intends to take greater action to mitigate climate change, transitioning to a sustainable low-carbon economy. To do this they intend to create an independent Climate Commission tasked with managing carbon budgeting. The Climate Commission would advise the government on significant viable options of GHG mitigation to pursue. In addition, Labour have proposed including agriculture in the New Zealand emissions trading scheme (ETS) within their first term. They have suggested agriculture would have a free allocation of $90 \%$ initially, meaning the sector would be responsible for $10 \%$ of their emissions (New Zealand Labour Party, 2017). The inclusion of agriculture into the ETS could incentivise the use of emission mitigation technology to account for the industries $10 \%$, however it is likely the industry would begin with simpler solutions.

Adoption of methane inhibitors and/or vaccines is likely to come down to two factors;

1. Methane reduction resulting in increased animal performance.

2. The government encouraging use through direct regulation or subsides/cost reduction.

PGgRc's technologies are still some years away from market, during which time there may be positive or negative developments. The inhibitor is targeting $>30 \%$ reductions in methane production for ruminant animals, and the vaccine is targeting $>20 \%$ reductions. Ideally, the technologies will be found to have some productivity benefits for the animals they are used on, offering greater value to farmers than simply reducing emissions that currently do not cost them anything. As things stand farmers gain little commercial benefit from reducing methane emissions. However, as action to mitigate climate change grows so will pressure on the agricultural sector to reduce their emissions. As previously discussed there are multiple possible options available for mitigating methane, of which inhibitors and vaccines are but a part. For farmers who don't wish to convert pasture into arable land or forestry plantation, or those working land unsuitable for horticulture, methane vaccines and inhibitors would offer an option for mitigating their GHG emissions without reducing herd size. If future governments support use of the technology to help create a sustainable low-carbon economy, through regulation or subsidies, it will change the value proposition for farmers. If using the technologies can avoid a carbon cost and doesn't add significant costs to farm operations farmers are likely to use it. If farmers are using technology based on regulation or subsidies the challenge becomes how it will be regulated and measured. 
Farmers could buy the inhibitor and/or vaccine then leave it in the shed. Government involvement could require new monitoring infrastructure to ensure compliance and use, depending on the point of compliance. If the point of compliance isn't on farmers, it may be easier to regulate methane vaccine and inhibitor use.

\subsection{Methane Inhibitors and Vaccines Overview}

PGgRc's inhibitors and vaccines inhibit methane by targeting methane producing microorganisms in the rumen of livestock. Both technologies aim to inhibit the growth and methane pathways of organisms known as methanogens. Inhibitors are chemical compounds with a short effective duration per dose, requiring regular re-administration (approximately daily). Vaccines aim to utilise antibodies generated by the animal's immune system as inhibiting compounds, providing a sustained inhibition over months to a year at a time. This section provides details on methane production and development of the technologies.

Greenhouse gas emissions are an inevitable part of ruminant livestock-based agriculture, as methane production is a core process of normal rumen function. Methane production removes $\mathrm{H}_{2}$ from the rumen, preventing $\mathrm{H}_{2}$ build-up that would interfere with hydrogenase activity and limit oxidation of sugar (McAllister, et al., 2015). Because methane production plays a key role in efficient rumen function, animal welfare must be considered when trying to reduce methane emissions. A collaborative French and New Zealand study found that lambs without methanogenic archaea can be reared to adulthood in controlled conditions. The study found that a group of microorganisms know as acetogens will reduce $\mathrm{H}_{2}$ in rumen ecosystems when methanogens are absent but are outcompeted by methanogens when present (Fonty, et al., 2007). These findings show that normal growth is possible in rumen ecosystems without methanogens, and there are non-methanogenic microorganisms in the rumen that can remove $\mathrm{H}_{2}$.

Methanogens come from a distinct group of microorganisms, archaea. Due to differences in protein expression it is possible to target archaea for inhibition without directly inhibiting other rumen microorganisms. With evidence that the rumen will function adequately without methanogens, research has been conducted to identify the composition of the rumen ecosystem. The Global Rumen Census included scientists from around the world, and utilised genetic data to identify major population groups. A report utilising the data from Global Rumen Census collaborators found that major microorganism groups were common to rumen populations globally. Methanogenic archaea compositions were remarkably similar globally, meaning an inhibitor that functioned in one country was likely to retain its effectiveness in other countries 
around the world (Henderson, et al., 2015). The two largest groups of methanogens, belonging to the Methanobrevibacter gottschalkii and Methanobrevibacter ruminantium clades, accounted for $74 \%$ of all archaea. Including the next three most dominant groups, Methanosphaera sp. and two Methanomassiliicoccaceae-affiliated groups, accounted for $89.2 \%$ of the archaeal communities (Henderson, et al., 2015).

Researchers in New Zealand and globally have sequenced the genomes of some methanogenic archaea, identifying proteins absent in other rumen microorganisms. The first rumen methanogen genome to be sequenced was of Methanobrevibacter ruminantium, M1 which belongs to the most common group of methanogens found in the rumen (Leahy, et al., 2010). A database of sequenced methanogen genomes is being built, The Hungate 1000, with the goal of providing researchers better tools for identifying potential routes for methanogen inhibition. PGgRc is investing in this project. Identifying proteins or enzymes common to the major methanogen but absent from the rest of the rumen ecosystem can provide a target for inhibition. Four methods of methane mitigation are under development by PGgRc, two of which directly target methanogens; inhibitor compounds and vaccination. Both are intended to function by reducing the population of methanogens in the rumen, thus reducing methane emissions from cow eructations. Inhibitors do this by interrupting enzyme pathways within methanogens necessary for survival or methane production. Vaccines aim to reduce methanogen numbers by generating an immune response to specific antigens in the host animal resulting in antibodies being expressed in their saliva that will target the relevant methanogens in the rumen.

\subsection{Lead Testing}

\subsubsection{Inhibitors}

Through the Global Rumen Census project researchers have information on which methanogens are viable targets for inhibition, based on global presence and unique enzyme expression. Inhibitors are further along the development pipeline currently, and as such are likely closer to commercial release than vaccines. Hundreds of genes have been revealed through global research and compiled as part of The Hungate 1000 project. Methanogen genomes are compared across the catalogue of sequenced methanogens, looking for genes common across multiple groups. Inhibitor development pipeline begins by identifying methanogen specific genes for enzyme expressions, whereas vaccine development is based on identifying surface proteins for antigen targeting (Attwood, et al., 2011). 
Inhibitor development begins with genomic analysis of the target methanogen, looking for enzymes with methanogen-specific features that are involved in methane production, or vital cell function. Targets are prioritised based on factors such as importance to methanogen function; size; number of subunits; and existing assays and inhibitor data. Selected genes are amplified and cloned into E. coli cells via plasmid vectors. Once transformed, the E. coli produce the enzyme encoded in the plasmid vector. Once grown the enzymes are extracted from the $E$. coli using nickel-affinity chromatography. Assays are developed to assist in research. Researchers characterise the bio-chemical processes the enzyme is part of, which are used to identify existing compounds that affect these enzyme pathways. For example, a target enzyme may facilitate the conversion of one compound into another compound necessary for cell membrane production. Through testing drugs that inhibit methanogen growth against this enzyme pathway, you can identify if the drug achieves this inhibition by targeting this pathway. Novel compounds for inhibition are identified using high throughput screening. During this process, many different compounds are tested against an identified enzyme pathway. Compounds that best inhibit the enzyme pathway are then selected for further development. In silico screening is also used, where enzyme structure is modelled with computer software. Enzyme structures can be modelled based on the structure of evolutionary linked enzymes. In silico screening provides another option for inhibitor identification, as it can lead to untested inhibitors in homologous systems (Pastoral Greenhouse Gas Research Consortium, 2014, pp. 48-49).

\subsubsection{Vaccines}

Vaccine development pathway is quite different from that of the inhibitors. The vaccine will use antigens and an adjuvant in combination with a delivery system to stimulate methanogen antibody production in the saliva of vaccinated animals. The saliva will deliver antibodies to the rumen resulting in reduced methanogen activity. To do this, proteins on the methanogen cell (antigens) are identified which can be used to produce antibodies in the host animal when vaccinated. Various vaccines are formulated from the identified antigens. Antibodies produced by the vaccinated animal will bind to the antigens expressed on the methanogens, inhibiting growth and methane production. The vaccine doesn't need to kill the methanogen to be effective. Two mechanisms of action are envisaged; first is directly through antibodies binding to methanogen surface proteins related to growth; the second is antibody-induced cell agglutination (clumping cells together to move them through the rumen faster). The effectiveness of the vaccine is tested in vitro, using pure methanogen cultures in rumen fluid. In one study utilising sheep, the animal 
participants were vaccinated at 9-11 months, and then administered a vaccine booster three weeks later. Antisera is collected from 'pre-immune' animals, the single vaccination sheep, and again once the booster has been administered. The antisera, sera from blood containing antibodies, are added to the methanogen cultures and the levels of methane concentration are measured. The different vaccines are evaluated based on methane concentrations, compared to each other and the pre-immune antisera. The vaccines that generate the most methane reduction indicate which antigen generating methanogen fragments are best to pursue for future vaccine development (Pastoral Greenhouse Gas Research Consortium, 2014, pp. 56-58). If reduced methane concentrations are identified, the vaccine will be tested with a larger set of animals. Ultimately, this larger set of animals will be tested in respiratory chambers to confirm they do reduce methane emissions in a ruminant animal.

\subsection{Current Findings}

Currently inhibitor development has progressed much further than vaccine development. Two-day respiration chamber trials have refined the current inhibitor substance leads to four which showed methane inhibition of $30 \%$ without affecting general rumen function. Based on the two-day respiration chamber trials and further chemical analyses, 16-day and 28-day respiration chamber trials have taken place with several classes of compounds in sheep. Animals are adjusted to the trial feed for 10 days before baseline methane emission levels are made. Once a baseline is established the inhibitor being tested is added to feed, and additional measurements are taken immediately. The animals spend two weeks in a controlled environment with measurements taken at the end of each week. Two weeks is an industry standard to avoid short-term adaptions in the rumen ecosystem skewing data (NZAGRC \& PGgRc, 2017).

PGgRc has identified four classes of inhibitors. Some of the inhibitors contain multiple specific chemical compounds as part of their function. Longer-term trials of the most promising compounds from currently completed 16-day trials need to be undertaken, to identify how they affect animal health, welfare, and productivity. Longer-term trials are also an opportunity to determine whether the inhibitors will leave any residue in the animal products.

Alongside New Zealand research and development, there are other organisations globally exploring methane inhibitors. DSM have identified a compound, 3-nitrooxypropanol (3NOP), and undertaken longer-term trials with the compound. A 3NOP study in the United States used 48 cows in a randomised block design, with a two-week control period followed by a 12-week data collection period. Over the course of the study methane emissions were linearly decreased by 
$3 N O P$, averaging about $30 \%$ below the control group. With 3NOP milk protein and lactose yields were increased, and body weight gain was $80 \%$ higher than the control group. The increase requires further research to verify its significance. Milk production and composition, and feed intake were not negatively affected by 3NOP (Hristov, et al., 2015). The inhibitor was effective over the 12-week period, so offers an effective option for methane mitigation in livestock industries.

New Zealand farms are predominantly grazing systems, where animals are feed on pastural diets. In grazing systems, farmers do not usually see their animals every day and current inhibitors require frequent doses to maintain their effectiveness. Alongside inhibitor development is the challenge of identifying or creating an inhibitor delivery mechanism. Options such as bolus capsules are being investigated for their potential to administer an inhibitor continuously over a long period of time. For such systems to work, the inhibitor would need to be effective at a very low dose rate.

Vaccines offer an alternative option to the inhibitors, with many benefits when compared to the former. If a vaccine can be produced that provides suitable methane reductions it would be suitable for any farm system. The appeal of this concept is twofold; it offers a simpler solution for farmers than regularly administering inhibitors; and as a technology New Zealand is leading global research. Current research hasn't found any reason for it not to work, but development is still in very early stages.

\subsection{Into the Future}

Currently a New Zealand produced inhibitor is unlikely to be commercially available until 2025 and a vaccine until after 2026 (NZAGRC \& PGgRc, 2017). Thorough testing of potential inhibitors and vaccines must be undertaken to rule out any negative impacts on animal health, welfare and productivity which takes years to provide suitable levels of confidence in the technologies. If residues or health concerns arise from testing, that iteration of an inhibitor or vaccine would be eliminated as a potential product. When combined with further testing as part of global food and animal product requirements, there is a risk that some inhibitors and vaccines in development may still be struck out and abandoned before commercial release.

The DSM developed inhibitor is scheduled for released by 2019 based on the existing research undertaken, as its current development stage offers a head start on certifications a PGgRc inhibitor will have to go through. This may provide New Zealand with an inhibitor option by 2019 but would require the development of an appropriate delivery mechanism as our pastoral 
grazing systems are unsuited to the daily administration an inhibitor compound would require. There is research being undertaken by PGgRc already to find such a delivery mechanism, which is a potential strength for their products competing with the DSM products.

\subsection{Development Strategy}

PGgRc aims to have an inhibitor product for market around 2023, with a release date for vaccine technology still uncertain. PGgRc intends to develop their technologies to a proof of Concept $(\mathrm{PoC})$ stage before approaching established companies about commercial partnerships to produce final products. The specific development strategies for both the inhibitors and vaccines are outlined below.

\subsubsection{Inhibitor strategy}

PGgRc believes that licensing the inhibitor IP portfolio to a large company capable of developing it to a market ready product is the most effective commercialisation route. Because of how inhibitors function, commercial partners involved in animal health and feed and nutrition would best align with production and marketing of the technology. Having protection in place for their IP before engaging any potential partners is crucial, as discussing the technologies without controlling the IP could undermine its commercial opportunity.

To strengthen their IP portfolio PGgRc has also been investigating potential technologies for slow release of methane inhibitors. This provides three benefits, first of which is control of a delivery mechanism suitable for New Zealand farm systems. The second benefit is placing PGgRc in a stronger negotiation position when discussing the inhibitor IP with potential commercial partners. Finally, it offers a PGgRc inhibitor a competitive advantage over the DSM inhibitor when used in pastoral farm systems.

All inhibitor leads that become part of the IP portfolio will need to be tested for animal and human safety. Evaluating the toxicology and identifying any residues generated by inhibitors will require significant investment, which provides further reason to seek a licensing partnership with a large company able to field those costs or minimise them through use of their own infrastructure.

In summary, PGgRc's development strategy for their inhibitors is as follows:

1. Develop IP portfolio of inhibitor leads to PoC.

2. Test leads for safety and efficacy. 
3. Approach suitable companies for partnership, those involved with animal health and feed and nutrition.

\subsubsection{Vaccine strategy}

Vaccine technology is still very early in development, as a result any commercialisation strategy is subject to more variables than with inhibitors. Due to their limited infrastructure and market experience PGgRc believes that successfully commercialising a methane vaccine will require a licensing partnership. Animal health companies with suitable manufacturing capabilities, market knowledge, and global presence are the desired partner. To balance the development costs taking a PoC vaccine lead to final product PGgRc intends to license their IP portfolio on an exclusive basis.

Vaccines require three components, which are antigens, adjuvants, and a delivery system. AgResearch, a partner in the PGgRc UJV, have great experience and knowledge of ruminant methanogens. PGgRc is utilising AgResearch to identify lead antigens for their IP portfolio. The goal is to then bring their antigen IP to potential partners, who can provide or develop the adjuvants and a delivery system. Alternatively, adjuvants and delivery system could be licenced from another company.

In summary, PGgRc's development strategy for their vaccine IP is as follows:

1. Develop IP portfolio of vaccine antigen leads to PoC.

2. Approach animal health companies for partnership, those that can provide adjuvants and delivery systems.

3. License IP to company, who will then develop a final product.

\subsection{Business Model}

PGgRc aims to employ a licensing business model for their methane vaccine and inhibitor technologies. A licensing model is well suited for commercialising of PGgRc's technologies as it allows them to retain control of their IP integral to the inhibitor and vaccine technologies while bringing in market knowledge and production capabilities they currently lack. As a relatively small organisation, bringing in additional expertise will greatly improve PGgRc's market opportunities for the final methane vaccine and inhibitor products.

PGgRc has considered the idea of a New Zealand incorporated business providing methane mitigation globally, or a hybrid model where product manufacturing occurs in New Zealand and distribution occurs through licensing internationally. When compared to a licensing partnership 
with a suitable multi-national corporation the requirements to successfully establish such a business in New Zealand are of greater risk but could offer greater reward. PGgRc would have to invest capital in infrastructure and devote many years to the development of any methane vaccines or inhibitors and assume responsibility for the additional risks that entails. In return, they would gain greater control over the value chain of any methane vaccine and inhibitor products. It could be more profitable than licensing fees, and PGgRc would have more control over final product features. However, it could still require production of products to occur internationally, as New Zealand in limited in available manufacturing capabilities and it could be outside PGgRc's ability to establish them.

\subsection{The Research Question and Objectives}

This thesis focuses on the methane vaccine and methane inhibitor technologies PGgRc is developing. PGgRc and other consulted parties expect the success of these technologies in development to hinge on how profitable it can be for farmers. This is supported by previous research done into the attitudes of dairy farmers about GHGs and climate change which identified cost as the primary limitation for mitigating emissions (Newton, 2009; Fowles \& Weaver, 2009). The Commonwealth Scientific and Industrial Research Organisation (CSIRO) performed a study of Australian landowners and identified perceived superiority of a novel technology over its predecessors ('relative advantage') as the key factor of innovation adoption (Pannel, et al., 2006). However, in the years since this previous research was conducted awareness of the potential impacts of climate change has grown which may affect the value proposition of methane mitigation technologies. More recently a technical report for the Waikato Regional Council (Kaine \& Wright, 2016) highlighted that the complexity of a technology affects the willingness of dairy farmers to adopt or replace that technology. Which is to say, the more complex a technology is to implement or replace, the longer it will take for that technology to be adopted and the greater the risk it will be opposed.

The research question, 'What concerns do farmers have about PGgRc's technologies in development, and how do they feel about their use and design?' aims to validate the expectation that profitability is key and provide an indication of technologies 'relative advantages' and perceived complexity of use for farmers.

Alongside the primary research question, there are other variables that must be considered when exploring commercialisation of any PGgRc technology. PGgRc is hoping their methane inhibitors and vaccines will be commercially viable in a New Zealand market, with the 
option to enter global markets. The success of this goal is dependent on a variety of factors; such as the development of the vaccines and inhibitors resulting in a functional product, a market landscape suitable for the technologies, and ruminant farmers having appropriate incentive to use an inhibitor and/or vaccine. The objectives for this thesis are focused on the latter two factors, the existence of a market for the technologies and farmer adoption and use of them. As such, the main objectives are;

1. Investigating what farmers see as the strengths and weaknesses of the technologies. Highlighting where existing value is, and identifying new risks while validating those already identified;

2. Applying the findings from the investigative stage to validate the commercial potential of the technologies. Identify the opportunities and barriers presented and propose possible solutions to them;

3. Outline how PGgRc should proceed with the continued development of their technologies based on this project. Discuss which stakeholders will need to be contacted and what will be required from them for the best odds of commercial success.

\subsection{Key Project Success Factors}

There are four key success factors regarding this research project related to PGgRc's research and technologies. These factors are outside the scope of this research but are never-theless critical for project outcomes and commercial potential of the methane mitigation technologies. They are as follows;

1. The methane mitigation technologies can be produced at a cost that provides value to farmers while generating revenue for PGgRc. The price farmers pay for inhibitors and/or vaccines will be less than the savings resulting from use of the products, while still generating returns for PGgRc.

2. That methane mitigation technologies will be able to provide the mitigation they intend to and will reach market. There is no evidence to suggest this won't occur, but there is still a risk that issues may be identified in the later stages of product testing that destroy the viability of a promising lead.

3. Both proposed technologies are similar enough as final products in use and function to utilise the same business model. The same organisation is developing the two 
technologies, but there are still risks such as one of the technologies being unable to find a commercialisation partner.

4. The final methane inhibitor and vaccine products will be ready for market before they are supplanted or made redundant. There is competition from other inhibitor technology, and the agricultural sector is likely to undergo a shift as synthetic food technologies continue to develop and grow. However, it is unlikely that conventional farming will be replaced or saturated with competing technology before products are ready for market.

\subsection{Project Scope}

This research project aims to present a broad overview of farmer concerns and hopes about the PGgRc technologies under development. Farmer interactions with the technologies are the focus of this research as they are crucial for the success of this project. The primary function of methane vaccines and inhibitors is to reduce methane emissions from ruminant livestock, so farmers need to be able and willing to administer these technologies to their animals for this function to occur.

While the New Zealand agricultural industry and government are large stakeholders in the success of PGgRc's technologies, they are not the focus of this research. Government regulation and industry support will certainly affect the market potential of methane vaccines and inhibitors and are discussed throughout this project. However, farmers are the one stakeholder that will have to interact with the technologies, so it is critical to understand their expectations and concerns about any product upon release. With estimated releases for inhibitors at least five years away and vaccines at least ten years away, there is time to further explore the issues around market regulation and licensing partnerships. By focusing on farmers now, this project aims to highlight critical success factors from the one stakeholder that must adopt PGgRc's technologies.

\subsection{Thesis Structure}

Due to the nature of this master's programme, this thesis is structured slightly differently to a conventional thesis. For the most part a standard structure is followed. Chapter 2 describes the methodology employed in this research. Chapter 3 presents the findings and analysis. Chapter 4 discusses how the findings and analysis have impacted on the project. Chapter 5 presents recommendations in the form of a business case. As a result, chapter 5 is presented in a more 
commercial manner, intended as an accessible document for PGgRc and any potentially interested parties. Finally, Chapter 6 concludes the thesis. 


\section{Chapter 2 - Methodology}

This chapter covers core assumptions regarding the development strategy, business model and research design and describes the methodology used to collect and analyse the data. The validity of assumptions made is discussed, and their inclusion justified. The methods utilised are outlined in detail, and the process of data analysis is explained. This chapter concludes with a discussion about any changes to the methodologies over the course of the research project.

\subsection{Research Scope}

Consultation with Suzi Kerr, PGgRc, and course peers was used to narrow down the research focus and identify a target group for data collection. PGgRc has already begun to explore potential commercialisation partners and continue to develop their vaccine and inhibitor IP portfolios, but have done little research into how farmers perceive and value the technologies as part of their farm system.

It was clear from the consultations that farmers were the critical stakeholder in the success of methane vaccine and inhibitor technology. While government and agricultural organisations are likely to be key stakeholders in the success of any methane vaccines and inhibitors, without farmer adoption and use, the technology cannot achieve its primary function of reducing methane emissions from ruminant livestock.

Further discussion with PGgRc and Suzi Kerr asserted that farmer adoption and use of methane reduction technologies would hinge on the profitability of the products. To put it simply, if the product offered by PGgRc costs more than the value it provided the product alone would be unlikely to sell. Exploring this assumption was identified as the research focus for this project, as there are many unexplored variables that could influence the value of the technology for farmers. Understanding these variables will better position PGgRc to communicate what will be required from the other key stakeholders of government and agricultural industry to achieve successful commercialisation of the methane mitigation technologies.

\subsection{Assumptions}

Before making any assumptions regarding this research project, consultation of various parties was undertaken to build a better understanding of the potential market. Mark Aspin, of PGgRc, provided information about the status of the technologies, and the research consortium's current plans for commercialisation. Suzi Kerr advised on the potential economic factors that may influence farmer adoption of the proposed technologies. Course peers, also involved in their own 
master's research, highlighted alternative solutions and problems by offering their own perspectives on the project. Finally, discussion with my mentor helped to direct my research focus. There are two categories that the assumptions have be assigned to; assumptions regarding the development strategy, and assumptions regarding the business model.

\subsubsection{Development strategy assumptions}

As discussed in the previous chapter, PGgRc's methane vaccines and inhibitors will be the focus of this research project. PGgRc has identified development strategies for their technologies which are the basis for the assumption within this section. The following assumptions are applicable to both development strategies.

A primary goal for both technologies is mitigating methane emissions to $>30 \%$ for inhibitors and $>\mathbf{2 0} \%$ for vaccines. There is no evidence disproving these goals are achievable for both technologies, as such it has been assumed that both technologies will function and achieve their desired mitigation levels. Additionally, the methane vaccine and inhibitor will both function in similar ways when reducing methane emissions.

The safety of the proposed technologies for consumers and animals is of great importance. If the technologies detrimentally effect animals, it is unlikely a farmer will be willing to use them. For example, if the inhibitor reduces methane in dairy cattle, but also reduces milk solid production, the costs to that farmer may be too high. Likewise, if use of either technology leaves residues within the milk and meat of the animal, the broader public may be concerned about consuming contaminated or unnatural produce. It is assumed that methane vaccines and inhibitors can be produced without their safety becoming a point of contention.

Both technologies in development are intended to reduce only methane. While a major GHG, there isn't currently much market for methane mitigation technology. This could be because there aren't many methane mitigation options currently, rather than methane not being a mitigation focus. It is possible that the development of methane mitigation technology alongside reductions in $\mathrm{CO}_{2}$ and $\mathrm{N}_{2} \mathrm{O}$ will result in policy implementation targeting methane. This research assumes that policy against methane and ability to act will generate a desire to utilise PGgRc's technologies by the time they are commercially available products.

The chosen development strategies for each technology have assumptions specific to either the inhibitors or vaccines. 


\section{Inhibitor development strategy assumptions}

The following assumptions have been made about the inhibitor development strategy within the context of this project:

1. Multiple forms of inhibitor administration can be developed. Having more methods for delivering an inhibitor to animals expands the number of farm systems suitable for the technology. The potential market scope is much greater if the inhibitor could be administered via feed, bolus, and water systems.

2. Commercial release of a PGgRc inhibitor in approximately 5 years is achievable. Based on their development strategy PGgRc hopes to go from PoC to commercial product in about 5 years. This timeframe is assumed to be possible within this research project.

3. Methane inhibitors will be of commercial interest to potential licensing partners based on increased action against GHG emissions. While animal productivity gains through use of the inhibitor would provide the technology with value, it is assumed that increased action globally to mitigate climate change will create value in methane mitigation.

\section{Vaccine development strategy assumptions}

The following assumptions have been made about the vaccine development strategy within the context of this project:

1. Commercial release of a PGgRc vaccine in approximately 10 years is achievable. Based on their development strategy PGgRc hopes to go from PoC to commercial product in about 10 years. This timeframe is assumed to be possible within this research project.

2. A licensing partnership can be successfully created to bring methane vaccines to market. While animal productivity gains through use of the vaccine would provide the technology with value, it is assumed that increased action globally to mitigate climate change are valuable enough to be of commercial interest to potential partners.

\subsubsection{Business model assumptions}

PGgRc believes a licensing model is best suited for getting their technologies from PoC to commercial products. Due to the various interested parties in the end results of PGgRc's research they are currently pursuing licensing partnerships with large international companies, as this is perceived as the safest option for successful commercialisation. PGgRc does not currently possess the infrastructure required for manufacturing and distribution of their intended products. 
Licensing their technology IP portfolios to existing organisations with the capabilities and experience to produce vaccine and inhibitor products on the required scale is a safer commercial route. An ideal organisation would bring market knowledge and distribution networks that PGgRc currently lacks.

While PGgRc is the sole owners of the vaccine and inhibitor IP portfolios, under a licensing model the commercial partner will drive the development of final vaccine and inhibitor products. This research assumes both of PGgRc's technologies are similar enough as final products in use and function to utilise the same business model and can find commercial partners.

However, the current model could shift commercialisation partner focus based on how their interested parties view the market opportunities for methane vaccines and inhibitors. PGgRc has explored the idea of a New Zealand incorporated business should partnership discussions with large international companies fail to produce results. It is assumed for this project that a New Zealand incorporated business will not occur.

\subsection{Methodology}

This section outlines the methodological approach used for collecting data, and the analysis techniques used. The details of the data collection are explained and justified. It discusses the evolution of the research methodology. Outlining the reflection process and any recommendations made. It concludes with an acknowledgment of the limitations and challenges faced during the research process.

\subsubsection{Participants}

The participants in this study are farmers from around New Zealand, contacted though personal connections, PGgRc or participant recommendation. Farmers are a core stakeholder in the success of the methane vaccine and inhibitors. Without farmer adoption and use, the technology cannot reduce methane emissions within the agricultural sector. Participants were cold called, and/or emailed, and provided with an outline of the research before being asked if they would be interested in participating in a 30-minute interview. If contacted farmers expressed their interest in participating they were provided with an interviewee consent form and information sheet. Additional information regarding the potential technologies was available upon request, discussing the proposed technologies function and use in greater detail.

The time limitations for this research necessitated a smaller sample size, ultimately resulting in 16 participants. To minimise bias within this small sample, participants were sourced 
from a range of locations and farm systems around New Zealand. The farm systems were dairy, beef and lamb, as these are the core ruminant stock types that produce methane emissions. Deer farmers were originally intended for inclusion, but none asked were willing to participate. The age and experience of participants varied with some participants having less than five years work experience, and others over 40 years of experience. The sample includes farmers from multiple regions around New Zealand: Southland, Otago, Canterbury, Manawatu-Wanganui, Taranaki, Hawke's Bay, and Auckland. Not all participants are owners of the farms they work on, but all work full time upon their respective farms. The range of backgrounds and experiences provided variation within the sample size and improves the applicability of any findings to New Zealand farming countrywide.

\subsubsection{Interviews}

Semi-structured interviews (Adams, 2015; McIntosh \& Morse, 2015) were used to collect qualitative data regarding farmer perspective on PGgRc's proposed technologies. Interview content was established through consultation with Motu and PGgRc. Motu have conducted research into farmer adoption of zero-cost GhG mitigation systems and technologies, which provides some context and overlap with PGgRc's proposed products.

The interviews ran for approximately 30-minutes and contained four key sections, farm information, technology costs, technology risks, and technology benefits. Farm information focused on some quantitative data such as years farming, and system details such as stock numbers and farm size. This quantitative data provides a foundation for comparison of the collected qualitative data. For example, if a group of farmers within the data set dislike inhibitors this can be compared to quantitative data such as experience or location to see if there is a common feature that links them. The three sections about technology focused on identifying farmers concerns, potential solutions participants were already aware of, and any strengths participants could perceive in the technologies. The idea with the technology focused questions was to identify how best to shape and market PGgRc's technologies as they continue to develop.

The semi-structured format allowed interview participants to contribute their thoughts on topics outside of questions directly asked, while still providing a framework to maintain interview progression and core content. This provided a deeper pool of data, as concerns related to the technologies but not within the structure of the primary questions could still be introduced. Almost all interviews were conducted in person, with one done via Skype. Interviews were recorded for reference to assist in accurate transcription of their content. 
For the semi-structured interview outline see Appendix 1.

\subsubsection{Thematic analysis}

Thematic analysis was used to interpret the qualitative data collected. It is a method of analysing qualitative data to identify and interpret the patterns within (Braun \& Clarke, Thematic analysis, 2016), and is not confined to anyone field of research (Lapadat, 2012). This research utilises the process outlined in the paper, Using thematic analysis in psychology (Braun \& Clarke, Using thematic analysis in psychology, 2006).

There were multiple aspects to consider before beginning the thematic analysis. When identifying themes, they must be considered based on prevalence within the data. In this research, themes were identified based on frequency across the data set. How themes were determined remained consistent throughout the analysis. The purpose of this data analysis was determined to be a focused exploration of a particular theme. As stated in the assumptions, there is already a broad understanding of how farmers will react to the proposed technologies. This research is focusing on themes that relate back to use and adoption of the technology, to identify details about farmer concerns and desires for methane mitigation products.

There are two approaches to analysis under Braun \& Clarke's process. The inductive approach which is very data driven and uses themes identified within the data set, or the theoretical approach which is analyst driven and shaped by the researcher's theoretical or analytic interest in the area. A theoretical approach was utilised for data analysis as this research has been shaped by established ideas outlined in section 1.13, with some higher themes based on more inductive processes. The level of identified themes can be semantic or latent. Semantic themes are identified at an explicit or surface level, where what is said is the meaning. Latent themes are the underlying ideas of the data that shape the semantic content. Both semantic and latent analysis were employed within this research.

The process of thematic analysis used has been broken down into a set of phases according to Braun \& Clarke (2006):

Phase One - Becoming familiar with the data. When dealing with verbal data, which this project does, it must be converted into text for analysis. The process of transcription was an opportunity to become more familiar with the data. Initial ideas about how to format the data coding were formed during this phase.

Phase two - Generating initial codes. This began once a strong familiarity was established with the data. During this phase data was coded based on semantic or latent features 
identified within the previous phase. The aim was to collate the data into meaningful groups, but not to group it by themes yet. Extracts were coded for as many potential themes as possible, including surrounding data to retain context. Some data extracts were coded multiple times into different groups.

Phase three - Identifying candidate themes. This phase was an exploration of the collated data, searching for themes to group the extracts within. Visual representations in the form of mind-maps were used sort the different codes into themes, forming an initial 'thematic map,' see Appendix 2. Some codes became main themes, while other codes formed sub themes or were discarded. It was important not to abandon any identified themes during the third phase, as their validity was uncertain until reviewed during the next phase. Phase four - Reviewing themes. Once identified, the candidate themes needed to be checked on their consistency with the coded data and their relationship to the entire data set. Themes that lacked the coded data to support them were discarded. Some themes were merged, and other themes broken down into multiple themes to better represent the data contained. The reviewing process began by examining the themes at the coded level for consistency. If the coded data was consistent, the relevant theme could move onto the next step. If the coded data lacked coherency within a theme, that theme had to be reworked or replaced. This stage led to a candidate 'thematic map', see Appendix 3, which was evaluated against the entire data set. Additional themes were added based on data missed during earlier coding. If the map works, move onto the next phase. If the map doesn't, review and revise till it does.

Phase five - Defining and naming themes. This phase built upon the candidate 'thematic map', refining it into a final form, see Appendix 4. The core concept of each theme was defined, and the primary aspect of the data contained within determined. This was done by going back to the coded data within each theme and ensuring they were suitably organised and consistent. Each theme required a detailed analysis, identifying the 'story' of each theme and how it fit within the broader overall 'story' the of the data related to the research question.

Phase six - Report write-up. With a fully worked-out set of themes the final analysis and write up of the report was undertaken. This is detailed in the next chapter, Findings and Analysis. 
Audio recordings of the interviews were transcribed into text using Microsoft Word and formatted for auto-coding via NVivo, a software tool designed to organise, store, and retrieve data. Auto-coded data was grouped into nodes, providing a convenient way to identify themes based on the grouped data samples. Nodes can be added and removed as needed and were adjusted during each phase of thematic analysis. NVivo was also used to form 'thematic maps' which could then be converted into nodes, facilitating the constant adaption of coded data into themes as each phase progressed.

\subsubsection{Methodology evolution}

Due to the structure of the research there was little methodological evolution during this project. The largest meaningful evolution was within the semi-structured interviews. Because the interviews were guided there was room for participants to discuss ideas or concerns not directly related to the interview questions, which presented an opportunity to obtain novel data related to potential farmer interactions with methane vaccines and inhibitors. Some of these tangential ideas were of interest and integrated into subsequent interviews.

\subsubsection{Limitations}

The focus of this research project was to better understand how New Zealand farmers feel about PGgRc's technologies currently being developed. In relation to this project scope there were some research limitations. These factors were:

\section{Access to participants}

Finding farmers who are willing to participate in the research was difficult. Managing a farm is a year-round occupation with little down time, so farmers could have evaluated research participation against maintaining farm operations. In-person interviews were targeted to highlight the researcher's commitment to the interview and show appreciation for the participants' time. Some farmers suggested their willingness to participate was because of this decision.

\section{Sample size}

Because of the difficulty in finding participants, the sample size was limited to 16 participants. PGgRc provided contact details for 15 potential participants, however these farmers were limited to beef and lamb systems. Only four of the 14 farmers were interested in being interviewed, with the other farmers being uninterested or failing to respond to contact attempts. 
Personal contacts were used to find another nine participants, five dairy, three beef and lamb, and one lamb and wool. A further three participants, two beef and lamb and one dairy, agreed to interviews after initial participants suggested contacting them. Unfortunately, the sample didn't include any deer farmers whose livestock could potentially receive methane vaccines or inhibitors, despite attempts to find interested participants. While the sample is too small to indicate more than general thoughts among the New Zealand farming community, it was qualitative data which is better suited to smaller sample sizes than quantitative data.

\section{Measure used for data collection}

Semi-structured interview questions were used as data collection tools because of their versatility when acquiring quantitative data. Following the interview structure ensures key questions are answered, but participants are free to discuss tangential ideas as they arise which can identify novel areas for analysis. Within the context of this research semi-structured interviews were valuable for identifying farmer concerns related to methane vaccines and inhibitors that hadn't arisen in project discussions with PGgRc. Novel concerns could be integrated into latter interviews to obtain more data on the topic. However, novel concerns couldn't be discussed with participants who had already been interviewed. 


\section{Chapter Three - Findings and Analysis}

This chapter explores the data obtained during the research and presents an exploration of how it affects this project. The analysed data is presented and discussed for both semantic and latent themes. Sixteen participants were part of this research, who have been coded as F1 through to F16. This will allow opinions expressed across themes to be linked to a specific source.

\subsection{Observations}

Three semantic themes have been identified within the data after conducting a thematic analysis. These themes are Farmer Concerns About PGgRc's Technologies, What Value Farmers Perceive in PGgRc's Technology, and Farmer Access and Use of the Technologies. There are multiple sub-themes that contribute to each of the three which are detailed in this section, which have been coded S1 through to S10.

\subsubsection{Semantic Theme 1 - Farmer concerns about PGgRc's technologies}

All 16 farmers who participated in the research had concerns related to using PGgRc's technologies in development. The most frequent causes of concerns were related to affordability of technology and risks to animal health, alongside potential negative public reaction, use of the technologies over natural alternatives and how PGgRc is going to manage the commercialisation of the technologies. This is explored in Table 1 Farmer concerns about PGgRc's technologies.

Table 1 Farmer concerns about PGgRc's technologies

\begin{tabular}{|c|c|}
\hline Sub-theme & Representative quotes \\
\hline $\begin{array}{l}\text { Concern regarding the } \\
\text { affordability of technologies } \\
\text { (S1). } \\
\text { Expressed by } 14 \text { Participants. } \\
\text { There were multiple costs } \\
\text { perceived by the interviewed } \\
\text { farmers in using methane } \\
\text { vaccines and/or inhibitors on a } \\
\text { farm. The upfront cost of } \\
\text { purchase was once area of } \\
\text { concern for some participants, } \\
\text { along with concern relating to } \\
\text { labour costs for administration } \\
\text { of product. }\end{array}$ & $\begin{array}{l}\text { F9 - "... it's just once cent a dose, but across the animals, on a daily } \\
\text { basis, it is a significant cost. } 10-12 \text { years ago [2005], we could produce } \\
\text { at } \$ 1.80 / \mathrm{kg} \text { of milk solids. Now, keeping everything really tight we can } \\
\text { produce at } \$ 3 / \mathrm{kg} \text { of milk solids." } \\
\text { F10 - "[what are the] immunisations and vaccines going to cost, I don't } \\
\text { know } \$ 5 \text { or } \$ 10 \text { an animal, you know you're looking at for us, } 500 \text { cows } \\
\text { and } 500 \text { [vaccines] a year, } \$ 5,000 \text { or } \$ 10,000 \text { isn't it? It's quite a lot of } \\
\text { money, how do we get that back I guess?" } \\
\text { F12 - "The cost of the vaccine will be more expensive, [but compared to } \\
\text { the day to day cost of labour] ... I'd say they'd be more likely to fork out } \\
\text { for the cost of the vaccine than have to pay us to do it every day." }\end{array}$ \\
\hline $\begin{array}{l}\text { Concern about potential risks } \\
\text { to animal health (S2). } \\
\text { Expressed by } 16 \text { Participants. }\end{array}$ & $\begin{array}{l}\text { F3 - "No, I mean it's only that often things come out and get approved } \\
\text { and } 10 \text { years down the track there's issues that, or side effects or } \\
\text { effects or whatever, that were never anticipated." }\end{array}$ \\
\hline
\end{tabular}




\begin{tabular}{|c|c|}
\hline $\begin{array}{l}\text { The potential impacts } \\
\text { inhibitors/vaccines could have } \\
\text { on the health of their animals } \\
\text { was a large concern for many } \\
\text { interviewed farmers. Any } \\
\text { detrimental effects on animal } \\
\text { health or productivity was } \\
\text { viewed as too great a cost to } \\
\text { make the product worthwhile. }\end{array}$ & $\begin{array}{l}\text { F8 - "I wouldn't use it on our sheep unless it was proven not to affect } \\
\text { their wool, or anything else. I just think if you're going to inhibit } \\
\text { something that is part of their natural digestive system, there would } \\
\text { have to be, I just can't see how there wouldn't be a catch." } \\
\text { F15 - "If this technology is targeting the rumen, here we are pumping } \\
\text { special mixes of grain and mineral, and sweeteners so they actually eat } \\
\text { the grain and roughage, just to develop the rumen. So, when the } \\
\text { animals are young it's all on about the rumen. This has got to be } \\
\text { targeted at adult animals." }\end{array}$ \\
\hline $\begin{array}{l}\text { Concern about negative } \\
\text { public opinion (S3). } \\
\text { Expressed by } 8 \text { Participants. } \\
\text { Public use of and consumption } \\
\text { of farm produce is crucial to } \\
\text { the success of a farm business. } \\
\text { Some farmers interviewed had } \\
\text { concerns that use of the } \\
\text { technologies could have } \\
\text { detrimental impacts on public } \\
\text { perception of their goods, } \\
\text { affecting their profitability. }\end{array}$ & $\begin{array}{l}\text { F1 - "The risks I see is public perception... Irrespective of whether it's } \\
\text { safe or not, it's about what the public think. [we could have all the } \\
\text { science support, but the public could say we're not comfortable with } \\
\text { jamming stuff down an animal's throat]" } \\
\text { F6 - "My question then is, if I take a New York townie around my farm, } \\
\text { are they happy with everything that I'm doing. And so, if I say, oh yeah, } \\
\text { we put those bolus down their [throats]... People buy on feelings, not } \\
\text { facts." } \\
\text { F8 - "The only [way] I can see that farm animals are going to sell, is } \\
\text { because it's a natural product, and not factory produced, and } \\
\text { environmentally done right. So how is the consumer going to perceive } \\
\text { that we're giving a vaccine to alter how an animal functions naturally } \\
\text { when we try and sell our product." }\end{array}$ \\
\hline $\begin{array}{l}\text { Concern about the } \\
\text { commercial management of } \\
\text { technologies (S4). } \\
\text { Expressed by } 5 \text { Participants } \\
\text { Some farmers interviewed } \\
\text { raised concern that any } \\
\text { products may prioritise profit } \\
\text { over affordability for farmers. } \\
\text { There were also some } \\
\text { concerns about poor } \\
\text { management of technology } \\
\text { licensing leading to a market } \\
\text { monopoly. }\end{array}$ & $\begin{array}{l}\text { F9 - "We have to be very careful about what new technology we take } \\
\text { on. So, really important yes, I want your companies to be viable, you } \\
\text { have to be profitable to put a product out there. But please have great } \\
\text { consideration to what end costs are going to happen to us, as users." } \\
\text { F16 - "[in terms of the commercialisation of a vaccine] If that goes to } \\
\text { one company, and then they have a monopoly. That means they can } \\
\text { control that. The market doesn't determine the price, or the market } \\
\text { isn't able to drive improvements of that product. If the vaccine could be } \\
\text { spread across a range of companies, [] that creates competition, where } \\
\text { they have to improve that thing." } \\
\text { F8 - "[using a vaccine/inhibitor offsets a methane cost] All that is going } \\
\text { to do is feed big companies that produce the vaccine, isn't it? And help } \\
\text { the environment supposedly. Whereas, why don't they just take into } \\
\text { account the organic matter we're building up anyway, and it's all } \\
\text { honkey dory." }\end{array}$ \\
\hline $\begin{array}{l}\text { Concern about focusing on } \\
\text { use of methane vaccines and } \\
\text { inhibitors over natural } \\
\text { alternatives (S5). } \\
\text { Expressed by } 9 \text { Participants. } \\
\text { Some interviewed farmers } \\
\text { raised concerns about creating } \\
\text { a solution for a problem when }\end{array}$ & $\begin{array}{l}\text { F4 - "The ultimate would be [] to find sheep that [] are doing it } \\
\text { naturally. That'd be a far better solution, but there is a fair cost of all } \\
\text { that work." } \\
\text { F6 - "This thing we love about biology, and hate, is that it takes time. } \\
\text { And also, just on that point, we believe technology's not going to save } \\
\text { the world, as such, it is biology." }\end{array}$ \\
\hline
\end{tabular}


there may be natural ways of overcoming the issue.
F8 - "I would rather, the research be done into what are these animals eating that's creating this issue in the first place. Is it a question of, too many animals, in which case we reduce stock numbers, or is it that the food we're giving them is not correct and it's changed their gut? I think using a vaccine should be the absolute final option."

\subsubsection{Semantic Theme 2 - What value farmers perceive in PGgRc's technologies}

The most common aspect of product value was mitigating methane costs which is to be expected given the purpose of the technologies in development. Additional themes related to value were identified in positive public opinions and in addressing climate change. This is explored in Table 2 What value farmers perceive in PGgRc's technologies.

Table 2 What value farmers perceive in PGgRc's technologies

\begin{tabular}{|c|c|}
\hline Sub-theme & Representative quotes \\
\hline $\begin{array}{l}\text { Mitigating methane costs is } \\
\text { valuable (S6). } \\
\text { Expressed by } 11 \text { Participants. } \\
\text { A clear benefit for most farmers } \\
\text { interviewed is the ability of the } \\
\text { proposed technologies to } \\
\text { mitigate carbon costs. }\end{array}$ & $\begin{array}{l}\text { F1 - "If I'm going to get taxed I don't really care where the solution } \\
\text { comes from, I just want a [cost effective solution]." } \\
\text { F7 - "Yeah, I suppose, cut short. Whether you believe it or not if } \\
\text { you're going to be taxed on it you've got to either mitigate or pay the } \\
\text { tax." } \\
\text { F14 - "If it's going to factor into reducing any price on methane if that } \\
\text { does come through, then that's another bonus. Potential benefit } \\
\text { there." }\end{array}$ \\
\hline $\begin{array}{l}\text { Addressing climate change is } \\
\text { good (S7). } \\
\text { Expressed by } 13 \text { Participants. } \\
\text { Most farmers interviewed were } \\
\text { aware of the discussion around } \\
\text { climate change, with some } \\
\text { more invested than others. For } \\
\text { those most interested the } \\
\text { ability of the technology to } \\
\text { mitigate methane was a benefit } \\
\text { but had little commercial value. }\end{array}$ & $\begin{array}{l}\text { F3 - "So, the reality is we've got to expect that agriculture is going to } \\
\text { be dragged in, and so it should be, it accounts for } 50 \% \text { of our } \\
\text { emissions. It's the elephant in the room that everyone's ignoring, and } \\
\text { it's going to have to be dealt with." } \\
\text { F7 - "Um, I suppose anecdotally it does I suppose. But yeah, it's } \\
\text { nothing you can physically see, as a benefit." } \\
\text { F5 - "Well, if it does what they say it's going to do, then yeah, I think } \\
\text { there will be a benefit. But it's a long-term thing, that we cannot see } \\
\text { any results, we may not see in our lifetime those results. I think that is } \\
\text { something you have to bear in mind, that we're doing all this stuff and } \\
\text { we're not going to see the results in our lifetime." }\end{array}$ \\
\hline $\begin{array}{l}\text { Technologies could generate } \\
\text { positive public opinion (S8). } \\
\text { Expressed by } 8 \text { Participants. } \\
\text { There is currently some tension } \\
\text { between city and rural } \\
\text { populations in New Zealand } \\
\text { over environmental issues. The } \\
\text { technologies are a potential }\end{array}$ & $\begin{array}{l}\text { F3 - "If it can be done without affecting production, it's a no brainer } \\
\text { really, I think. Because, I think, more from a, not that I think GHGs } \\
\text { from animals are that big of a deal personally. But the general public } \\
\text { does, and if we can reduce them and it's not going to cost anything. } \\
\text { Yeah." } \\
\text { F9 - "You're not just producing a healthy product for food but what } \\
\text { you're doing with your methane reduction you're helping to save the }\end{array}$ \\
\hline
\end{tabular}


tool for farmers interviewed to

display active participation in

mitigating environmental

issues, hopefully improving

public relations. climate of the world. That's a pretty powerful thing. And, if the public can buy into that and accept that, and we can get a little bit of a margin back for our product because of, then would be pretty cool..."

F2 - "Not risks, definitely benefits. Probably benefits to agriculture as a whole in New Zealand, we're trying to do our best sort of thing. I'm sure we're the only country that are looking at it. Because we're the only ones that'll come under it."

\subsubsection{Semantic Theme 3 - Farmer access and use of the technologies}

This final theme explores how farmers access and utilise the proposed technologies. There are two main aspects of product use that were highlighted by the interviews, product preference and subsidies for product use. This is explored in Table 3 Farmer access and use of the technologies.

Table 3 Farmer access and use of the technologies

\begin{tabular}{|c|c|}
\hline Sub-theme & Representative quotes \\
\hline $\begin{array}{l}\text { A methane vaccine is the } \\
\text { preferred product (S9). } \\
\text { Expressed by } 12 \text { Participants. } \\
\text { While the two technologies } \\
\text { operate under similar } \\
\text { mechanics, their methods of } \\
\text { administration and duration are } \\
\text { substantially different. Based on } \\
\text { the data obtained there is a } \\
\text { preference for a methane } \\
\text { vaccine over an inhibitor due to } \\
\text { potential costs and labour } \\
\text { required. }\end{array}$ & $\begin{array}{l}\text { F5 - "Inhibitor isn't going to suit us. Maybe in [another farmers] case, } \\
\text { his system maybe. But then it's got to be cheaper than the vaccine } \\
\text { anyway." } \\
\text { F8 - "Well they both interfere with what is going on in the gut, and the } \\
\text { vaccine would be easier to administer [than the inhibitor]." } \\
\text { F13 - "If the vaccine is only yearly, hopefully you could tie it in with } \\
\text { other vaccines or things you're doing. Everything gets done in the } \\
\text { autumn for lepto, so maybe tie it in with that would work well. But } \\
\text { the additive, we don't have in shed meal feeding, and only one of our } \\
\text { farms has an inline doser trough, water dispenser. So, for that side of } \\
\text { it we would be restricted." }\end{array}$ \\
\hline $\begin{array}{l}\text { Farmers have positive and } \\
\text { negative interest in technology } \\
\text { subsidies (S10). } \\
\text { Expressed by } 11 \text { Participants. } \\
\text { Farm subsidies in New Zealand } \\
\text { were ended in } 1984 \text { (Edwards \& } \\
\text { DeHaven, 2003). There is still } \\
\text { support for the agricultural } \\
\text { sector by government through } \\
\text { investment in agricultural } \\
\text { infrastructure. Many of the } \\
\text { farmers expected the } \\
\text { introduction of subsidies under } \\
\text { certain circumstances. Some of } \\
\text { the farmers interviewed } \\
\text { expressed doubt that the }\end{array}$ & $\begin{array}{l}\text { F11 - "Well, that would sort of depend on a lot of things wouldn't it? } \\
\text { like how much it was going to cost and all that sort of things, and what } \\
\text { benefits the farmer might gain, he might get a production benefit out } \\
\text { of it. We don't know yet, do we?" } \\
\text { F3 - "Well, I mean I kind of expect it. Mmm. It hinges on the cost of } \\
\text { them really. I guess, if it's a huge one-off cost and it's mandatory to } \\
\text { use it, you know, or becomes mandatory to do something then there } \\
\text { might be an argument to transition into it with a bit of help from the } \\
\text { government. Personally, I think most farmers are against subsidies, } \\
\text { and I'm the same." } \\
\text { F1 - "I don't know. I might be a bit odd. I've always been a hugely } \\
\text { averse to subsidies of any form, because the day you let someone } \\
\text { inside your business, they get a say about your business. My pure }\end{array}$ \\
\hline
\end{tabular}


government would be willing to subsidise the technology for farming but were open to the possibility if the products would be prohibitively expensive otherwise. There were participants uninterested or opposed to subsidies. view of the world of success is if you have a problem you sort it out. That would be my pure view of the world."

\subsubsection{Matrix of farmer/sub-theme interactions}

The intention Table 4 Matric displaying farmer/sub-theme interactions is to visually present where farmers have contributed to multiple sub-themes, and where they may have had little interest or provided no relevant data.

Table 4 Matrix displaying farmer/sub-theme interactions

Key

\begin{tabular}{|l|l|}
\hline Beef, Lamb and Wool & Expressed Evidence \\
\hline Dairy & No Evidence \\
\hline
\end{tabular}

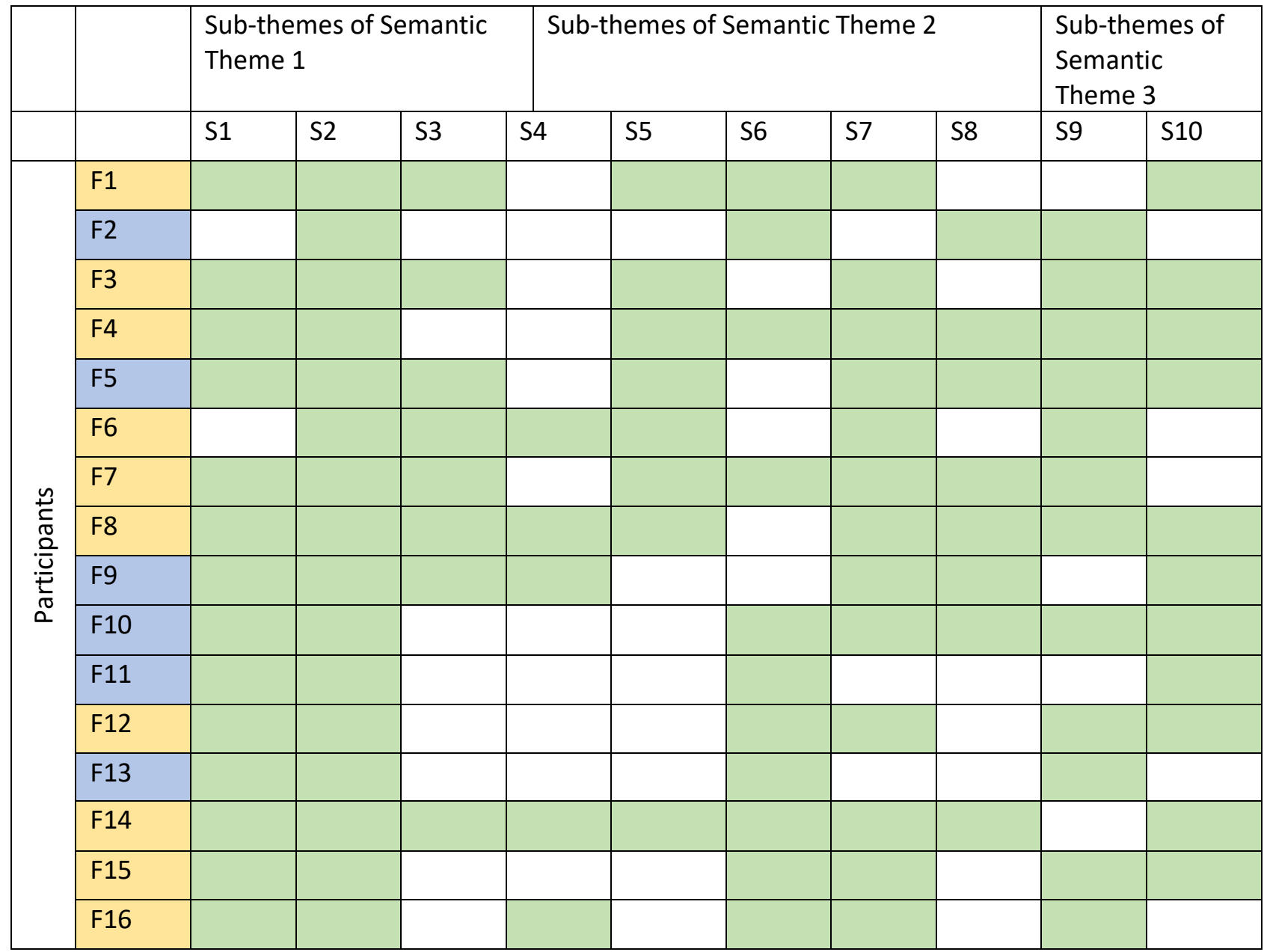




\subsection{Interpretations}

Three latent themes have been identified based on the previous section. These themes are Farmer Interest in Natural Options, Farmer Adoption of Technology, and Farmer Views on Mitigating Methane. The preference for a natural option over a commercial product such as the technologies PGgRc is developing was common across many of the participants. The perceived usability of the technologies varied across participants, but there were many common trends related to affordability and administration. The final theme portrays how many participants viewed methane mitigation and the evolving agricultural sector. Each theme is outlined, then the evidence is presented, and concluded by applying the findings to the research objectives.

\subsubsection{Latent Theme 1 - Farmer Interest in natural options}

This theme builds upon the semantic sub-theme, Concern about focusing on use of methane vaccines and inhibitors over natural alternatives, identified earlier. It explores how other sub-themes combine among participants to create interest in natural alternatives over PGgRc's potential methane vaccines and inhibitors. Natural options for mitigating or offsetting methane emissions were of interest to 9 of the 15 participants over a commercial product such as the technologies PGgRc is developing. The supporting sub-themes are, Concern about negative public opinion, Concern regarding the affordability of the technologies, Concern about potential risks to animal health and Concern about the commercial management of technologies. This is explored in Table 5 Farmer interest in natural options.

Participants grouped within this theme proposed or were aware of alternative solutions to PGgRc's methane mitigation technology. Supporting participants are grouped into Cost Driven (CD) and Natural Process Driven (NPD). There were five CD participants, and four NPD participants. In addition, both groups should be considered as also being profit driven relating to actual use of the mitigation technologies as profitability is a fundamental motivation for any farm business.

\section{Table 5 Farmer interest in natural options}

\begin{tabular}{|l|l|}
\hline $\begin{array}{l}\text { Cost Driven participants } \\
\text { Exemplified by F1, F5, F7, F13, } \\
\text { F14 }\end{array}$ & Supporting Quotes \\
\hline $\begin{array}{l}\text { The CD group is categorised by } \\
\text { their interest in natural } \\
\text { alternatives based on their } \\
\begin{array}{l}\text { comparative value to methane } \\
\text { vaccines and inhibitors. A desire } \\
\text { for a more 'natural' farming }\end{array}\end{array}$ & $\begin{array}{l}\text { F1 - "That's the conundrum, you know. When you guys come to the } \\
\text { market with this product we've got to know what the cost is } \\
\text { compared to other options. If I've still got to write out a huge check } \\
\text { just chop their heads off." }\end{array}$ \\
\hline
\end{tabular}


process isn't driving their preference, rather it is based on a need to mitigate their emissions in the most cost-effective manner. This group are aware of the potential carbon costs and/or the potential impacts of climate change and are trying to identify the most profitable way of addressing these issues. These participants view natural mitigation options as potentially cheaper, for example, if soil carbon fixation was considered a measurable carbon sink then they could reduce emissions by focusing on improving their pastures rather than purchasing a product. It is a combination of minimising work required and maximising the benefits of the action taken.

\section{Natural Process Driven participants \\ Exemplified by F3, F4, F6, F18} The NPD group faces the same profitability concerns as the $C D$ group while also desiring a more natural farming process. The motivation for this desire to operate more 'naturally' can be attributed to various factors. For some participants it is a desire to avoid GMO and GE affiliation, others disliked the idea of interfering with the natural function of their livestock, and for others it is a belief that more natural farming is the future of their industry. The defining feature of this group is their reasons for preferring a natural solution aren't based on profitability alone. Three NDP participants (F4, F6, and F8) were operating farm systems differently to mainstream practices. Some examples of this are lowered use of nitrogen fertiliser and drilling pasture over tilling pasture.
F7 - "You cultivate a paddock, I understand a lot of carbon is released. But if you farm a grass, and you don't cultivate all the time or grow crops you should benefit from that. You can see it, but you don't get any benefit from it."

F14 - "From a farming perspective it's the same, if you're adding a cost what other ways could you achieve the same goals."

\section{Supporting Quotes}

F4 - "The ultimate would be, which would be expensive, is to find sheep that have got [low methane] naturally. Out of the bell curve, some [animals] are the best and some are the worst productivity. It's about identifying lines naturally, that are doing it naturally. That' $d$ be a far better solution, but there is a fair cost of all that work."

F6 - "This thing we love about biology, and hate, is that it takes time. And also, just on that point, we believe technology's not going to save the world, as such, it is biology."

F8 - "I don't think using drugs, or chemicals, or what have you is the way to go. I just think it's a backwards step. It's the doctor writing the prescription technique. I'd prefer a more holistic approach, where you're looking into why these things are happening, and what you can do to avoid it in the first place. Not just giving the poor sheep or cow an injection to stop what it's body is naturally designed to do." 


\begin{tabular}{|c|c|}
\hline $\begin{array}{l}\text { Participants who valued soil } \\
\text { carbon as a methane offset } \\
\text { Exemplified by } F 6, F 8, F 14\end{array}$ & Supporting Quotes \\
\hline $\begin{array}{l}\text { While limited, current } \\
\text { options for GHG mitigation within } \\
\text { the farming sector are } \\
\text { predominantly based on land use } \\
\text { and management, as a result } \\
\text { some of the participants who are } \\
\text { acting to mitigate climate change } \\
\text { are doing so in 'natural' ways. } \\
\text { Three participants have } \\
\text { conducted their own research } \\
\text { into climate change mitigation } \\
\text { and believe soil carbon is a viable } \\
\text { option for offsetting livestock } \\
\text { emissions, as it can be increased } \\
\text { through management of pasture } \\
\text { and stock. Use of an inhibitor or } \\
\text { vaccine was seen by these } \\
\text { participants as a commercial } \\
\text { venture or unnecessary fix to a } \\
\text { problem that could be addressed } \\
\text { through natural means. However, } \\
\text { soil carbon isn't currently viewed } \\
\text { by government as a suitable } \\
\text { carbon sink due to difficulties in } \\
\text { regulation and measurement as it } \\
\text { can vary within a single paddock } \\
\text { and between different farms. }\end{array}$ & $\begin{array}{l}\text { F6 - "So, we have completely changed our system, to now sequester } \\
\text { carbon, to build topsoil, and to mitigate against climate change... So, } \\
\text { now instead of just rye-grass clover in a monoculture on our farm, } \\
\text { we now plant } 12-15 \text { different species, with different roots, big deep } \\
\text { root systems... So that the deeper your roots the more carbon } \\
\text { you're drawing in." } \\
\text { F8 - "What's concerning me at the moment is that they're saying } \\
\text { that we're producing all this nitrogen, and nitrates, but they're not } \\
\text { taking into account that we're building our soils all the time." } \\
\text { F14 - "Trying to build the health, and carbon content of our soils } \\
\text { going forward... the opportunity cost of focusing on vaccines and } \\
\text { inhibitors is the work I think we should be doing, basically focused } \\
\text { on soils and ecosystem function." }\end{array}$ \\
\hline $\begin{array}{l}\text { Participants who concerned } \\
\text { about the potential health risks } \\
\text { of methane vaccines and } \\
\text { inhibitors } \\
\text { Exemplified by } F 1, F 3, F 4, F 5, F 6 \text {, } \\
F 7, F 8, F 13, F 14\end{array}$ & Supporting Quotes \\
\hline $\begin{array}{l}\text { Both CD and NPD groups were } \\
\text { concerned about the potential } \\
\text { impact of inhibitors and vaccines } \\
\text { on animal wellbeing. As novel } \\
\text { technologies administered to } \\
\text { animals the inhibitors and } \\
\text { vaccines are a potential risk to } \\
\text { farm success. Any detrimental } \\
\text { effect on the animals or the milk, } \\
\text { meat and wool they produce } \\
\text { would negatively affect farm } \\
\text { profitability. While one of the } \\
\text { participants (F4) was confident } \\
\text { that any product on the market } \\
\text { would be sufficiently tested and } \\
\text { safe, the other eight participants }\end{array}$ & $\begin{array}{l}\text { F4 - "I just expect them to work. I'd be the first to jump up and down } \\
\text { if they didn't." } \\
\text { F3 - "Well I suppose if there's any other animal health side effects, } \\
\text { that's a concern. Yeah, that's probably the main thing. Unforeseen } \\
\text { effects down the road, we want to be sure they've been effectively } \\
\text { field trialled and everything has been investigated properly." } \\
\text { F8 - “I wouldn't use it on our sheep unless it was proven not to } \\
\text { affect their wool, or anything else. I just think if you're going to } \\
\text { inhibit something that is part of their natural digestive system, there } \\
\text { would have to be, I just can't see how there wouldn't be a catch." } \\
\text { F14 - "You're dealing with an animal's microbiome. Similar, } \\
\text { unfathomable complexity as trying to deal with soils, right? So, who } \\
\text { knows what kind of unintended consequences you're having. They }\end{array}$ \\
\hline
\end{tabular}




\begin{tabular}{|c|c|}
\hline $\begin{array}{l}\text { were cautious that unforeseen } \\
\text { consequences of using the } \\
\text { technologies could arise years } \\
\text { after their release. }\end{array}$ & $\begin{array}{l}\text { might not be measurable in the first } 10 \text { years, then they might have } \\
\text { massive impact. There is always risks, and I think if you're quite } \\
\text { aggressively selecting for or against something as part of that } \\
\text { system, is really dangerous." }\end{array}$ \\
\hline $\begin{array}{l}\text { Methane vaccines and inhibitors } \\
\text { are a potential risk to market } \\
\text { value } \\
\text { Exemplified by } F 1, F 3, F 6, F 8\end{array}$ & Supporting Quotes \\
\hline $\begin{array}{l}\text { Four participants across } \\
\text { both CD and NPD groups viewed } \\
\text { use of the technologies as a } \\
\text { market risk. Consumers are } \\
\text { becoming more aware of the } \\
\text { environmental impacts of the } \\
\text { goods they use and consume. In } \\
\text { this regard, the 'natural' status of } \\
\text { New Zealand milk, meat and wool } \\
\text { is a potential strength compared } \\
\text { to the 'unnatural' synthetic } \\
\text { options that are being developed. } \\
\text { GE and GMO are still } \\
\text { uncomfortable ideas for many } \\
\text { consumers, and natural } \\
\text { alternatives to synthetic } \\
\text { flavouring and colouring are } \\
\text { selling points for many food } \\
\text { products. These participants were } \\
\text { concerned that by using vaccines } \\
\text { or inhibitors on their livestock, } \\
\text { they could potentially harm } \\
\text { consumer goodwill about } \\
\text { purchasing a natural product over } \\
\text { a synthetic alternative. }\end{array}$ & $\begin{array}{l}\text { F3 - "Certainly a bit of GMO might be a significant issue for market } \\
\text { place, and so on, so it would have to be, I can't imagine it getting } \\
\text { over the hurdle, I think that would be a shot too far... I mean the } \\
\text { market's always right, and the customer's always right." } \\
\text { F6 - "My question then is, if I take a New York townie around my } \\
\text { farm, are they happy with everything that I'm doing... People buy on } \\
\text { feelings, not facts. Is that right?" } \\
\text { F8 - "Just to look from a marketing view. All the, the world at the } \\
\text { moment, there's this factory producing artificial protein, all that sort } \\
\text { of thing is really on the go. The only way I can see that farm animals } \\
\text { are going to sell, is because it's a natural product, and not factory } \\
\text { produced, and environmentally done right. So how is the consumer } \\
\text { going to perceive that we're giving a vaccine to alter how an animal } \\
\text { functions naturally when we try and sell our product." }\end{array}$ \\
\hline $\begin{array}{l}\text { The technologies offering large } \\
\text { enough benefits would be } \\
\text { enough for participants to use } \\
\text { them } \\
\text { Exemplified by } F 1, F 3, F 4, F 5, F 6 \text {, } \\
F 7, F 8, F 13, F 14\end{array}$ & Supporting Quotes \\
\hline $\begin{array}{l}\text { All participants with a preference } \\
\text { for natural non-vaccine and } \\
\text { inhibitor solutions were still open } \\
\text { to the technologies if the benefits } \\
\text { they provided were great } \\
\text { enough. If the technology could } \\
\text { offer productivity benefits or } \\
\text { mitigate a methane cost } \\
\text { efficiently then it was viewed as } \\
\text { worthwhile. }\end{array}$ & $\begin{array}{l}\text { F6 - "It would have to add the benefits; not just tell us it reduces } \\
\text { gases." } \\
\text { F4 - "If it stopped the government from bringing in a fart tax. And if } \\
\text { this technology is cheaper than the cost of the tax it's a goer. It just } \\
\text { depends where we're at, what happens." } \\
\text { F8 - "If something can be proven to work, without detriment. Then } \\
\text { I'm all for anything to help the environment. But I am very wary of } \\
\text { anything that interferes with the way an animal is naturally set to } \\
\text { work." }\end{array}$ \\
\hline
\end{tabular}




\section{Significance for PGgRc}

This latent theme highlights the potential barriers to PGgRc's technologies being adopted beside the costs of purchase and administration. While five of the participants who were interested in natural options for methane mitigation/offset were so because they believed alternative solutions could be more profitable, there were still four participants who weren't interested in methane vaccines and inhibitors because of personal beliefs about animal management/health. The later participants were opposed to the technologies on personal grounds, and as such could be unlikely to change their perspective based on regulations or minor productivity benefits from use of vaccines and inhibitors. This presents a novel variable to the expectation that profitability is key to adoption of methane vaccines and inhibitors.

All participants who contributed to this theme would still use the technologies if they offered enough value, but it may be difficult to reach this value point for some farmers. As such, when considering the available market for their technologies PGgRc should account for possible consumers who are opposed to their products for non-commercial reasons.

\subsubsection{Latent Theme 2 - Farmer adoption of technology}

This theme builds upon the semantic sub-theme, $A$ methane vaccine is the preferred product, which it combines with Farmers have positive and negative interest in technology subsidies and Concern regarding the affordability of technologies to explore why methane vaccines are preferred among the participants. This is detailed in Table 6 Farmer adoption of technologies.

Out of all 16 participants, 12 would prefer vaccines as their method of methane mitigation, with vaccines being described as a necessity for four beef, lamb and wool farmers if inhibitors couldn't provide longer duration. The possibility of subsidies to encourage farmer use could be important to the adoption of PGgRc's technologies. This would be welcomed by seven participants, accepted by three participants, and avoided by one. This theme explores the reasons behind technology preferences, identifies key costs that could affect the viability of using inhibitors and vaccines, and the potential for required subsidies.

Table 6 Farmer adoption of technology

\begin{tabular}{l|l} 
Most participants preferred & Supporting Quotes \\
vaccines because they could & \\
require less effort in & \\
administration than inhibitors & \\
Exemplified by $F 2, F 3, F 4, F 5, F 6$, & \\
$F 7, F 8, F 10, F 12, F 13, F 15, F 16$ & \\
\hline
\end{tabular}


The effort of administering inhibitors on a frequent basis was the primary feature driving vaccine preference for eight participants operating beef, lamb and wool systems and four participants operating dairy systems. Beef, lamb, and wool farmers don't regularly handle their livestock except for specific events during the year such as drenching or shearing. Due to this limited animal contact administering an inhibitor on a daily, weekly, or even monthly basis would be a substantial time cost for these farmers, possibly requiring them to restructure their farm system.

\section{Four participants stated daily inhibitors wouldn't work for them Exemplified by F5, F6, F8, F16}

For these participants vaccines would be the only viable option if inhibitor administration costs weren't suitably decreased. This was predominantly based on each farmer's farm system, as F6, F8, and F16 were all beef, lamb and wool systems and $\mathrm{F} 5$ was a dairy system without in-shed feed systems.

F13 - "If the vaccine is only yearly, hopefully you could tie it in with other vaccines or things you're doing. Everything gets done in the autumn for lepto, so maybe tie it in with that would work well. But the additive, we don't have in shed meal feeding, and only one of our farms has an inline doser trough, water dispenser. So, for that side of it we would be restricted."

F16 - "With the inhibitor, the cost is more time and effort in your day, daily, feeding out this stuff, in whatever quantum it is. Which is much less attractive."

F15 - "[the way we run the farm, the vaccine would be much easier] [doing vaccinations anyway] From a farmer's point of view, it's all about cost."

\section{Supporting Quotes}

F6 - "Oh yeah, [inhibitors] that's a no-go. [unless the duration after administration is improved]."

F8 - "The inhibitor is a no go, because unless you put it out in troughs you'd be feeding it to them, then you'd have to have water proof troughs. And how do you get them to eat it."

F16 - "If you look at most of New Zealands sheep and beef production, $80-85 \%$ of the land mass is hill country. So, [daily inhibitor] is not doable, because you're not necessarily doing daily jobs with them. And there is the added challenge of getting around or getting "the stuff' around."

\section{Supporting Quotes}

Four participants didn't have a preference between vaccines or inhibitors

Exemplified by F1, F9, F11, F14

For these participants whether the methane mitigation was in the form of a vaccine of inhibitor wasn't a significant concern, if it was cheap to use. Two beef and lamb farmers interviewed (F1, F14) assumed inhibitors could be provided in a form comparible to activities they already perform. Dairying systems have frequent opportunities to interact with their livestock, as the animals come in daily for milking. Two dairy farmers interviewed (F9,
F1 - "No, I don't care which one it is. Just get it to me cheap and get it to me so I don't have to do it very often."

F9 - "So, 1, as far as farmers are concerned an annual vaccine under the skin would be fine. 2, a water-soluble product. We can administer it in our water systems on our farms."

F11 - "I don't think it would matter in our case."

F14 - "The inhibitors thing, if you could deliver it the same way we deliver stock minerals. That wouldn't actually be a big cost, depending on the quantity you need to feed." 
F11) have in-shed feeding systems which could be used to provide cattle with a daily dose of inhibitor when they come in for milking.

Feeding inhibitors could be less distressing for the animal Exemplified by F5, F8

Two participants preferred the non-invasive aspect of inhibitor use on animals compared to vaccinations. Inhibitors are administered orally which is likely to cause less stress for an animal than injecting a vaccine, and with the right form of administration, like via trough water systems, be less effort too.

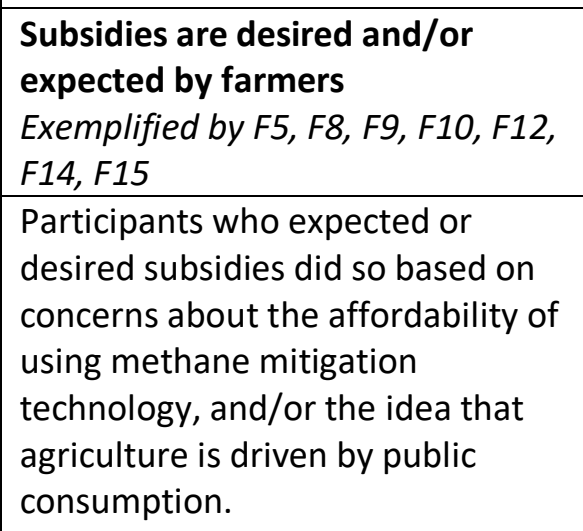

Supporting Quotes

F8 - "[Sheep hate needles. So, if it could be done down the throat, it would be far better, rather than vaccine.]

F5 - "They are animals, and they do kick. As I said, they don't like needles. "

F10 - "I do. I absolutely do. Because you gotta remember [dairy farming] contributes a lot for the New Zealand economy."

F12 - "If you can't get a mindset shift, then you're going to need a subsidy. Because there is no benefit for farmers, except for the crazy greeny ones... But unless [the public and farmers] are actually thinking about [climate change], then yeah, it's got to have some sort of subsidy."

F14 - "Yeah [subsidies are expected]. Maybe not directly to the farm gate. Kiwi farmers are quite anti subsidy, looking at extreme cases in Europe, [where they need the government to keep them viable], I think that's a healthy scepticism."

\section{Subsidies would be accepted and used if provided \\ Exemplified by F3, F4, F11}

These participants did not expect subsidies (F4, F11) or were opposed (F3) but would still use them if available. This isn't unexpected as profitability is a major aspect of farm operations, and subsidies should improve the value of the technologies to farmers.

\section{Supporting Quotes}

F3 - "Well, I mean I kind of expect it. Mmm. It hinges on the cost of them really. I guess, if it's a huge one-off cost and it's mandatory to use it, you know, or becomes mandatory to do something then there might be an argument to transition into it with a bit of help from the government. Personally, I think most farmers are against subsidies, and I'm the same. But, on the other hand it's not like beef and sheep farmers are making vast amounts of money and can afford whatever comes around the corner. So, if you want to get take up, maybe it's a reasonable option."

F4 - "We haven't had any government subsidies yet, so l'd be surprised if we got one. If they wanted to subsidise it, I wouldn't say "no, go away" if they wanted to do it. But l'd be surprised if they did want to." 


\begin{tabular}{|c|c|}
\hline & $\begin{array}{l}\text { F11 - "Well, that would sort of depend on a lot of things wouldn't } \\
\text { it? like how much it was going to cost and all that sort of things, } \\
\text { and what benefits the farmer might gain, he might get a } \\
\text { production benefit out of it... So no, I wouldn't realistically expect } \\
\text { it to be subsidised unless there were issues around it." }\end{array}$ \\
\hline $\begin{array}{l}\text { Subsidies were not expected } \\
\text { Exemplified by } F 1, F 2\end{array}$ & Supporting Quotes \\
\hline $\begin{array}{l}\text { These farmers interviewed had no } \\
\text { expectation for subsidies, and were } \\
\text { opposed to their implementation } \\
\text { in the case of F1 didn't want or } \\
\text { expect subsidies }\end{array}$ & $\begin{array}{l}\text { F1 - "I've always been a hugely averse to subsidies of any form, } \\
\text { because the day you let someone inside your business, they get a } \\
\text { say about your business. My pure view of the world of success is if } \\
\text { you have a problem you sort it out. That would be my pure view of } \\
\text { the world." } \\
\text { F2 - "Nah. Not really. They haven't subsidised anything for us in a } \\
\text { long time, can't see them starting now." }\end{array}$ \\
\hline $\begin{array}{l}\text { Concern that subsidies could } \\
\text { garner negative public reactions } \\
\text { Exemplified by F9 }\end{array}$ & Supporting Quotes \\
\hline $\begin{array}{l}\text { One participants raised concerns } \\
\text { about public response to subsidies } \\
\text { or trying to place any methane } \\
\text { mitigation costs on the consumer. } \\
\text { Consumers are unlikely to react } \\
\text { positively to raised product prices } \\
\text { to offset increased farm cost, } \\
\text { instead purchasing cheaper } \\
\text { alternatives if available. In } \\
\text { addition, consumers could view } \\
\text { direct subsidies as a government } \\
\text { handout which is has the possibility } \\
\text { of generating public backlash tax } \\
\text { payers shoring up unsustainable } \\
\text { farming practices. }\end{array}$ & $\begin{array}{l}\text { F9 - "You have to be very careful how you administer what you call } \\
\text { a subsidy. Why not just reduce the price to start with? You got } \\
\text { backing for the other side of it, so to speak. Really split it up... Got } \\
\text { to be careful about public backlash on us, because of that. Saying } \\
\text { we're getting another handout. So be very careful with that side of } \\
\text { it." }\end{array}$ \\
\hline
\end{tabular}

\section{Significance for PGgRc}

This latent theme highlights a preference for methane vaccine technology, but in doing so reveals that it is unlikely any one product will be suitable for every farm system. Vaccines are predominantly preferred among the farmers interviewed because they could offer fewer administration costs than frequent use of an inhibitor. This should be of most importance to beef, lamb and wool farmers are limited in their options for regularly administering a product to their stock, with suitable animal contact only occurring during a few significant events over the year. For dairy systems there is greater opportunity for regular animal contact as their stock come in for milking on a daily schedule, which could make administering a vaccine or inhibitor a much simpler 
process than with beef and lamb systems. Subsidies could improve farmer adoption of PGgRc's technologies, but could incur minor push back from the farming community or broader public if implemented poorly.

Overall, the preference for a product was based on the profitability of its use, both price of purchase and administration costs. If inhibitors are cheaper than vaccines for farmers after purchase and administration, then farmers will use the cheapest option. There is an exception to this for some farmers whose farm systems are ill suited for frequent product administration, as using inhibitors would require completely restructuring their farm.

Based on this theme, it is in PGgRc's interest to continue developing both methane vaccine and inhibitor technologies as it is unlikely one or the other will suit all farm systems. Offering both technologies could improve the overall adoption of methane mitigation products.

\subsubsection{Latent Theme 3 - Farmer views on mitigating methane}

This theme is built upon the sub-themes of Mitigating methane costs is valuable, Addressing climate change is good and Technologies could generate positive public opinion. It explores how farmers currently feel about climate change, and whether PGgRc's technologies can offer them value related to emission mitigation. This is detailed in Table 7 Farmer views on mitigating methane.

As business operators and employees none of the 16 research participants want to face methane emissions costs, but some are aware that action needs to be taken. PGgRc's technologies offer farmers a methane mitigation option which could be financially beneficial if farm level emissions costs are put in place. Any use of the technologies must be considered against other available products and possible courses of mitigation. This theme explores the value of methane mitigation technology and identifies key factors that contribute to this value.

\section{Table 7 Farmer views on mitigating methane}

\begin{tabular}{|l|l|}
\hline $\begin{array}{l}\text { Participants believe that methane } \\
\text { mitigation is important } \\
\text { Exemplified by F1, F3, F4, F5, F6, F7, } \\
F 8, F 9, F 10, F 12, F 14, F 15, F 16\end{array}$ & Supporting Quotes \\
\hline $\begin{array}{l}\text { Thirteen participants believed that } \\
\text { methane emissions are important } \\
\text { within the farming sector and/or to } \\
\text { society as a whole. These } \\
\text { participants were in support of } \\
\begin{array}{l}\text { action to mitigate climate change for } \\
\text { environmental or societal reasons. }\end{array}\end{array}$ & $\begin{array}{l}\text { F3 - "Well, I mean the reality is, regardless of who's in power we } \\
\text { can't just stick our heads in the sand and pretend that we're not } \\
\text { going the other way with our carbon emissions... we've got to } \\
\text { expect that agriculture is going to be dragged in, and so it should } \\
\text { be, it accounts for } 50 \% \text { of our emissions... it's going to have to be } \\
\text { dealt with." }\end{array}$ \\
\hline
\end{tabular}


Climate change is a concern of society, so it becomes a concern for farmers

Exemplified by F1, F4, F12

Three of the thirteen participants didn't necessarily believe that action against climate change was beneficial or needed but understood that if other sectors of society were making changes it would be in their interest to do so too. These participants viewed methane mitigation as important for social and commercial reasons.

F14 - "And looking at the actual warming effect, also the temperature effect of, there are a whole lot of choices and options to make as a society. As opposed to what time frames of emissions we're concerned about, whether we're talking about peak temperatures or warming, the significance of methane. But we also know that any reduction in it is going to have a positive impact, if it makes sense in of itself then let's do it."

\section{Supporting Quotes}

F1 - "The conversation globally is if you fundamentally believe in this and want to be a good citizen you have to play your part. Really hard to play your part, I have a different view of the world, I don't care what other guys do, as long as I do my bit. [a lot of people won't address an issue unless other people do it too]."

F4 - "Because, [I don't] think GhG from animals are that big of a deal personally. But the general public does, and if we can reduce them and it's not going to cost anything. Yeah."

F12 - "Yeah, I'd say so. Feel good, look good factor. [mitigating methane] makes us look better than [the public] think we are"

\section{Potential for mitigating methane costs is of interest to farmers Exemplified by $F 1, F 2, F 4, F 7, F 10$, $F 11, F 12, F 13, F 14, F 15, F 16$}

Eleven of the farmers interviewed were interested in the ability of PGgRc's technologies to reduce potential methane costs, indicating the government introducing a methane tax or charge could create more value for the methane mitigation of inhibitors and/or vaccines.

Concern that creation of the technologies could create cost rather than provide benefits Exemplified by F5, F8

Two participants were uninterested in the development of PGgRc's technologies. They were concerned that the creation of these technologies would result in the government introducing methane regulations creating costs which may be too large for their business even

\section{Supporting Quotes}

F4 - "I could see, if there was a real value shown from a New Zealand point of view. If it stopped the government from bringing in a fart tax. And if this technology is cheaper than the cost of the tax it's a goer. It just depends where we're at, what happens."

F7 - "Yeah, I suppose, cut short. Whether you believe [in climate change] or not if you're going to be taxed on it you've got to either mitigate or pay the tax."

F13 - "[technology value] Just boils down to the bottom line, at the end of the day. How much the carbon tax is."

\section{Supporting Quotes}

F5 - "If they start taxing us on emissions trading, and then want us to go and buy this stuff then it's being stung twice. That's not good enough. They want us to do it, but we'll do it on our own terms. Rather than being told we're going to tax you, and then turn around and make you buy this vaccine as well. "

F8 - "[methane costs are] a real concern to me, because, if you create the vaccine, the government will think, right, we'll create a tax now, they can get out of it. Therefore, we shouldn't put any 
after using the vaccines and inhibitors to mitigate methane. money into creating vaccines and therefore the government, we don't have any way of paying for it. The sooner it's knocked on the head the better."

\section{Significance for PGgRc}

This latent theme highlights that many farmers believe acting against climate change is important. However, willingness to act on climate change is related to the profitability of doing so. If use of methane mitigation technologies has a negative impact on a farm's profitability it is unlikely any farmers will adopt them because they are reducing GHG emissions. Mitigating government costs is a much more tangible benefit for farmers and should provide more perceived value for any methane reduction using PGgRc's technologies than action against climate change would. There was concern among two farmers interviewed that creation of methane vaccines and inhibitors would lead to the government introducing methane costs. However, it is likely methane costs will be introduced at some point without the technologies existing in which case this concern loses its relevancy.

Based on this theme, it would be beneficial if PGgRc can identify additional value in their technologies in addition to methane mitigation. If this cannot be done, government regulations introducing methane costs could be crucial in getting farmers to adopt and methane vaccines and inhibitors.

\subsubsection{Summary of key findings from latent themes}

The following are the key findings based on the latent themes identified. The primary finding is that profitability is core to farmer interest in any methane mitigation technology, as this was expressed in some form across all themes.

There were also additional variables identified that could be important to the commercialisation of methane vaccines and inhibitors. The first of which is the potential for some farmers to oppose PGgRc's technologies even if the offer productivity gains or cost mitigation, Secondly, just methane vaccines or inhibitors are unlikely to suit all farm systems, as each farm location and management system will create different value priorities. Finally, identifying productivity gains in PGgRc's technologies could mitigate the need for government regulations introducing methane costs by providing tangible value over methane mitigation. 


\section{Chapter 4 - Discussion}

This chapter explores the major findings of the research and discusses their importance to the project goals. This includes the potential opportunities and barriers presented by farmers identified during the research and their impact on this project.

The objectives of this project outlined in chapter 1 were to:

1. Investigate what farmers see as the strengths and weaknesses of the technologies.

2. Apply the findings from the investigative stage to validate the commercial potential of the technologies.

3. Outline how PGgRc should proceed with the continued development of their technologies based on this project.

Points 1 and 2 will be the focus of this discussion, with point 3 being explored in greater detail in chapter 5 - Discussion (Business Case).

\subsection{Major Findings}

There are four main findings from the analysis chapter that are the focus of this discussion. These findings highlight the potential strengths and weaknesses of PGgRc's technologies and are explored in detail to identify the opportunities and barriers each presents.

\subsubsection{Finding 1 - Farmers value the technologies if they can mitigate methane costs.}

Eleven of the participants would value the methane vaccines and inhibitors if they could mitigate methane costs. This isn't an unexpected finding as PGgRc and Suzi had identified profitability as the key success factor for the technologies during discussions. However, it was important to confirm that methane mitigation could be viewed as a key part of the technologies value proposition.

There are limited options currently available to farmers looking to reduce their methane emissions. Having choices for mitigating methane costs is valuable to farmers, even if they do not intend to utilise either of the technologies. Knowing the technologies are there allows farmers to plan for their implementation should it become necessary.

Two participants were concerned that creation of the technologies would be used as justification to implement methane costs. There is some logic behind this concern as the creation of methane vaccines and inhibitors would allow the government to regulate agricultural methane knowing farmers had the ability to reduce their emissions. However, the current Labour government already intends to take greater action against climate change than the previous 
government and regulating methane emissions will need to occur before 2050 if the government follow through on their Net Zero emissions goal. Knowing that methane regulations are likely in the future regardless of the methane mitigation options available, having options available should still be beneficial even if they lead to methane regulations being implemented at the same time.

Two participants were willing to field a little cost in using the inhibitors and vaccines to avoid larger costs and regulations down the line.

\section{Feasibility}

This finding and the related concerns and benefits indicate that methane mitigation technology is feasible in New Zealand if the government introduce some form of methane cost. While there was some concern among participants that the creation of methane vaccines and inhibitors will accelerate the introduction of those costs, it will still be more valuable long-term to have these technologies than reach a point were methane regulations are introduced irrespective of such technologies being available.

\section{Opportunities and Barriers}

The following are opportunities and barriers to the project based on the value PGgRc's technologies provide through mitigation of methane costs.

Government action against climate change/GHGs is a great opportunity for methane vaccines and inhibitors. The Labour government have expressed their intention to take greater action against climate change than the previous government. If they choose to enact policy regulating GHGs at the farm level, it will create emission costs which could be mitigated by the inhibitors and vaccines. However, simply integrating agriculture into the ETS would not encourage farmers to adopt methane vaccines or inhibitors if there are other more convenient or profitable GHG emissions mitigation/offset options available. The greatest opportunity for PGgRc's technologies would arise if methane emissions are specifically targeted as this would maximise the potential impact of the vaccines and inhibitors.

No government regulation around agricultural methane would be a barrier to technology success. Without a methane cost in place, the value of methane mitigation is limited to market demands. If consumer behaviour shifts to prioritise low emission products, then farmers adopting the technologies will improve their ability to remain competitive. However, there isn't necessarily a profitability benefit in this situation, as low emissions may be viewed as an expectation rather than value added by consumers. Identifying benefits to animal live weight gains/milk production 
during technology development and testing would help mitigate this barrier but is an uncertainty at this point.

These opportunities and barriers will require monitoring as PGgRc continues to develop their technology. Lobbying of government could influence the introduction of regulation, but changes in consumer behaviour would be harder to achieve.

\subsubsection{Finding 2 - Methane emissions are viewed as important}

13 of the participants believed that methane emissions are important, either as an environmental or as a commercial concern. It was uncertain beginning this research how many farmers believed in or thought about GHGs and climate change.

Of the participants who believed in methane emissions, 10 supported action to mitigate climate change because they believed it was an important issue outside of their own farm operations. Climate change is likely to affect agriculture in a significant way, but these participants were also thinking about the broader impacts of climate change on all countries and industries. The other three participants viewed action to mitigate methane as a response to market/societal changes. For these participants the importance or existence of climate change was still unclear, but if society had defined it as a problem requiring action then they would play their part. Growing public awareness of anthropogenic climate and its causes could eventually lead to consumer behaviour changes which would detrimentally affect agriculture as it stands, so taking proactive action now could be of commercial benefit for farmers in the future.

However, if using a methane vaccine or inhibitor costs more than the value of the methane reduced, the importance of methane emissions isn't significant enough to get farmers using the technologies. As a business, farmers must maintain profitable operations or go out of business. If PGgRc's technologies cost more than the methane they mitigate it is expected that farmers will pay the methane cost, as this will have less negative impact on the profit margins of their farm.

\section{Feasibility}

While the participating farmers viewed methane mitigation as positive action against climate change, this alone doesn't create enough value for technologies to feasibly have a market. Changes in consumer behaviour could provide the technologies with needed value to farmers if market trends shift towards low GHG emission products, improving their feasibility. 


\section{Opportunities and Barriers}

The lack of perceived value in methane mitigation for individual farmers is a barrier to these technologies succeeding. The benefits of mitigating methane are not immediate and visible to farmers, which makes it difficult to value in the day to day operation of a farm. However, changes in market preferences in favour of low GHG emission could provide the technologies with an opportunity to succeed.

Consumer behaviour is potentially an opportunity or barrier but determining which it will be isn't possible for this research project. If consumer behaviour shifts towards valuing low emissions products then adoption of the technologies by the agricultural sector is an opportunity, especially if it is a global trend. The potential barrier is that consumers do not prioritise low emissions and oppose the idea of interfering with natural processes in an animal. In this situation the use of methane mitigation technology isn't of commercial benefit to the farmer and choosing to not administer vaccines or inhibitors could provide a market advantage over those who do.

As an export focused sector, New Zealand agriculture will be affected by any methane or emissions-based regulations foreign nations implement. There is potential for international regulations to become a market opportunity. If these technologies are made available worldwide it may encourage implementation of methane regulations as inhibitors and vaccines could actively mitigate those emissions. If New Zealand agriculture has already adopted these technologies, they will be well positioned to capitalise on any resulting market shift to low methane production. Conversely there is a risk that nations New Zealand exports to do not implement regulations that encourage lower farm methane emissions, but New Zealand does. This would be a major barrier to the technologies succeeding as the additional operation costs for New Zealand farmers would put them at a disadvantage against international competition who do not have to account for those costs.

\subsubsection{Finding 3 - Technology preferences}

\section{The vaccine technology is preferred by farmers interviewed}

There is a clear preference among the research participants for six-monthly or annual vaccines over daily or weekly inhibitor administration. This preference was found across dairy and beef, lamb and wool farm systems. The more frequently a product is administered, the greater the labour cost resulting from its use. This is of particular importance for beef and lamb farmers, as they only handle their stock during a few key periods of the year. Daily, weekly, or even monthly 
administration of inhibitors to their stock could require a significant overhaul of how they operate their farm system. In some situations, it may simply be too difficult to get inhibitors reliably to their stock for the technology to effectively function.

Implementing daily or weekly inhibitors into New Zealand dairy systems could be easier than beef and lamb systems. Dairy farmers have more regular animal contact and opportunity for handling as their stock come in once or twice a day for milking. Some farmers have feed systems installed in their milking sheds which would allow for each animal to receive a dose of the inhibitor each time they come in for milking. However, of the six participants operating dairy farms in this research, only two had the required infrastructure for in-shed feeding. For those farmers without feed systems in place, frequent inhibitor administration would require additional expenditure to set up feeding infrastructure in their milking sheds, or to cover the labour of ensuring each animal receives an inhibitor dose.

Four participants operating beef, lamb and wool systems were much more open to inhibitors if their duration was increased or different routes of administration were possible. Possible methods of achieving this could be through use of a bolus or development of watersoluble inhibitors.

\section{Feasibility}

Methane vaccines have the best potential in the New Zealand agriculture market because of the convenience their duration and administration provide. In both dairy and beef, lamb and wool systems integrating a vaccination into existing healthcare schemes is simpler than adding a daily or weekly inhibitor administration. If inhibitor duration cannot be improved, it is reasonable to expect dairy systems to be the only viable market that technology in New Zealand. However, if improved methods of administration and/or increased duration can be identified then inhibitors are feasible as products competing with vaccines. Inhibitors distributed through feed and water systems could require less work than administering a vaccine to all stock.

\section{Opportunities and Barriers}

Based on the research findings inhibitors requiring daily or weekly administration would be too great of a cost for the technology to be viable for many beef, lamb and wool farmers. This barrier would be hard to overcome, but it is possible PGgRc will be able to develop or identify an administration system for inhibitors that reduces the required labour to two to three times a year per animal. Alternatively, if they can develop an inhibitor that can be added to a farms water 
system it would require very little labour for the farmer to administer regular doses without animal contact. This is an opportunity to create an inhibitor that could compete with a vaccine on pastoral grazing systems.

Dairy systems present an opportunity for inhibitor technology in New Zealand even if the duration cannot be improved. Regular milking schedules facilitate the frequent administration inhibitors would require. Use of milking shed feed systems would further minimise the administration costs but would require infrastructure investment for those farmers without feed systems already in place.

A barrier to creating inhibitors with longer duration and easier administration could be the compound(s) the make up an inhibitor. The primary compound(s) of an inhibitor could limit the options available to improve administration or duration of the product. For example, for inhibitors to be distributed through a water system they would need to be water soluble while retaining their functionality upon entering the rumen. This could require a solvent to make the product soluble or may not be possible at all. Any additional compounds added to improve duration or administration would also need to be tested for safety which presents another barrier to inhibitor use.

\section{Half of participants would prefer options that weren't vaccines or inhibitors}

Nine participants wanted to have options that weren't vaccines or inhibitors available for addressing methane emissions. The profitability of different methane mitigation methods was a core aspect of this preference. Soil carbon and re-evaluating how trees are measured for carbon credits were two ideas raised by four participants as potential offset for methane emissions instead of using a vaccine or inhibitor to directly reduce emissions.

Four of these participants were driven to find alternative methane mitigation options for reasons outside profitability. These participants wanted 'natural' methods for mitigating or offsetting their methane emissions based on a variety of factors such as avoidance of GMO/GE, feeling uncomfortable about interfering with the natural processes of their livestock, and a belief that use of vaccines and inhibitors would be detrimental for the future success of farming.

The first two drivers for 'natural' methods are based on individual beliefs and therefore could be hard to change. GMO/GE avoidance can often be attributed to discomfort about modification of DNA or insertion of foreign genes from one organism into another. Alternatively, concern about the potential repercussions of playing around with nature could cause antiGMO/GE perspectives. Being uncomfortable about interfering with an animal's natural functions 
can be reason enough to avoid a product. There are risks to modifying an animal's rumen, and some participants are opposed to artificially modifying a natural process before exploring any potential natural solutions.

The final drive for 'natural' preferences is based on how each farmer perceives the future of farming. Synthetic meat and milk will soon become an option for everyday consumers. These products can be produced with less water and none of the methane a ruminant generates. This presents a potential threat to current livestock farmers, as the more environmentally focused consumers will have little reason to choose conventionally farmed meat and milk over lab grown. However, synthetic meats and milks are not 'natural' products like those produced using a pastoral system, and recent market trends have been moving away from additives and synthetic compounds towards natural substitutes. Adopting methane vaccines and inhibitors to reduce methane emissions could make the meat and milk produced more environmentally friendly, but cost farmers the 'natural' benefit their products have over their laboratory counterparts.

\section{Feasibility}

Half of the research participants would prefer other routes of methane mitigation or offset be considered before vaccines or inhibitors. For some this is a personal belief, and for others it is about the most profitable option. It is not possible to determine if this preference is significant within the farming community from this research, but it is worthy of further investigation. For the majority of participants in this finding, the preference is based on profitability which indicates if PGgRc's technologies can be priced competitively when compared to the cost of natural options many farmers would still be open to using them. However, the participants personally opposed to the 'unnatural' vaccines and inhibitors are unlikely to utilise the technologies unless the market or regulations demand it. Based on these findings, the market for methane vaccines and inhibitors could be limited by farmer preferences. However, if the products can be sold for cheap enough there should still be around $3 / 4$ of the market interested.

\section{Opportunities and Barriers}

Getting participants opposed to using vaccines or inhibitors for reasons beyond the cost of purchase and administration will be a difficult barrier to overcome. Regulations incentivising use are likely to be meet with resistance, and for adoption based on the technologies benefits the opportunity cost of not using them would need to be too great to ignore. 
However, more of the participants were interested in natural options for methane mitigation based on the value they offered. Offering methane vaccines and inhibitors for the right price could be enough to encourage these participants to purchase PGgRc's technologies. The production of the technologies at low cost while remaining profitable would be an opportunity capture more of the market.

Public perceptions related to farming and food purchasing preferences could be crucial here. If enough consumers decide to support farmers using methane vaccines and inhibitors, they will be presenting a message that those technologies are OK to use. This could help overcome any anti-GMO/GE and additive free biases within the farming community.

\subsubsection{Finding 4 - Some farmers are interested in subsidies}

Seven of the participants in this research wanted or expected subsides for methane inhibitors and vaccines, if there was going to be a cost in their use. If the technologies were required and resulted in a cost to the farmers there were concerns about their affordability, having a third party impose extra costs is rarely welcome. Some of these participants believed that the cost of the inhibitors and/or vaccines shouldn't solely be the farmers responsibility and proposed some different methods for subsidising them. These ranged from subsidising the

production costs to introducing an environmental tax that contributes to any technology subsidies. There was one participant within this group who raised concern about the public response to any subsidies introduced. Subsidises at the farm gate for inhibitors and vaccines could be viewed by the public as government handouts for a problem caused by that industry, which could invoke a negative public response. If a tax on goods produced by ruminant stock was introduced to subsidise the technologies, the additional cost on meat and milk could result in consumers changing purchasing behaviour away from New Zealand products to cheaper imported goods.

One participant didn't want or expect subsides, because they haven't had any since they were ended, and they were opposed to greater government involvement in their farm operations. While another was opposed to subsidies for similar reasons but would be accept them if they helped maintain farm profitability. Across the participants, some expressed doubt that other farmers would welcome inhibitors.

If during further development of PGgRc's inhibitors and vaccines the technology can be found to provide benefits in live weight gain or milk solids etc. there may be no need for subsidies. 


\section{Feasibility}

If acquiring and administering the methane mitigation technology results in a cost to farmers, some form of subsidy may be required for farmer adoption. PGgRc could possibly subsidise initial product purchase, but this would not be sustainable long term. Government based subsidies could provide support over a longer term but would require the value of methane mitigated to offset the cost of government support to be easily justified. If subsidising the technologies is costing the government more than the methane reduction is worth it is more financially sensible to pay the methane cost instead. However, when considering the technologies by the Labour Government's Net Zero goal, paying to reduce methane may still be valuable to their objective.

In the situations the commercial feasibility of the technologies is improved by the introduction of subsidies, but if benefits of the technologies are found or the cost of their purchase and use are small enough then subsidies may not be needed.

\section{Opportunities and Barriers}

Subsidies may be introduced to overcome costs that discourage or prevent farmers from adopting PGgRc's technologies. These subsidies would be an opportunity for farmers to adopt the technologies with minimised risks to their business, in turn improving PGgRc's share of the market. How farmers react to the vaccines and inhibitors after adoption and use could determine what form subsidies continue in, if at all.

Subsidies that pay farmers to use the technology should be considered unlikely. PGgRc cannot afford to pay farmers to adopt and use their technology, and any government subsidies should be valued against the cost of the methane mitigated by the technologies. If the technologies cost too much compared to any returns, there is little reason for the government to invest money into their use unless there are no better options available.

A barrier to subsidies is the accompanying regulatory infrastructure that could be required to ensure compliance. If the government are subsidising third-party technologies, it is reasonable to expect they will require reliable methods of measuring technology use. Farmers purchasing the technologies to gain the regulatory benefits but not administering the product to their animals due to the labour costs could occur. Implementing any regulatory infrastructure would be an additional cost for the government to consider when determining the value of subsidising methane vaccines and inhibitors. 


\subsection{Project Implications}

Based on the findings discussed above there are three major scenarios that will affect the commercial viability of PGgRc's technologies. These scenarios are:

1. Technology can provide benefits to animal performance which mitigates farmers concerns about health and provides value above mitigating methane.

2. Technology doesn't provide benefits to animal performance but can mitigate methane costs introduced in New Zealand and overseas. Subsidies may be required.

3. Technology doesn't provide benefits to animal performance and no methane costs are introduced. Subsidies required for technology adoption and use.

Option 1 is a best-case scenario, where commercialisation of methane inhibitors and vaccines in New Zealand is most likely to succeed. In this situation methane inhibitors would still be limited by their duration between administrations but would have value in feed lot systems common in developed countries internationally. Vaccines should be the same viability across all farm systems but would face more competition from inhibitors than in the following two scenarios.

Option 2 presents a scenario where commercialisation in New Zealand is still likely to succeed, but farmers will be less open to the technology and some form of subsidy may be required. Theoretically the mitigation of methane costs through use of the technologies should be value enough for farmers to use the technologies. If only the inhibitor is available there will be major costs to overcome for beef and lamb farmers unless duration between administrations is improved, which would likely require subsidies to see successful adoption. Vaccine technology should be less likely to require a subsidy as the costs of purchase and administration per animal should be common across all farm systems.

Option 3 is a worst-case scenario, unlikely to result in successful commercialisation in New Zealand for vaccines or inhibitors. PGgRc's technologies do not have any real value to farmers, there is no methane cost to mitigate and they don't benefit animal performance. Subsidies would be required to have farmers use the technology, which are very unlikely as farmers are not required to use the technologies so would have little reason to field any costs. As a result, the technologies would have to be entirely subsidised, or even require paying farmers to use them.

Commercialisation of PGgRc's technologies should be planed for under scenarios 1 and 2, as both offer reasonable commercial opportunities for PGgRc. Option 1 would present the easiest route to market, as the productivity benefits would be of great interest to potential licensing partners and to the farmers ultimately using the products. Option 2 is still viable, but the 
technologies are unlikely to be viewed as positively as in option 1. In this situation the use of technologies is in response to costs imposed upon them, not adoption of technologies because they present commercial benefits. Option 3 would mean no commercial market in New Zealand, at which point any potential for commercialisation would be in foreign agricultural sectors. Option 3 is unlikely to occur if New Zealand continues to strive for their emissions goals, as agricultural emissions are too significant to ignore.

\subsection{Contribution to Field and Industry}

Based on this research any action to mitigate agricultural emissions will require it to be profitable for farmers to welcome it, and regulation for adoption if action is of negligible benefit to farm profitability or creates a cost. Imposing costs on farmers could result in backlash, like the protests in 2003 against proposed methane taxes (Fickling, 2003). These protests were a driving factor in the end of any "fart tax" discussion.

This research indicates that for methane inhibitors to have commercial potential in many pastoral farm systems they will require administration tools that decrease the frequency at which they must be administered. This highlights how vital it is to consider administration costs for farmers when developing any commercial or charitable solutions to methane and GHG emissions from livestock.

Positively, farmers are aware of climate change and many are willing to act against it if solutions can be offered for the right price or incentive. 


\section{Chapter 5 - Recommendations (Business Case)}

This chapter is intended to augment PGgRc's existing commercialisation plan. This research relates to one of PGgRc's three core objectives, "to maximise the research opportunities and benefits primarily for New Zealand farmers and where compatible with the priority, the profitability of the Joint Venture." The information presented within this section aims to improve upon their ability to fulfil this objective by improving their understanding of how New Zealand farmers relate to their technologies.

\subsection{Executive Summary}

This Chapter presents the key implications of the research findings on the commercialisation of PGgRc's technologies, with the goal of improving the available knowledge when making decisions about the continued development of methane vaccines and inhibitors.

There are four key findings based on the research and analysis that PGgRc should consider when proceeding with development of their technologies.

1. Profitability is core to any technology adoption. Throughout all the findings there was constant consideration to how technologies would affect the farm business. This was expected, but there were some areas where profitability wasn't the biggest factor. Some farmers were opposed to modifying the natural processes that occur in their animals when there could be other methods to achieve similar results. For these farmers profit is not the driving force behind technology adopting, only influencing their decisions if not adopting would be too great a cost to their operations.

2. Many farmers are aware of climate change and believe it should be addressed but don't want to field the cost. This links back to profitability, as climate change was viewed as important by many farmers interviewed but acting on it could incur a cost. It is possible that methane mitigation options offered at no cost could be adopted by some of the participants who believe in action against climate change. For some climate change wasn't a concern, and they saw little reason to take actions to address it. In all of these situations, being able to afford any methane mitigation was crucial.

3. Variety of Administration Forms is Important. If inhibitors are only available as daily administrations they are unlikely to be adopted by many New Zealand farmers, whereas vaccines with a yearly administration would be acceptable. However, if the frequency of inhibitor administration can be reduced, there is potential for it to achieve 
wider adoption. There is no one product that would suit all farmers, some products will suit one system where another would not and vice versa.

4. Subsidies could provide incentive to adopt methane vaccines and inhibitors among the farming community. As previously stated, profitability is a constant consideration for farmers. If PGgRc produces a product that doesn't do more than mitigate methane it is likely some form of subsidy will be require for any adoption to occur. Understanding who could provide subsidies will be important for PGgRc if their technologies don't improve animal performance.

PGgRc is intending to license their IP to larger companies with the experience and production capabilities to get PGgRc's technology to market. In doing so they will be shifting the burden of later development onto their licensing partners. The contents of this chapter reflect that, recommending actions PGgRc can take now and in early in their future development cycle to achieve their commercialisation goals.

\subsection{Company Description}

\subsubsection{Purpose of PGgRc}

Anthropogenic GHG emissions are contributing to climate change. This is a global problem that almost all countries are acting to mitigate, best shown by the Paris Agreement under which participating countries aim to limit global warming to $2^{\circ} \mathrm{C}$. The two largest GHGs contributing to climate change are methane and $\mathrm{CO}_{2}$, the former of which is of importance to New Zealand. As discussed in Chapter 1.2 agriculture is the major contributor of methane emissions. PGgRc was established in $\mathbf{2 0 0 2}$ to reduce methane emissions from ruminant animals. Since then they have been developing technologies to mitigate agricultural GHGs with a focus on methane.

Two technologies are the focus of PGgRc's commercialisation efforts, methane vaccines and inhibitors.

\subsubsection{Business model}

PGgRc's business model has been discussed in Chapter 1.12, which is built upon in this section.

PGgRc has access to world leading research into ruminant methanogens to build vaccine and inhibitor IP portfolios. As a result, they are intending to operate under a licensing business model. Once they have identified suitable IP and developed it to PoC, they hope to find suitable 
licensing partners for their technologies. Inhibitor IP would probably align best with animal health or feed and nutrition companies, while vaccine IP would align with animal health companies. Once a licensing agreement is formed, the licensing partner would take over responsibility for the final development and release of methane mitigation products.

PGgRc is a small organisation compared to the large companies they are considering as potential partners. Forming partnerships with suitable companies would bring in market experience and development/manufacturing infrastructure that PGgRc lacks, facilitating the creation and release of commercial methane vaccine and inhibitor products. Taking PGgRc's IP from PoC to commercial product will require millions of dollars in R\&D investment, not factoring in the resulting marketing and distribution of any products. A licensing agreement would shift this cost from PGgRc onto the large partner better suited to carry financial burden, reducing the risks to the consortium.

The support of large companies for methane vaccines and inhibitors could make the difference between limited adoption and widespread adoption. However, in doing so PGgRc will no longer have control over the final products released, so it will be crucial that the IP licensing terms ensure any methane vaccine and inhibitor products are suitable for New Zealand farmers.

\section{New Zealand incorporated model for inhibitors}

This is model is discussed in Chapter 1.12 , this section provides a summary.

If a suitable licensing partnership fails to form around PGgRc's inhibitor IP they could attempt a New Zealand Incorporated approach to product development. This is not currently being pursued as the inhibitor business model as it places more risks upon PGgRc and their affiliates. However, it is worth considering as an option should the priorities for methane inhibitor commercialisation change.

\subsubsection{Opportunities and constraints}

Determining the suitability of companies with potential as licensing partners for PGgRc requires more than those companies' interest in PGgRc's technologies. Delivering benefits primarily for New Zealand is an objective of the research consortium, which must be considered when evaluating potential licensing partners.

While use of vaccine technology should be comparable across the world, inhibitors are better suited to Total Mixed Ration (TMR) feeding systems used predominantly in indoor farms. TMR systems combine all the dietary requirements of an animal into once prepared feed mix that 
is offered to the livestock. Releasing an inhibitor for use in TMR systems would be the most convenient option for a licensing partner as these are common across the USA, Canada, and Europe and suitable for an inhibitor additive. However, New Zealand has very few farmers operating farm systems appropriate for TMR. If PGgRc licences their inhibitor IP to a company which releases a product for TMR systems it will benefit international farmers above New Zealand farmers, opposing PGgRc's core objective outlined in the introduction to this chapter. Because of this, any licensing agreements PGgRc forms will need to produce a product suited for pastoral systems common in New Zealand.

Theoretically there should be fewer constraints on appropriate licensing partners for vaccine IP, as vaccines should be suitable for all livestock systems globally. It is hoped the vaccines will have a duration of around a year and will be administered by injection. The long duration and ability to integrate the product into existing vaccination programmes would make vaccines comparable in administration costs across all livestock farm systems.

Table 8 SWOT analysis of PGgRc's methane vaccines and inhibitors has been provided augment the discussion in this section.

Table 8 SWOT analysis of PGgRc's methane vaccines and inhibitors

\begin{tabular}{|c|c|}
\hline STRENGTHS & WEAKNESSES \\
\hline $\begin{array}{l}\text { Technologies could reduce methane emissions } \\
\text { from livestock in a manner not currently } \\
\text { possible. } \\
\text { World leading vaccine research, no other } \\
\text { patents in the space internationally. } \\
\text { Inhibitor development alongside research into } \\
\text { administration methods for non-TMR feeding } \\
\text { systems. }\end{array}$ & $\begin{array}{l}\text { Value of technology dependent on theoretical benefits } \\
\text { to animal productivity and government } \\
\text { regulations/subsidies. } \\
\text { Inhibitor will not be first to market, DSM product slated } \\
\text { for } 2019 \text { release. } \\
\text { Inhibitor technology is prohibitively time intensive } \\
\text { without improved methods of administration }\end{array}$ \\
\hline OPPORTUNITIES & THREATS \\
\hline $\begin{array}{l}\text { Current New Zealand Labour government } \\
\text { have suggested bringing agriculture into the } \\
\text { New Zealand emissions trading scheme. } \\
\text { If the technologies can improve animal } \\
\text { performance, it could be a value added } \\
\text { technology for farmers. } \\
\text { Mitigating agricultural methane emissions } \\
\text { could have a significant positive impact on } \\
\text { New Zealand's total GHG emissions. }\end{array}$ & $\begin{array}{l}\text { DSM inhibitor will release before a PGgRc product, but } \\
\text { this product is only suited for TMR feed systems rare in } \\
\text { New Zealand. } \\
\text { Not acting against climate change is more affordable } \\
\text { than using the technologies if regulations aren't } \\
\text { introduced/technologies don't improve animal } \\
\text { performance. } \\
\text { The agricultural industry is constantly advancing, it is } \\
\text { possible that novel competing technologies could be } \\
\text { introduced as development continues. }\end{array}$ \\
\hline
\end{tabular}




\subsection{Market Analysis}

PGgRc has done little research into farmer perspectives on these technologies and understanding what strengths and weaknesses farmers perceive in them could help direct development of the final product.

\subsubsection{Target market}

PGgRc's technologies are designed for use with ruminant livestock, therefore any commercial products will be targeting agricultural sectors in New Zealand and internationally.

As discussed in chapter 1.7, ruminants produce methane in their rumen because of microorganisms known as methanogens, and there are currently limited options for mitigating these emissions. Methane vaccines and inhibitors could offer new solutions for reducing ruminant methane emissions that otherwise must be addressed indirectly through reducing stock numbers or utilising plantations for $\mathrm{CO}_{2} \mathrm{e}$ offset. $\mathrm{PGgRc}$ believes there is potential for their products to improve animal productivity, but if this doesn't occur they are assuming that regulations will be introduced in New Zealand and internationally that incentivise farmers to reduce their methane emissions.

Based on the research conducted New Zealand farmers could be open to using PGgRc's technologies if they provide animal productivity benefits or mitigate regulatory costs. Assuming farmers internationally share similar opinions, which is reasonable when considering other pastoral farm systems, any product successfully commercialised in New Zealand should have a reasonable chance of succeeding in international markets.

\subsubsection{Current market solutions}

Methane vaccines and inhibitors have no current equivalents, but there is research and development in this field occurring internationally. Mitigating methane is currently limited to indirect measures such as reducing stock numbers or offsetting emissions. There are various methods for directly inhibiting methane being researched, but inhibitor compounds seem to have the most promise of a resulting commercial product.

DSM Nutritional products are developing an inhibitor, 3NOP, which is slated for a 2019 release. The DSM technology presents a major competitor for any PGgRc methane inhibitors. However, in its current form the DSM inhibitor is best suited for TMR feed systems which are common in many developed nations agricultural sectors. New Zealand and other countries with predominantly pastoral grazing farm systems would face difficulties in administering the DSM 
inhibitor to their livestock because of the frequent doses required. Additionally, the DSM inhibitor is unsuited for sustained delivery systems such as a bolus. PGgRc could use this fact to their advantage if they can identify an inhibitor suitable for bolus or other sustained delivery system.

PGgRc's vaccine research and development is still ahead of the field. The only relevant patents to come from a patent search using the software, PatSnap, and the search terms "methane AND methanogen AND vaccine" belonged to PGgRc. Administering PGgRc's methane vaccine should be a familiar process for farmers who already have vaccinations as part of their animal health programme. The simplicity of using a vaccine product combined with the goal of a yearly administration period should result in a competitive product even if inhibitors are established within the agricultural market.

\subsubsection{Barriers to changing market behaviour}

Methane mitigation adds a cost into farm operations, if the products don't improve animal performance in a meaningful way some other incentive will be required for the technologies' adoption. This section details two situations that could provide incentive for using methane vaccines and inhibitors, highlighting the barriers they introduce before concluding with a discussion of potential solutions.

\section{Situation 1}

The first situation is bringing in government regulations that incentivise methane mitigation. This could be a methane tax, emissions trading schemes, or some other form of cost based on $\mathrm{CO}_{2} \mathrm{e}$. Introducing regulation that creates a $\mathrm{CO}_{2} \mathrm{e}$ cost for agriculture, and in relation to PGgRc's technology methane emitted by ruminant livestock, could be poorly received by farmers and the market. The existence of PGgRc is an example of how large the agricultural backlash to carbon costs can be, as its inception was a compromise between the New Zealand government and lobbying farmers and agricultural organisations. Assuming regulations targeting GHG emissions are introduced, which the current Labour government have suggested they intend to within their first term, methane vaccines and inhibitors must then mitigate methane enough to be valuable. It is unlikely PGgRc's technology will be as valuable to farmers if it can only reduce methane emissions, as this would be cost mitigation rather than the value add of improved animal productivity. However, some farmers are aware that action is required global warming is to be limited to $2^{\circ} \mathrm{C}$ and understand that this technology would allow them to contribute to emissions goals while mitigating the cost to their business. 


\section{Situation 2}

The second situation relates to consumer behaviour. The consumer dictates the value of farm products, so a significant shift in consumer purchasing behaviour could shift the value proposition of PGgRc's methane mitigation technologies. If consumers are willing to pay a premium for low emission products their use could be value added to farmers. However, it is unlikely that premiums for low emission products would be sustainable if adoption of vaccines and inhibitors became widespread. If the majority of farmers are using the methane mitigation technologies it could become a market expectation, reducing the likelihood of consumers paying a premium for low emission products. Consumers expecting low emission products without a premium would remove value from methane mitigation for many farmers. PGgRc is hoping for widespread adoption among farmers as this would be required for methane emission reductions on a national level. It is reasonable to assume that successful commercialisation of the technology would be measured by quantity of methane mitigated and profit returns for PGgRc. The value of both these metrics should increase proportionally to the number of farmers using the vaccine and inhibitor technologies. Widespread adoption of PGgRc's technologies could lead to methane vaccines and inhibitors becoming a requirement to remain competitive. While this would drive demand for PGgRc's products, it could place further stress upon marginally profitable farms around New Zealand, potentially undermining their objective "to maximise the research opportunities and benefits primarily for New Zealand farmers..." It is difficult to benefit New Zealand farmers if PGgRc's products are placing further costs upon some already struggling farm systems.

\section{Potential solutions}

In both the aforementioned situations it is possible that introducing subsidies could mitigate the larger costs. Understanding who can provide subsidies and where they will be administered could be crucial if the methane mitigation technologies do not improve animal productivity. There are three potential providers of subsidies, of which two are sustainable.

The first and most limited option is for PGgRc to subsidise their own products at launch to encourage adoption of the technologies. In an ideal situation this would mitigate the initial operating costs involved in purchasing and administering unfamiliar vaccines and inhibitors, after which the subsidies could be ended once farmers were comfortable with their use. This situation 
still relies on ongoing costs being small enough that farmers will accept the continued administration of the products.

The second option is for government to subsidise PGgRc's technologies. Subsidies for PGgRc products implemented this way should be easier to sustain but could be limited by the cost to government when compared to other GHG mitigation options. Furthermore, the importance of any methane mitigation will be directly related to how government regulations prioritise GHGs. Assuming the government do introduce agricultural GHG regulations which consider methane a priority target for mitigation, getting farmers to adopt GHG mitigation tools which target methane will be important. An opt in system for subsidised mitigation products could be one method that wouldn't leave farmers feeling it was forced upon then. Alternatively, regulating carbon costs in $\mathrm{CO}_{2} \mathrm{e}$ for farm methane emissions could lead to faster technology adoption, but would generate greater backlash from the farming community. Whatever form of subsidy was implemented, the potential cost of methane mitigated by using PGgRc's technologies would need to be greater than the cost of the technologies after subsidies for it to make financial sense for farmers to adopt.

The final option would be support from industry organisations. There could be consumer goodwill in subsidising methane mitigation technologies, both from farmers and the broader public. If the government introduce methane regulations farmers around New Zealand will face increased operating costs. Ensuring farmers can maintain profitable businesses could be of importance for the agricultural organisations who support and are supported by them, as the health of the agricultural sector is ultimately linked to health at the farm level. By subsidising methane mitigation products, the industry organisations profiting from farm goods could ensure those goods continue to be produced. It is unlikely any one organisation would be willing or able to subsidise the industry, so if this form of subsidy were to occur it would likely be on a farm system basis, i.e. Fonterra supporting dairy farmers, Beef+LambNZ investing in beef and lamb farmers. While relying on industry would encounter similar problems to PGgRc attempting to subsidise the technologies the cost would be spread across multiple organisations instead of just one.

\subsection{Product Validation and Development}

This section explores the status of PGgRc's technologies, and what is still required for their continued development. 


\subsubsection{Current status of the technologies}

Both the vaccine and inhibitor technologies are unlikely to be released before 2023 based on their current development status. There are four lead inhibitor compounds undergoing continued development that PGgRc believes have potential for successful commercialisation. PoC in vivo for the vaccine technology is still to be established, but there is in vitro evidence for it being possible. This has been discussed in some detail in Chapter 1.9.

Further testing is required to identify if methane mitigation technologies can improve animal performance. Knowing this will determine how important government regulations could be and will provide PGgRc with a better understanding of the value their technology offers to farmers and potential commercialisation partners.

\subsubsection{Regulations}

It is important to understand what certifications and regulations methane vaccines and inhibitors will face in New Zealand and internationally. PGgRc's technologies will need to be certified in New Zealand by MPI under Agricultural Compounds and Veterinary Medicines (ACVM) Act 1997. The vaccines and inhibitors will need to be classed to determine their regulatory status. However, until PGgRc has a product that can undergo the required testing it will not be possible to continue with any certification processes in New Zealand. The regulatory bodies likely to be relevant to any regulatory certification in countries that PGgRc is most interested in have been outlined below in Table 9 Regulatory bodies in relevant counties PGgRc has patents.

Table 9 Regulatory bodies in the relevant countries $P G g R c$ has patents

\begin{tabular}{|l|l|}
\hline Country of release & Regulatory body \\
\hline New Zealand & Ministry of Primary Industries \\
\hline Australia & $\begin{array}{l}\text { Department of Agriculture and Water } \\
\text { Resources } \\
\text { The Australian Pesticides and Veterinary } \\
\text { Medicines Authority (APVMA) }\end{array}$ \\
\hline USA & $\begin{array}{l}\text { U.S. Food and Drug Administration (FDA) } \\
\text { United States Department of Agriculture } \\
\text { (USDA) }\end{array}$ \\
\hline Canada & Canadian Food Inspection Agency (CFIA) \\
\hline European Union & European Medicines Agency (EMA) \\
\hline Brazil & $\begin{array}{l}\text { Ministério de Agricultura, Pecuária e } \\
\text { Abastecimento (MAPA) }\end{array}$ \\
\hline China & $\begin{array}{l}\text { Ministry of Agriculture (MOA) } \\
\text { Veterinary Bureau } \\
\text { Bureau of Quality and Safety Supervision for } \\
\text { Agro-products }\end{array}$ \\
\hline
\end{tabular}




\subsubsection{IP protection.}

PGgRc is developing their technologies to PoC and patenting their core IP as they progress. The majority of patents filed so far have been related to vaccine technology. PGgRc has two provisional patents related to inhibitor IP but are yet to select which counties they will focus on. Originally 15 countries were identified as important vaccine patent locations, however with the creation of the Paris agreement PGgRc has re-evaluated how countries are prioritised. A tier system has been implemented with most essential patent locations in tier one, strategic locations in tier two, and locations of limited value in tier three, see Table 10 Priority of patent locations.

There are four patents related to vaccine IP, two of which are directly related to vaccine technology (Vaccine and Genome) and two which could have value to inhibitors or methane mitigation in general (Phage and Peptide).

Maintaining patents is expensive, so PGgRc is considering keeping the most valuable patents and allowing others to lapse. While this will mean loss of IP in lapsed situations, but any costs should be offset through the resulting savings.

\section{Table 10 Priority of patent locations}

Key

\begin{tabular}{|l|l|}
\hline Maintain Patent Applications & Allow Patents to Lapse \\
\hline Maintain Granted Patents & Lack of Data \\
\hline
\end{tabular}

\begin{tabular}{|l|l|l|l|l|}
\cline { 2 - 5 } \multicolumn{2}{l|}{} & \multicolumn{2}{l}{ Type of patent and year of application } \\
\cline { 2 - 5 } \multicolumn{2}{l|}{ Vaccine - 2007 } & Genome - 2008 & Peptide - 2007 & Phage - 2007 \\
\hline Tier One & & & & \\
\hline New Zealand & & & & \\
\hline Australia & & & & \\
\hline USA & & & & \\
\hline EU & & & & \\
\hline Canada & & & & \\
\hline Brazil & & & & \\
\hline China & & & & \\
\hline Tier Two & & & & \\
\hline Argentina & & & & \\
\hline
\end{tabular}




\begin{tabular}{|l|l|l|l|l|}
\hline India & & & & \\
\hline Uruguay & & & & \\
\hline South Africa & & & & \\
\hline Tier Three & & & & \\
\hline Japan & & & & \\
\hline Russia & & & & \\
\hline Mexico & & & & \\
\hline Chile & & & \\
\hline
\end{tabular}

\subsubsection{Testing}

Current testing of potential vaccine and inhibitors is detailed in chapter 1.8. Ongoing testing of vaccine and inhibitor components are likely to continue under previously outlined processes while incorporating new tests to collect data about the ongoing performance and safety of vaccines and inhibitors.

If PGgRc finds licensing partners for their technologies, it will become the responsibility of these partner companies to further test and develop of the IP from PoC to commercial product. Testing under partnership should still be investigating the effectiveness and safety of potential products as they develop.

\subsubsection{Key product features.}

This section outlines key features methane vaccines and inhibitors should have based on the findings and discussion in chapters 3 and 4. PGgRc's technologies are examined under the assumption that they mitigate methane and provide substantial animal productivity benefits, after which they are examined under the assumption that they mitigate methane emission costs but do not improve animal productivity.

The vaccine should be well positioned for widespread adoption. Vaccination administrations are understood and practiced by many farmers and the product should be effective for long enough that re-administration isn't a substantial labour cost. Ideally the vaccine will feature a duration suited for annual boosters. Less than annual administration could be inconvenient to integrate into existing vaccination programmes, likewise for durations over annual but less than biennial.

Inhibitors will be limited by their method of administration. It will be crucial that inhibitors feature an accompanying method of administration that dramatically reduces labour costs for 
farmer systems lacking regular animal handling opportunities. If the inhibitors require daily doses it is unlikely any possible productivity gains would be great enough to overcome the time and labour costs such frequent administration could create for beef, lamb, and some dairy systems.

Potential methods for minimising inhibitor administration costs could be using a bolus or formulating a water-soluble product. A bolus would work by delivering the inhibitor directly into the rumen for an extended period, mitigating costs of daily administration. A duration of $100+$ days could be enough to get many farmers interested, as this would require only three animal handling period each year. Alternatively, a water-soluble inhibitor could allow farmers with suitable water systems to administer the technology farm wide without having to actively distribute the product.

A summary of key features is provided in Table 11 Key features of methane vaccines and inhibitors.

Table 11 Key features of methane vaccines and inhibitors

\begin{tabular}{|c|c|c|c|c|}
\hline & $\begin{array}{l}\text { Currently expected key } \\
\text { features }\end{array}$ & $\begin{array}{l}\text { Common desired } \\
\text { key features }\end{array}$ & $\begin{array}{l}\text { Unique desired key } \\
\text { features }\end{array}$ \\
\hline \multirow{2}{*}{$\begin{array}{l}\stackrel{t}{0} \\
\frac{7}{0} \\
\frac{0}{2}\end{array}$} & Vaccine & $\begin{array}{l}\text { - Long duration, annual } \\
\text { administration } \\
\text { - Significant methane } \\
\text { mitigation }\end{array}$ & \multirow[t]{2}{*}{$\begin{array}{l}\text { - Productivity } \\
\text { benefits } \\
\text { - Safe for animals }\end{array}$} & \\
\hline & Inhibitor & $\begin{array}{l}\text { - No injection required } \\
\text { - Significant methane } \\
\text { mitigation }\end{array}$ & & $\begin{array}{l}\text { - Multiple forms of } \\
\text { inhibitor (additive, bolus, } \\
\text { and water soluble) } \\
\text { - Reduced frequency of } \\
\text { administration }\end{array}$ \\
\hline
\end{tabular}

\subsubsection{Potential market pricing}

Because PGgRc's technologies are still five or more years away from commercial release and don't have an existing equivalent on the market it is difficult to determine how much they will cost to produce and what price they can be sold at. However, it is sensible to try deliver and methane vaccines within the price range of vaccines currently on the market. Likewise, for inhibitors identifying a similar feed additive or animal health supplement and using this to as a benchmark for pricing.

\subsection{Project Implementation}

The actions required to get PGgRc's IP from PoC to commercial product. 


\subsubsection{Key skills required}

PGgRc has access to talented researchers and have been patenting key compounds and antigens they have identified to build their inhibitor and vaccine IP portfolios. However, they do not have experience marketing and selling products in the agricultural sector or the infrastructure to produce large quantities of vaccine and inhibitor products. By using a licensing business model PGgRc aims to combine their IP with the market knowledge and manufacturing capabilities of suitable large companies.

Any vaccine licensing agreement will need to bring something in addition to commercial experience and production infrastructure. Creating a vaccine requires three components, a suitable antigen, an adjuvant and an appropriate delivery system. PGgRc's vaccine IP will provide a suitable antigen, and a licensing partner will provide the adjuvant and delivery system to create a functioning vaccine product. Animal health companies have been identified as the most likely partner to provide the required resources.

For a summary of key skills and who can provide them see Figure 12 Visual representation of key skills required.

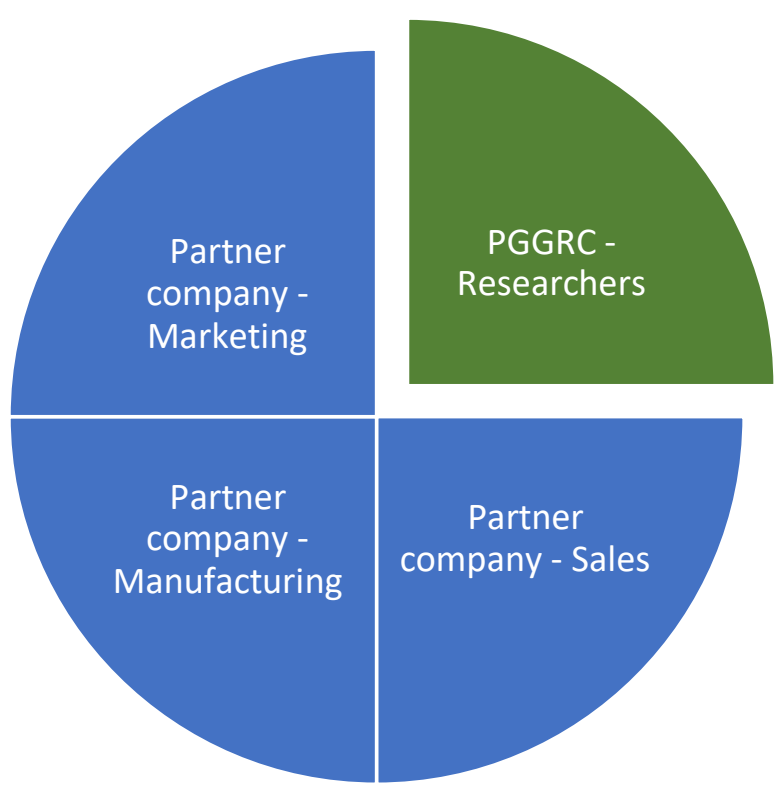

Figure 12 Visual representation of key skills required

\subsubsection{Development and manufacturing process}

Much of PGgRc's current development process has been detailed in Chapter 1.11. Because of their licensing business model much of the development and manufacturing process may not be PGgRc's responsibility. Once suitable PoC for methane vaccines or inhibitors is obtained the idea is 
to licence the relevant IP to a suitable partner who then continues development to create a commercial product.

\subsection{Timeline}

Any timeline for the development of inhibitors or vaccines is uncertain until PoC is achieved. Once PoC for a vaccine or inhibitor is obtained PGgRc estimates it will take another seven years for any commercial product to be available on the market. Based on a seven-year period a timeline has been proposed for the commercial development of PGgRc's technologies, see Table 13 Proposed commercialisation timeline.

Table 13 Proposed commercialisation timeline

\begin{tabular}{|c|c|c|c|c|c|c|c|c|c|}
\hline & & \multicolumn{8}{|c|}{ Year(s) following Proof of Concept } \\
\hline & & 0 & 1 & 2 & 3 & 4 & 5 & 6 & 7 \\
\hline \multirow{10}{*}{ 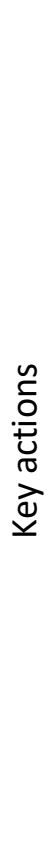 } & Safety testing & & & & & & & & \\
\hline & Begin contacting potential partners & & & & & & & & \\
\hline & Ongoing development & & & & & & & & \\
\hline & Exploration of regulatory environment & & & & & & & & \\
\hline & Licensing agreement / negotiations & & & & & & & & \\
\hline & Manufacturing and goods optimisation & & & & & & & & \\
\hline & Product certification & & & & & & & & \\
\hline & $\begin{array}{l}\text { Initial marketing activities for early } \\
\text { adopter market segments }\end{array}$ & & & & & & & & \\
\hline & Marketing activities prior to launch & & & & & & & & \\
\hline & Launch commercial product into market & & & & & & & & \\
\hline
\end{tabular}




\section{Chapter 6 - Conclusion}

This research project has highlighted key concerns a sample of the New Zealand farming community have about PGgRc's methane vaccines and inhibitors. It has explored the core strengths and weaknesses of the technologies based on these findings and recommended actions for further commercial development.

\subsection{Key Takeaways and Implications}

The research undertaken produced some valuable data related to the potential of PGgRc's technologies. After analysis there were four key findings related to regulations and/or product features that shaped the recommendations made in this thesis. These findings have been attributed to two scenarios that could present a reasonable opportunity for PGgRc's methane inhibitors and vaccines to successfully enter the New Zealand market.

\subsubsection{Scenario 1 -The technology can provide benefits to animal performance, and mitigates methane}

In scenario 1 , the technologies provide value by improving animal performance potentially leading to higher milk solid yield and live weight gain. This could improve the profitability of livestock administered with the technologies, which if substantial enough would be reason for farmers to adopt methane vaccines and inhibitors irrespective of any methane costs implemented. Assuming there is methane regulation creating a cost on livestock emissions, the technologies are potentially even more valuable as they could mitigate costs while improving productivity. While implementation of any methane cost would be unpopular with many farmers, if the technologies can mitigate emissions costs while providing profitability benefits greater than the cost of their purchase and use they could be very well received.

This scenario is a best-case future and would be most suited for PGgRc's intended licencing business model. The technologies are a value-add product, increasing the profitability of a farm system. Providing animal performance benefits is something potential partner companies could sell inhibitors and vaccines on. It should be easier to garner interest in their IP if it provides value understood by the end consumers of farmers. 


\section{Applying key findings}

There are two key findings that can be applied to this scenario, Farmer climate change awareness and Product and administration preference. Both findings are applicable if the methane vaccines and inhibitors are found to provide animal productivity benefits.

\section{Farmer climate change awareness}

Climate change was viewed as important by many farmers interviewed. To some climate change was a threat requiring action, others didn't necessarily believe in it but were willing to act if society deemed it important, and some others still proposed that climate change could have benefits to their farm. However, in all cases action against climate change wasn't valuable enough to justify paying for methane mitigation technologies.

However, if PGgRc's technologies provide positive value to a farm system while mitigating methane emissions the barrier of costs is removed for farmer who believe that acting against climate change is important. It should be easier for farmers interested in taking action to do so, and there would be fewer reasons for farmers who don't actively care about climate to avoid taking action.

\section{Product and administration preference}

Among the research participants there was a clear preference for vaccines over an inhibitor as feed additive. This was based primarily on the effort required to regularly administer the required inhibitor dosage to provide the target levels of methane mitigation.

A once yearly vaccine is much easier to manage and could be integrated into existing animal healthcare programmes. However, decreasing the required frequency of administering inhibitors could change some farmers preference for vaccines. With the right form of administration inhibitors could be provided to animals in a less invasive form than a vaccination, which requires an injection, while requiring little to no animal handling. Under these circumstances some farmers may prefer inhibitors over vaccines if they have the systems in place to facilitate an alternative form of administration.

Product administration and preference will be relevant in a scenario where methane vaccines and inhibitors have profitability benefits. If inhibitors are available before vaccines and can improve animal productivity farmers will want to find ways of using them, even if they are operating farm systems unsuited to the form of administration. Likewise, if either technology can provide better productivity benefits it is more likely that farmers will adopt that technology. It 
becomes a situation of maximising the available benefits of the technologies, rather than identifying the product with the lowest administration costs.

Additionally, there was interest among some of the farmers interviewed in alternative methods of methane mitigation/offset outside of vaccines and inhibitors. For some this was an economic decision, but for others it was based on how they manage their farm system. How these opinions would be influenced by vaccines and inhibitors offering productivity benefit is worth further investigation.

\subsubsection{Scenario 2 - The technology doesn't provide enough benefits to animal performance that it} would be adopted without regulation but can mitigate methane costs introduced in New Zealand and overseas.

In scenario 2, the technologies don't provide enough benefits to animal performance to be valuable but do mitigate methane costs. Ideally, the government are actively regulating GHG emissions and methane is a focus for reaching mitigation targets. Farmers are paying something for their emissions, which methane vaccines and inhibitors can mitigate. Reducing regulatory costs is the primary value of the technologies in this scenario. Other options for reducing methane costs would be directly competing with vaccines and inhibitors. The main advantage of the technologies would be their ability to mitigate costs without restructuring land usage and/or stock numbers. Because the value of the technologies in this situation comes from emissions cost, it is possible regulations would be needed before any potential partners would be seriously interested in a licencing agreement.

\section{Applying key findings}

There are two key findings that can be applied to this scenario, Mitigating methane costs is valuable for farmers and Potential interest in subsidies. Both findings are applicable if the methane vaccines and inhibitors do not provide animal productivity benefits but can significantly mitigate methane emissions.

\section{Mitigating methane costs is valuable for farmers}

Farms are operated as businesses, so there is value in technologies that can mitigate operational costs. This finding indicates some form of regulation creating methane costs would be beneficial for encouraging methane vaccine and inhibitor adoption. Some farmers in this research 
were concerned that creation of the technologies would cause the methane costs to be introduced.

If the government has introduced methane costs, then the methane mitigation of vaccines and inhibitors should be of positive value to farmers. The product would still need to be affordable enough that they can compete with other actions to reduce methane emissions. There should be value in their ability to directly mitigate the source of methane, if it can be integrated without substantial changes to a farm system. This should be much more appealing that other options like reducing herd size which would impact on the total productivity of a farm.

\section{Potential interest in subsidies}

New Zealand farmers have been subsidy free since 1984, and it was unclear how potential subsidies would be received. Most farmers interviewed were open to or actively supportive of subsidies depending on the cost of methane vaccines and inhibitors. One participant was opposed to them because of concerns about giving government more control over farm operations.

In this scenario there are methane costs in place, so subsides could be welcomed by many farmers who in-turn would use PGgRc's technologies. Subsidies would be offering a solution for emission costs. Ideally subsidies would only be required if the cost of the products is simply too large compared to the savings their methane mitigation would provide. Opposition to subsidies is unlike to change, but if the profitability of many farms are taking a hit then even farmers opposed to subsidies should be open to their use.

\section{Recommendations}

Based on the key findings and takeaways PGgRc should continue to develop their technologies. Both potential scenarios offer realistic opportunities for the successful commercialisation of methane vaccines and inhibitor.

\section{Future Development}

\section{Government policy}

Understanding where different political parties stand regarding mitigating methane is important, as the technologies are still over one election cycle away from release. Different policies will have different effects on the potential success of the technologies. Other countries policies could have great importance to New Zealand agriculture depending on how they are 
structured. If New Zealand's international markets care about agricultural emissions tied to imported products and New Zealand farmers have made changes to improve their emissions it could be a competitive advantage over agricultural products from other countries that have not reduced emissions.

In addition, within the New Zealand government different political parties are likely to have different views on subsidising methane mitigation technologies. It is possible that farmer adoption of methane vaccines and inhibitors could depend on subsidies.

\section{Industry support}

Getting the backing of major industry companies and organisation could be a huge benefit to uptake of PGgRc's technologies. The industry could back vaccines and inhibitors to potentially improve the sustainability of their sector. In addition, if consumer behaviour shifts substantially and low emission products are an expectation or premium then it could make financial sense to support farmers in adopting methane vaccines and inhibitors.

Discussion with industry is required to evaluate the potential for industry support. However, until there is a better understanding of how much the technologies will cost farmers, how they can be administered, and what level of mitigation can be achieved there would be little value gained from such interactions. 


\section{Appendices}

Appendix 1-Semi-Structured Interview Question Guide

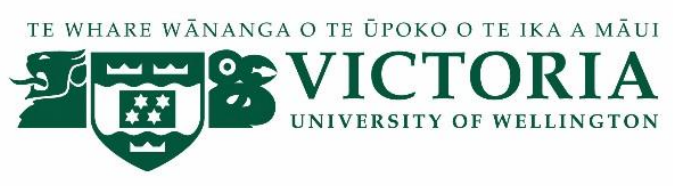

Exploring the Commercialisation of Methane Mitigation Technology for Ruminant Livestock

\section{SEMI-STRUCTURED INTERVIEW QUESTIONS GUIDE}

This document seeks to describe the semi-structured interview questions about farm systems and their interaction with methane emission reduction technology.

I plan to interview members of the New Zealand farming community who understand farm systems, such as farm owner/operators. Participants will be asked to talk about four main themes described below.

I. Farm system description. General information about their farm system; if it differs from norms how does it differ and why.

II. Potential costs of methane reduction technology. Identifying where costs can arise from the use of methane reduction technology; both monetary and other costs (such as time usage).

III. Potential risks of methane reduction technology. Identifying what risks are involved in the use of methane reduction technology; where could the methane reduction technology cause harm to the farm system, and outside of the farm system.

IV. Potential Benefits of methane reduction technology. Identifying how methane reduction technology can benefit the user; can it improve the farm system, and/or add value to the farmer. 


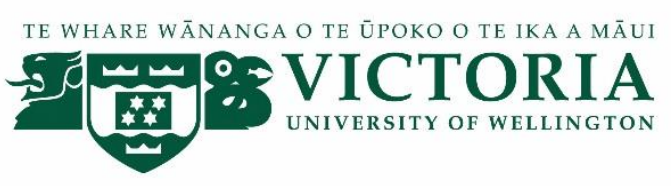

Exploring the Commercialisation of Methane Mitigation Technology for Ruminant Livestock

\section{SEMI-STRUCTURED INTERVIEW QUESTIONS GUIDE}

Below are some examples of the types of questions to be asked under each heading.

Section on general farmer behaviours, difficulties, attitudes, personality and life goals, etc.

\section{I.Farm system description.}

- What is your current farm system?

- How long have you been farming dairy/sheep/beef?

- What are the current difficulties you face on your farm?

- How often do difficulties arise, how have you designed your farm system to meet these challenges?

- Have you made any recent changes to your system? (How have these changes affected your system?)

- Do you work with advisors/consulting officers for any part of your farm business? (Who from?)

- What distinguishing factors does your farm system have?

\section{Potential costs of methane mitigation technology.}

- What animal healthcare do you currently use and administer, what difficulties are there in their usage?

- Are there any products you'd recommend to other farmers, why would you recommend them? (What makes them good?)

- Are there generic brand animal healthcare products, do farmers have brand loyalties i.e. Panadol?

- The proposed methane reduction technology comprises of a methane vaccine and/or a methane inhibitor, do you have any knowledge about their function and use?

- What costs do you perceive in using these? (Zero costs, small costs, large costs.)

- Would you prefer to use one mitigation method over the other? 
- If farming became part of the emissions trading scheme, or faces a carbon cost how would it change your perceptions of these costs?

- Is there an obvious solution to a cost you think isn't being thought of?

- If you were using a methane inhibitor and/or vaccine, would you preferentially use New Zealand produced? Why?

- Would you expect methane mitigation products to be subsidised, are you aware of the funding process for their development?

- How do you think your opinions compare to those held by other farmers/your peers? (link to question SIIp2)

\section{III.Potential risks of methane reduction technology.}

- What certification do you require for the current products you use?

- What certification does your produce undergo, how do you ensure your product is up to regulation?

- Are there new products commonly used on farms that you won't, because you do not believe the costs outweigh the benefits? (What are the products, and the costs?)

- New Zealand agriculture has a global reputation to maintain, what certification would you want before using this methane reduction technology?

- What risks do you perceive in the use of this methane reduction technology and would expect to be controlled or mitigated?

- Are there any major risks you feel aren't being addressed currently?

- Do you have any suggestions to minimise these risks?

\section{IV.Potential Benefits of methane reduction technology.}

- What animal health products do you use as part of good farm practice, and which do you use because of the value added? (Where do they add value, and how?)

- The primary effect of using this technology is reducing New Zealand's agricultural greenhouse gas emissions, does this benefit have much importance to you?

- Do you see any benefits in claiming improved sustainability in your farm system through use of this technology, when marketing your produce to consumers?

- If your farm was included in the emissions trading scheme, would this technology provide benefits worth pursuing?

- What associated benefits would you like/expect through using these products? 
Appendix 2-Initial Thematic Map

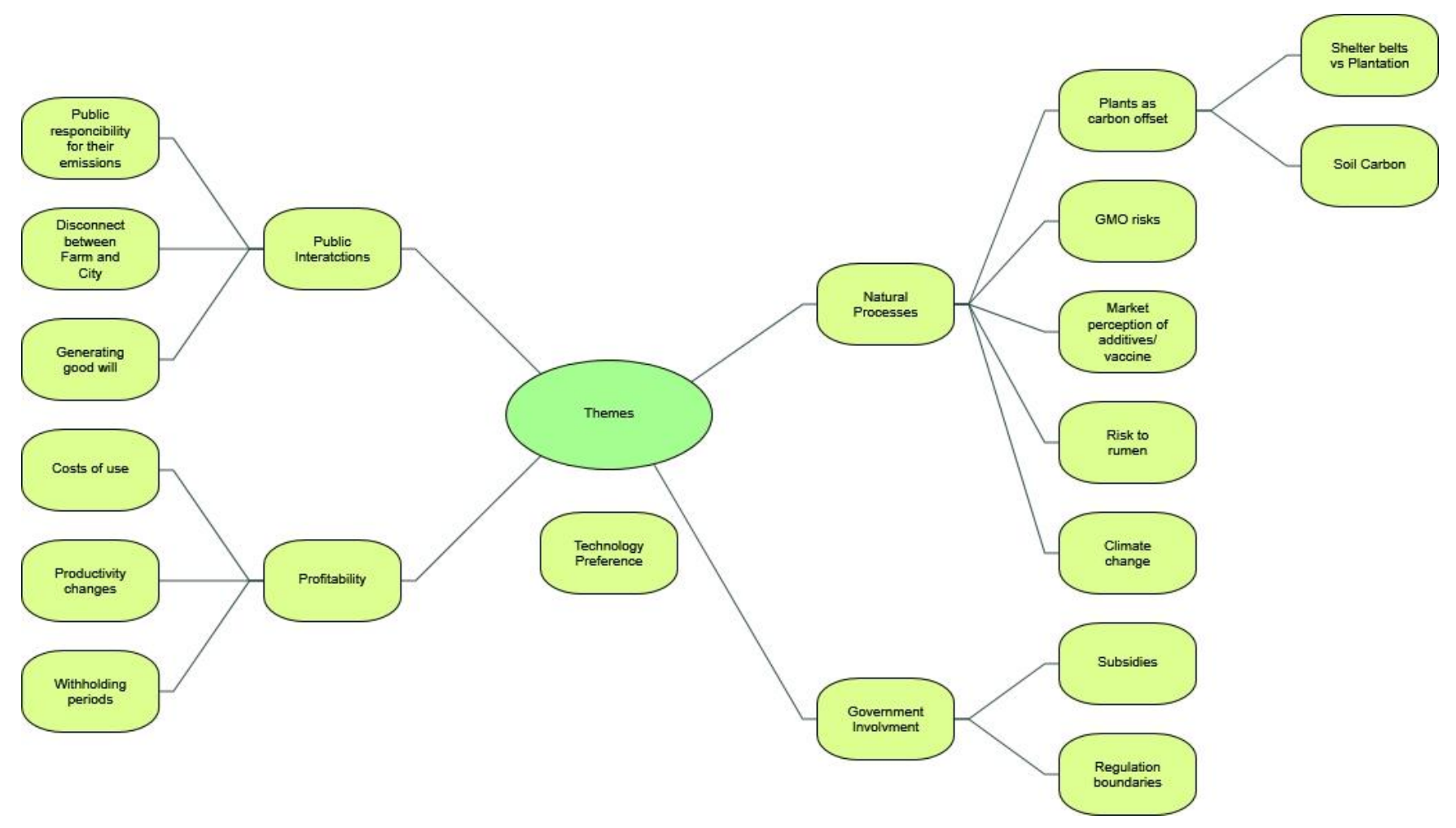


Appendix 3-Candidate Thematic Map

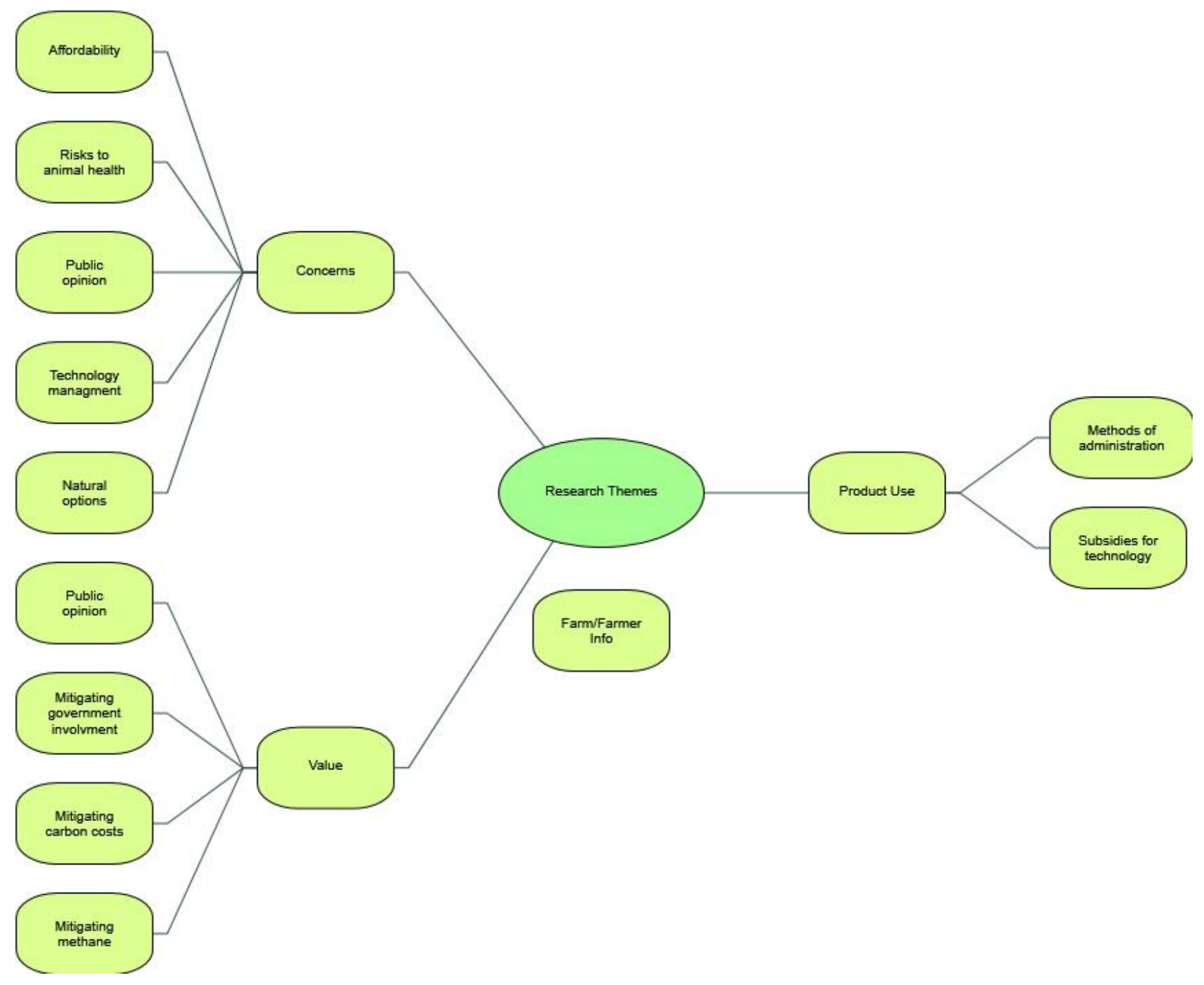


Appendix 4 - Final Thematic Map

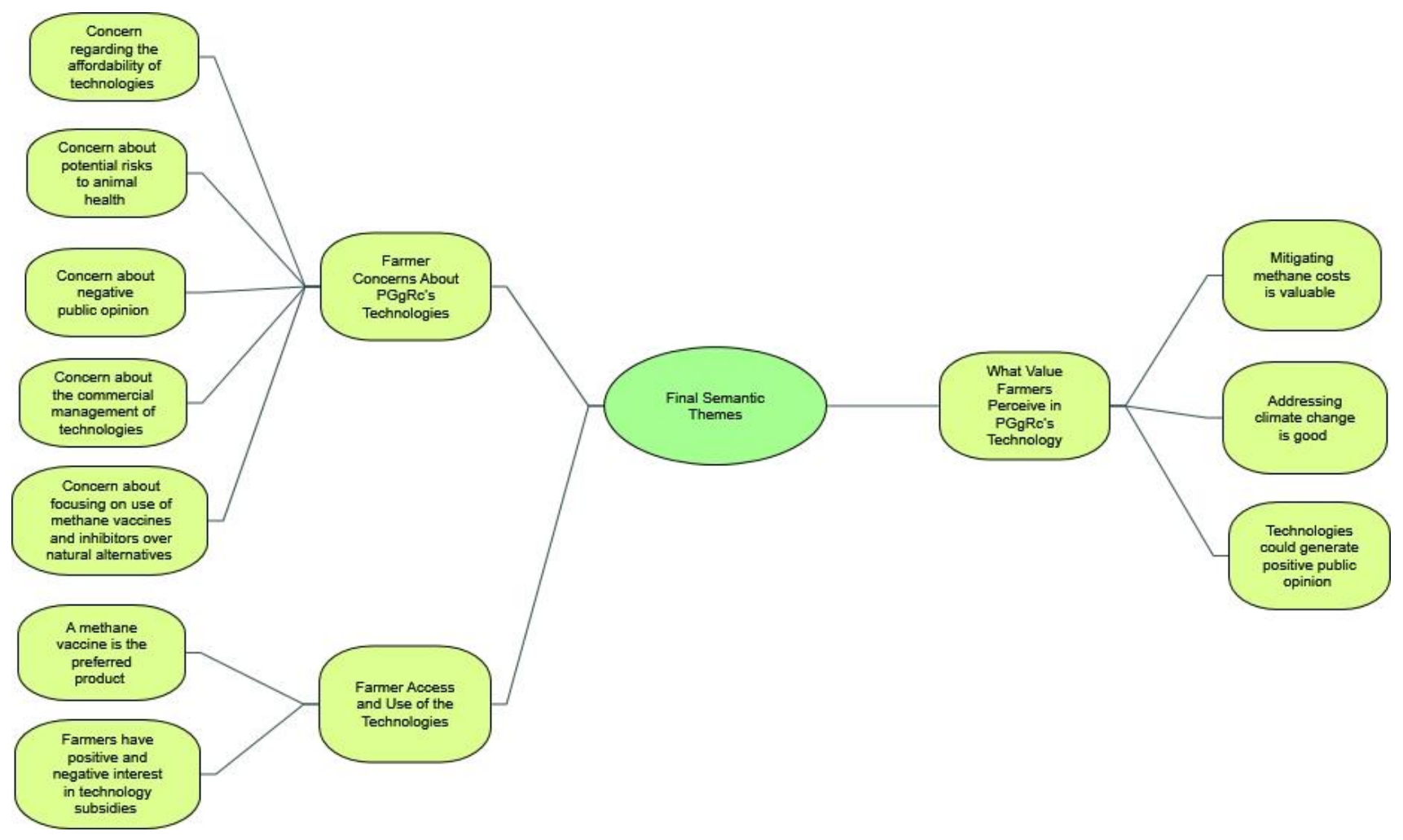




\section{References}

Abatzoglou, J. T., \& Williams, A. P. (2016). Impact of anthropogenic climate change on wildfire across western US forests. PNAS, 113(42), 11770-11775. doi:10.1073/pnas.1607171113

Adams, W. C. (2015). Conducting semi-structured interviews. In K. E. Newcomer, H. P. Hatry, \& J. S. Wholey, Handbook of Practical Program Evaluation, Fourth Edition (pp. 492-505). New Jersey: John Wiley \& Sons, Inc.

Attwood, G. T., Altermann, E., Kelly, W. J., Leahy, S. C., Zhang, L., \& Morrison, M. (2011). Exploring rumen methanogen genomes to identify targets for methane mitigation strategies. Animal Feed Science and Technology, 166-167. doi:10.1016/j.anifeedsci.2011.04.004

Barnett, J. (2011). Dangerous climate change in the Pacific Islands: food production. Regional Environmental Change, 11 (Suppliment 1), 229-237. doi:DOI 10.1007/s10113-010-0160-2

Beukes, P. C., Gregorini, P., Romera, A. J., Levy, G., \& Waghorn, G. C. (2010). Improving production efficiency as a strategy to mitigate greenhouse gas emission on pastoral dairy farms in New Zealand. Agriculture, Ecosystems and Environment, 136(3-4), 358-365.

Bolan, N. S., Laurenson, S., Luo, J., \& Sukias, J. (2009). Integrated treatment of farm effluents in New Zealand's dairy operations. Bioresource Technology, 100(22), 5490-5497.

Bosello, F., Nicholls, R. J., Richards, J., Roson, R., \& Tol, R. S. (2012). Economic impacts of climate change in Europe: sea-level rise. Climate Change, 112(1), 63-81. doi:10.1007/s10584-011-0340-1

Braun, V., \& Clarke, V. (2006). Using thematic analysis in psychology. Qualitative Research in Psychology, 77-101.

Braun, V., \& Clarke, V. (2016). Thematic analysis. The Journal of Positive Psychology, 12(3), 297-298. doi:10.1080/17439760.2016.1262613

Burke, M., Miguel, E., \& Hsiang, S. M. (2015, November 12). Global non-linear effect of temprature on economic production. Nature, 527(7577), 235-239. doi:10.1038/nature15725

Christian Aid. (2007). Human tide: the real migration chrisis.

Cook, J., Nuccitelli, D., Skuce, A., Jacobs, P., Painting, R., Honeycutt, R., . . Way, R. G. (2014). Reply to 'Quantifying the consensus on anthropogenic global warming in the scientific literature: A reanalysis'. Energy Policy, 73, 706-708. doi:http://dx.doi.org/10.1016/j.enpol.2014.06.002

Dorner, Z., \& Kerr, S. (2017). Implications of global emission policy scenarios for domestic agriculture: a New Zealand case study. Climate Policy, 17(8), 998-1013. doi:10.1080/14693062.2016.1215285

Edwards, C., \& DeHaven, T. (2003, March 3). Save the Farms - End the Subsidies. Retrieved from CATO Institute: https://www.cato.org/publications/commentary/save-farms-end-subsidies

European Commission. (2017, 09 19). Paris Agreement. Retrieved from European Commission: https://ec.europa.eu/clima/policies/international/negotiations/paris_en

Farbotko, C., \& Lazrus, H. (2012, May). The first climate refugees? Contesting global narratives of climate change in Tuvalu. Global Environmental Change, 22(2), 382-390.

doi:https://doi.org/10.1016/j.gloenvcha.2011.11.014

Fickling, D. (2003, September 5). Farmers raise stink over New Zealand 'fart tax'. Retrieved from The Guardian: https://www.theguardian.com/world/2003/sep/05/australia.davidfickling 
Fonty, G., Joblin, K., Chavarot, M., Roux, R., Naylor, G., \& Michallon, F. (2007). Establishment and Development of Ruminal Hydrogenotrophs in Methanogen-Free Lambs. Applied and Environmental Microbiology, 73(20), 6391-6401. doi:10.1128/AEM.00181-07

Fowles, C., \& Weaver, S. (2009). Dairy Industry under New Zealand's Emissions Trading Scheme: Analysis of Farmers' Attitudes towards Climate Change: The Expense Created by the NZETS and the Point that Farmers will Begin to Reduce Emissions. Wellington: Victoria University of Wellington.

Global Methane Initiative. (2016). Global Methane Emissions and Mitigation Opportunities. Global Methane Initiative. Retrieved from https://www.globalmethane.org/documents/gmi-mitigationfactsheet.pdf

Gluckman, P. (2018). Mitigating agricultural greenhouse gas emissions: Strategies for meeting New Zealand's goals. Auckland: Office of the Prime Minister's Chief Science Advisor.

Hallegatte, S., Patmore, N., Mestre, O., Dumas, P., Corfee-Morlot, J., Herweijer, C., \& Muir-Wood, R. (2008). Assessing Climate Change Impacts, Sea Level Rise and Storm Surge Risk in Port Cities: A Case Study on Copenhagen. OECD Environment Working Papers. No.3, OECD Publishing, Paris. doi:10.1787/236018165623

Henderson, G., Cox, F., Ganesh, S., Jonker, A., Young, W., Global Rumen Census Collaborators, \& Janssen, P. H. (2015). Rumen microbial community composition varies with diet and host, but a core microbiome is found across a wide geographical range. Scientific Reports, Article number: 14567 . doi:10.1038/srep14567

Hollis, M., de Klein, C., Frame, D., Harvey, M., Manning, M., Reisinger, A., . . Robinson, A. (2016). Cows, Sheep and Science: A Scientific Perspective on Biological Emissions from Agriculture. Wellington: Motu Economic and Public Policy Research.

Hristov, A. H., Oh, J., Giallongo, F., Frederick, T. W., Harper, M. T., Weeks, H. L., . . Duval, S. (2015). An inhibitor persistently decreased enteric methane emission from dairy cows with no negative effect on milk production. PNAS, 112(34), 10663-10668. doi:10.1073/pnas.1504124112

Kaine, G., \& Wright, V. (2016). Rates of adoption and compliance in dairy farming. Hamilton: Geoff Kaine Research.

Kerr, S. (2016). Agricultural Emissions Mitigation in New Zealand: Answers to Questions from the Parliamentary Commisioner for the Environment. Motu Economic and Public Policy Research.

Lapadat, J. C. (2012). Thematic Analysis. In A. J. Mills, G. Durepos, \& E. Wiebe, Encyclopedia of Case Study Research (pp. 926-927). Thousand Oaks: SAGE Publications, Inc. doi:10.4135/9781412957397

Leahy, S. C., Kelly, W. J., Altermann, E., Ronimus, R. S., Yeoman, C. J., Pacheco, D. M., . . Attwood, G. T. (2010). The Genome Sequence of the Rumen Methanogen Methanobrevibacter ruminantium Reveals New Possibilities for Controlling Ruminant Methane Emissions. PLOS ONE, 5(1), e8926. Retrieved from https://doi.org/10.1371/journal.pone.0008926

Machado, L., Magnusson, M., Paul, N. A., de Nys, R., \& Tomkins, N. (2014). Effects of Marine and Freshwater Macroalgae on In Vitro Total Gas and Methane Production. PLOS ONE, 9(1), e85289. doi:10.1371/journal.pone.0085289

Marcu, A., Gaspar, R., Rutsaert, P., Seibt, B., Fletcher, D., Verbeke, W., \& Barnett, J. (2015). Analogies, metaphors, and wondering about the future: Lay sense-making around synthetic meat. Public Understanding of Science, 24(5), 547-562. doi:10.1177/0963662514521106

McAllister, T. A., Meale, S. J., Valle, E., Guan, L. L., Zhou, M., Kelly, W. J., . . Janssen, P. H. (2015). RUMINANT NUTRITION SYMPOSIUM: Use of genomics and transcriptomics to identify strategies to 
lower ruminal methanogenesis 1,2,3. Journal of Animal Science, 93(4), 1431-1449. Retrieved from https://search-proquest-com.helicon.vuw.ac.nz/docview/1684391624?accountid=14782

McIntosh, M. J., \& Morse, J. M. (2015). Situating and Constructing Diversity in Semi-Structured Interviews. Global Qualitative Nursing Research, 2. doi:10.1177/2333393615597674

Ministry for the Environment. (2016). New Zealand's 2030 climate change target. Retrieved from http://www.mfe.govt.nz/climate-change/reducing-greenhouse-gas-emissions/New-Zealand's-post2020-climate-change-target

Ministry for the Environment. (2017). New Zeland's Greenhouse Gas Inventory 1990-2015. New Zealand Government.

New Zealand Agricultural Greenhouse Gas Research Center \& Pastoral Greenhouse Gas Research Consortium. (2016). Reducing New Zealand's Agricultural Greenhouse Gases: What Are We Doing (2 ed.).

New Zealand Labour Party. (2017). Climate Change. Manifesto. Retrieved from Labour: https://d3n8a8pro7vhmx.cloudfront.net/nzlabour/pages/8493/attachments/original/1504847668/ Climate_Change_Manifesto.pdf?1504847668

Newton, M. J. (2009). Values, attitudes \& beliefs of New Zealand dairy farmers towards climate change \& greenhouse gas abatement. Wellington: Victoria University of Wellington.

Nicholls, R. J., \& Cazenave, A. (2010). Sea-Level Rise and Its Impact on Costal Zones. Science, 328(5985), 1517-1520. Retrieved from http://www.jstor.org.helicon.vuw.ac.nz/stable/40656419

NZAGRC \& PGgRc. (2017). Reducing New Zealand's Agricultural Greenhouse Gases. NZAGRC \& PGgRc.

Paepcke, F. v. (2014). Statehood in Times of Climate Change: Impacts of Sea Level Rise on the Concept of States. Peter Lang $\mathrm{GmbH}$, Internationaler Verlag der Wissenschaften.

Pannel, D. J., Marshall, G. R., Barr, N., Curtis, A., Vanclay, F., \& Wilkinson, R. (2006). Understanding and promoting adoption of conservation practices by rural landholders. Australian Journal of Experimental Agriculture, 46(11), 1407-1424. doi:10.1071/EA05037

Pastoral Greenhouse Gas Research Consortium. (2014). 5 Year Science Progress Report 2007-2012.

Perfect Day. (2018). Perfect Day: FAQs. Retrieved from Perfect Day: https://www.perfectdayfoods.com/faq/

Powell, J. L. (2016). The Consensus on Anthropogenic Global Warming Matters. Bulletin of Science, Technology \& Society, 36(3), 157-163. doi:10.1177/0270467617707079

Price, C., \& Meyers, A. D. (2006). The 12-Step Innovation Roadmap: How to Analyze and Prioritize New Business Ideas. Physician Executive, 32(2), 52-55.

Raftery, A., Zimmer, A., Frierson, D., Startz, R., \& Lui, P. (2017). Less than $2{ }^{\circ} \mathrm{C}$ warming by 2100 unlikely. Nature Climate Change, 7, 637-641. doi:10.1038/nclimate3352

Ryan, C. (2015, April 10). Lab meat closer to reality. Meat Trades Journal, 1. Retrieved from http://link.galegroup.com/apps/doc/A411470597/ITOF?u=vuw\&sid=ITOF\&xid=1bc4e425

Sejian, V., Bhatta, R., Soren, N. M., Malik, P. K., \& Lal, R. (2015). Climate Change Impact on Livestock: Adaption and Mitigation. Springer India. doi:10.1007/978-81-322-2265-1_1

Singh, S. (2017, August 24). Bill Gates and Richard Branson Back Startup That Grows 'Clean Meat'. Retrieved from Bloomberg Technology: https://www.bloomberg.com/news/articles/2017-08-23/cargill-billgates-bet-on-startup-making-meat-without-slaughter 
StatsNZ. (2018, January 30). Global greenhouse gas emissions. Retrieved from StatsNZ:

http://archive.stats.govt.nz/browse_for_stats/environment/environmental-reportingseries/environmental-indicators/Home/Atmosphere-and-climate/global-greenhouse-gases.aspx

United Nations. (2017, 09 18). Depositary: Status of Treaties. Retrieved from United Nations Treaty Collection: https://treaties.un.org/Pages/ViewDetails.aspx?src=TREATY\&mtdsg_no=XXVII-7$\mathrm{d} \&$ chapter=27\&lang=_en\&clang=_en

United Nations. (2017, June 20). The Paris Agreement. Retrieved from United Nations Framework Convention on Climate Change: http://unfccc.int/paris_agreement/items/9485.php

Weissenberger, S., \& Chouinard, O. (2015). Adaptation to Climate Change and Sea Level Rise: The Case Study of Coastal Communities in New Brunswick, Canada. Springer Netherlands. doi:10.1007/97894-017-9888-4 